NATIONAL LABORATORY

\title{
Design, Operations, and Safety Report for the MERIT Target System
}

September 2007

Prepared by Van B. Graves Philip T. Spampinato 


\section{DOCUMENT AVAILABILITY}

Reports produced after January 1, 1996, are generally available free via the U.S. Department of Energy (DOE) Information Bridge.

Web site http://www.osti.gov/bridge

Reports produced before January 1, 1996, may be purchased by members of the public from the following source.

National Technical Information Service

5285 Port Royal Road

Springfield, VA 22161

Telephone 703-605-6000 (1-800-553-6847)

TDD 703-487-4639

Fax 703-605-6900

E-mail info@ntis.gov

Web site http://www.ntis.gov/support/ordernowabout.htm

Reports are available to DOE employees, DOE contractors, Energy Technology Data Exchange (ETDE) representatives, and International Nuclear Information System (INIS) representatives from the following source.

Office of Scientific and Technical Information

P.O. Box 62

Oak Ridge, TN 37831

Telephone 865-576-8401

Fax 865-576-5728

E-mail reports@osti.gov

Web site http://www.osti.gov/contact.html

This report was prepared as an account of work sponsored by an agency of the United States Government. Neither the United States Government nor any agency thereof, nor any of their employees, makes any warranty, express or implied, or assumes any legal liability or responsibility for the accuracy, completeness, or usefulness of any information, apparatus, product, or process disclosed, or represents that its use would not infringe privately owned rights. Reference herein to any specific commercial product, process, or service by trade name, trademark, manufacturer, or otherwise, does not necessarily constitute or imply its endorsement, recommendation, or favoring by the United States Government or any agency thereof. The views and opinions of authors expressed herein do not necessarily state or reflect those of the United States Government or any agency thereof. 
Nuclear Science and Technology Division

\section{Design, Operations, and Safety Report for the MERIT Target System}

Van B. Graves

Philip T. Spampinato

Date Published: September 2007

Prepared by

OAK RIDGE NATIONAL LABORATORY

Oak Ridge, Tennessee 37831-6283

managed by

UT-BATTELLE, LLC

for the

U.S. DEPARTMENT OF ENERGY

under contract DE-AC05-00OR22725 



\section{Table of Contents}

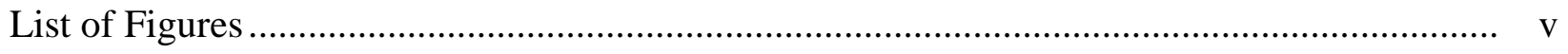

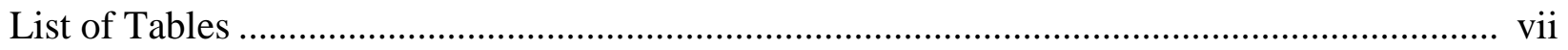

Executive Summary ……….................................................................................... 1

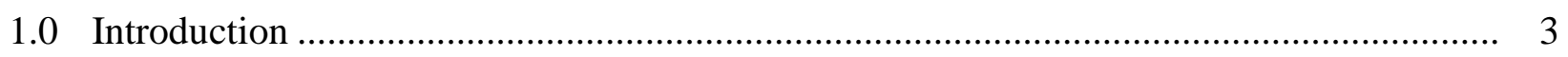

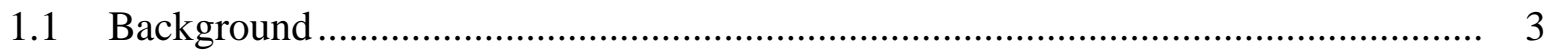

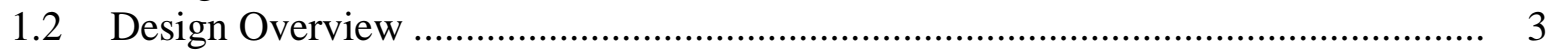

1.3 Material Compatibility........................................................................ 3

2.0 Design Specifications and Requirements ………..................................................... 7

2.1 Design Specification-ISO 2919 …………….................................................. 7

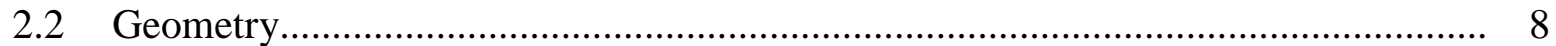

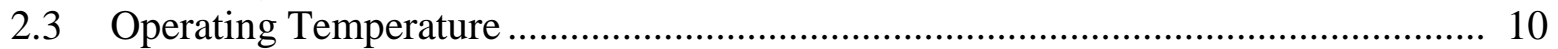

2.4 Mercury Containment Boundaries .................................................................. 10

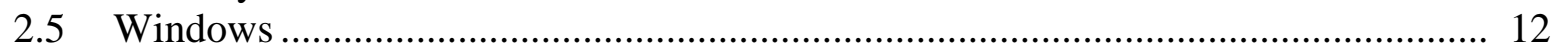

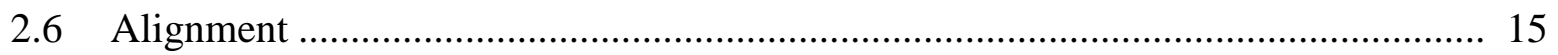

2.7 Assembly and Shipping .................................................................................... 15

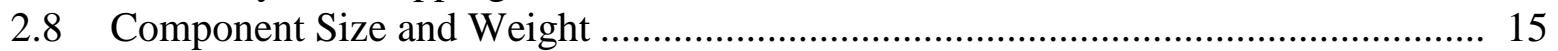

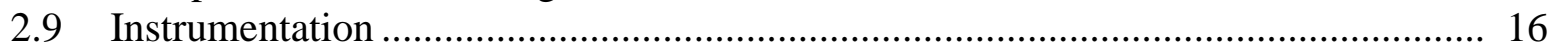

2.10 Stray Magnetic Fields ………………………................................................. 17

2.11 Radioactivation of Components...................................................................... 18

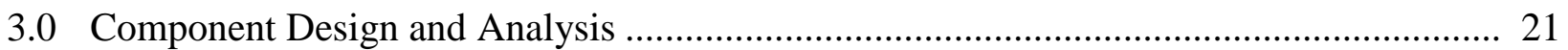

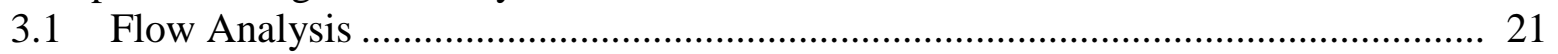

3.2 Syringe Pump System ................................................................................... 22

3.3 Primary Containment ....................................................................................... 25

3.4 Secondary Containment .............................................................................. 28

3.5 Baseplate Support Structures ……………………............................................ 30

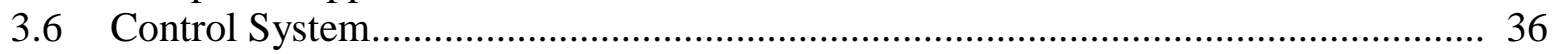

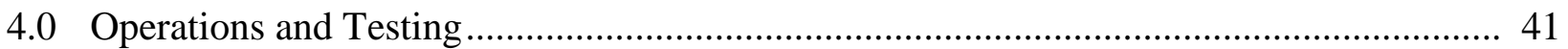

4.1 Filling and Draining Mercury …………….......................................................... 41

4.2 Mercury Vapor Filtration ............................................................................. 43

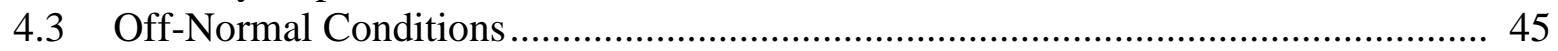

4.4 Equipment for Mercury Handling ........................................................................ 46

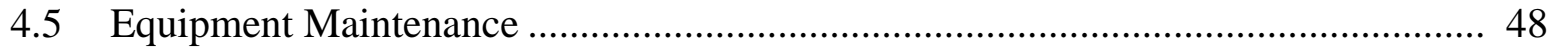

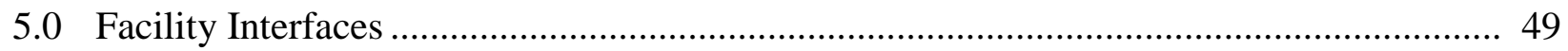

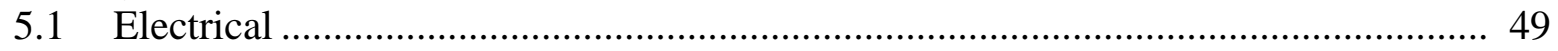

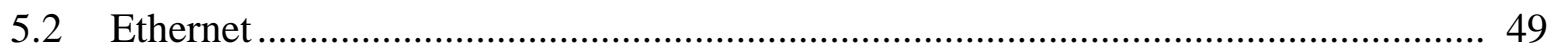

5.3 Target Equipment Installation............................................................................ 49 
6.0 Packing and Transportation ................................................................................ 51

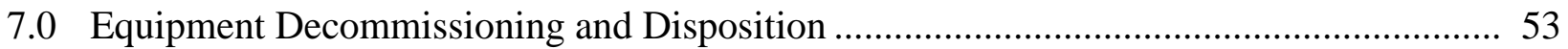

7.1 Estimated Dose Exposure to Personnel ...................................................... 53

8.0 Assembled Equipment Configuration ............................................................. 55

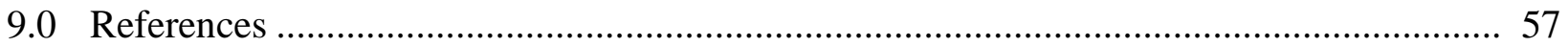




\section{List of Figures}

Fig. 1. Mercury target system within the secondary containment enclosure....................... 3

Fig. 2. MERIT baseline geometry configuration ......................................................... 9

Fig. 3. Nozzle and solenoid relative to beam ........................................................... 10

Fig. 4. Target system primary containment ................................................................ 11

Fig. 5. Target-system containment boundary schematic ................................................ 11

Fig. 6. Downstream beam window mounted to the secondary containment enclosure........... 12

Fig. 7. Laser diagnostic components, windows, and reflector; section cut taken at $\mathrm{Z}=0 \ldots \ldots .13$

Fig. 8. Passive optical diagnostic components and support bracket .................................. 14

Fig. 9. Sapphire window mounted between elastomer gaskets ..................................... 14

Fig. 10. Diagnostic reflector assemblies ................................................................ 14

Fig. 11. Stray magnetic field plot around the solenoid and the target equipment ................... 17

Fig. 12. Magnitude of the field contours ................................................................ 18

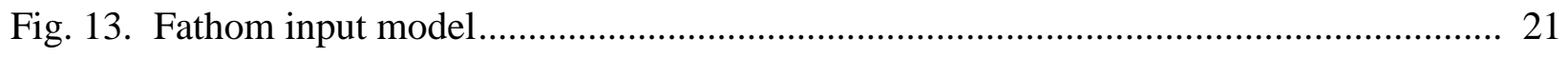

Fig. 14. Fathom stagnation pressure output ................................................................ 22

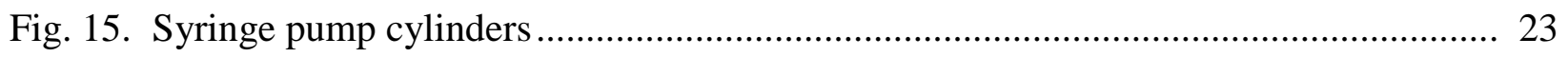

Fig. 16. Hydraulic pump system ................................................................................. 23

Fig. 17. Syringe HPU on-board controls ................................................................. 24

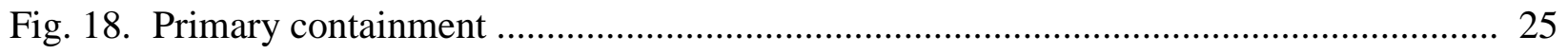

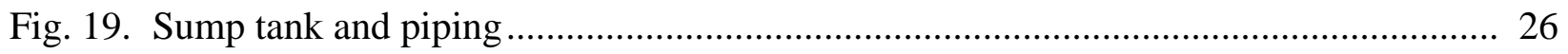

Fig. 20. Mercury axial flow force analysis ................................................................ 28

Fig. 21. Secondary containment left side ................................................................ 28

Fig. 22. Secondary containment right side ................................................................ 29

Fig. 23. Solenoid and mercury system on common baseplate .......................................... 30

Fig. 24. Baseplate support-structures design drawing .................................................... 31

Fig. 25. Common baseplate and support beam ............................................................. 31

Fig. 26. Induced stresses of baseplate on three rollers................................................. 33 
Fig. 27. Safety factor distribution for outer baseplate channel on three rollers

Fig. 28. Safety factor distribution for the jacking bracket weldment ................................. 34

Fig. 29. Target cart and supporting transporter .......................................................... 35

Fig. 30. Safety factor distribution for the cart structure ................................................ 36

Fig. 31. Safety factor distribution for solenoid support beam .......................................... 37

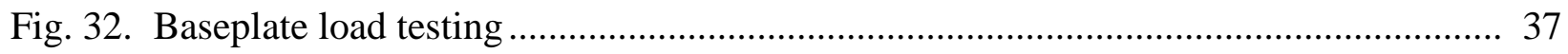

Fig. 33. MERIT layout in the CERN tunnels .............................................................. 38

Fig. 34. Labview control system operator interface ........................................................ 39

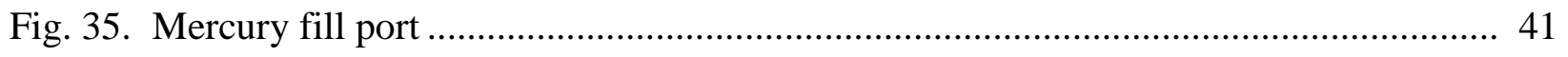

Fig. 36. Peristaltic pump for transferring mercury …................................................. 42

Fig. 37. Target equipment moving into TT2A............................................................. 50

Fig. 38. Target equipment inserted into solenoid ........................................................... 50

Fig. 39. Target equipment and solenoid inside a short sealand container ............................ 51

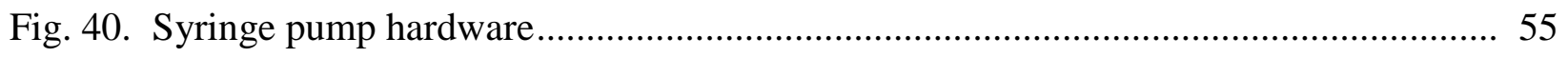

Fig. 41. MERIT mercury delivery system and project team (L-R): P. Spampinato, V. Graves, R. Hobson, A. Carroll................................................................ 56 


\section{List of Tables}

Table 1. Non-metallic materials used in mercury delivery system .................................... 4

Table 2. Estimated component sizes and weights ........................................................ 15

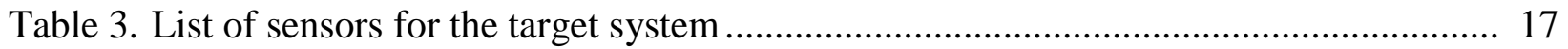

Table 4. Radioactivity of target system components .................................................... 18

Table 5. Syringe pump performance parameters ............................................................... 24

Table 6. Mercury supply component pressure ratings .................................................. 27

Table 7. Miscellaneous experiment support equipment ................................................ 47

Table 8. Estimated personnel dose rates for decommissioning MERIT …............................ 54 



\section{Executive Summary}

The Mercury Intense Target (MERIT) is a proof-of-principle experiment scheduled to operate at CERN in 2007. It employs a free-jet mercury target operating in a 15-Tesla magnetic field, interacting with a $24-\mathrm{GeV} / \mathrm{c}$ proton beam with proton intensity per pulse similar to a 4-MW target station. Due to activation limits, the integrated beam intensity is limited to $3 \times 10^{15}$ protons on the mercury target, and a maximum of $3 \times 10^{13}$ protons per pulse can be submitted. This singlepulse experiment is on a 30-min repetition rate. The target is designed to operate with up to 23liters of elemental mercury. At CERN, the target system and the solenoid will be located in the TT2A tunnel, the hydraulic pump equipment will be located in the TT2 tunnel, and the remote control station for the target will be located in Building 272, which is a 10-min walking distance. At the completion of testing and after an acceptable cool-down period, the target equipment, the mercury, and the solenoid will be shipped back to Oak Ridge National Laboratory (ORNL).

The design of the target system addressed numerous safety issues to ensure that the operation of the equipment, initially at ORNL and Massachusetts Institute of Technology, will meet all criteria for safe, reliable operations at CERN. This document addresses the general safety for operating the target system and describes what design features were incorporated to meet the conditions for safe operation. In addition, radiation safety was addressed as it relates to operating the equipment and decommissioning the target system; fire safety was a consideration for choosing an acceptable hydraulic fluid to operate the syringe pump; and the distribution of the magnetic field around the solenoid was investigated to assess its impact on operations.

The components that make up the target system are heavy, weighing up to 2 tonnes, and require handling by qualified rigging experts. Each component was carefully designed to include provisions for nylon lifting straps and hoist rings that will be pre-mounted to the equipment.

Finally, and perhaps most significantly, mercury handling was the most significant factor considered for developing the target system design. The same principles for handling mercury that were developed for the Spallation Neutron Source-Target Test Facility (TTF) at ORNL, were employed for MERIT. The experience gained during 6 years of successful operation of the TTF and dealing with large quantities of mercury without any incidents was brought to bear on this experiment. 



\subsection{Introduction}

\subsection{Background}

The Mercury Intense Target (MERIT) is a proof-of-principle experiment for a high-power production target proposed for a neutrino factory or a muon collider. Oak Ridge National Laboratory (ORNL) engineers have developed a design for a free-jet mercury $(\mathrm{Hg})$ target that will interact with a $24-\mathrm{GeV}$ proton beam inside a 15-Tesla solenoid. The experiment will be installed initially at the Massachusetts Institute of Technology (MIT) for integrated systems testing and later in the TT2A tunnel at CERN during a 1-month period in 2007 for tests with the proton beam.

\subsection{Design Overview}

The target system consists of primary and secondary containment boundaries, the mercury delivery system and related piping, proton beam windows, a laser-optics diagnostic provided by Brookhaven National Laboratory (BNL), and a support structure that also interfaces with the solenoid. The system is designed to produce a 1 -cm-diam free jet with a nozzle velocity of $20 \mathrm{~m} / \mathrm{sec}$, and a flow rate up to 95 liters per minute.

The primary function of the target system is to deliver the mercury jet in the form of a continuous stream into the high-magnetic field solenoid while simultaneously intersecting a high-energy $(24-\mathrm{GeV})$ proton beam. The duration of the jet must be sufficient to overlap the 1 -sec duration of the peak field in the solenoid. The target system provides the means for discharging the mercury jet and collecting and recycling elemental mercury through a syringe pump system. The mercury delivery system is installed within a secondary containment boundary. Figure 1 is a CAD model of the MERIT system.

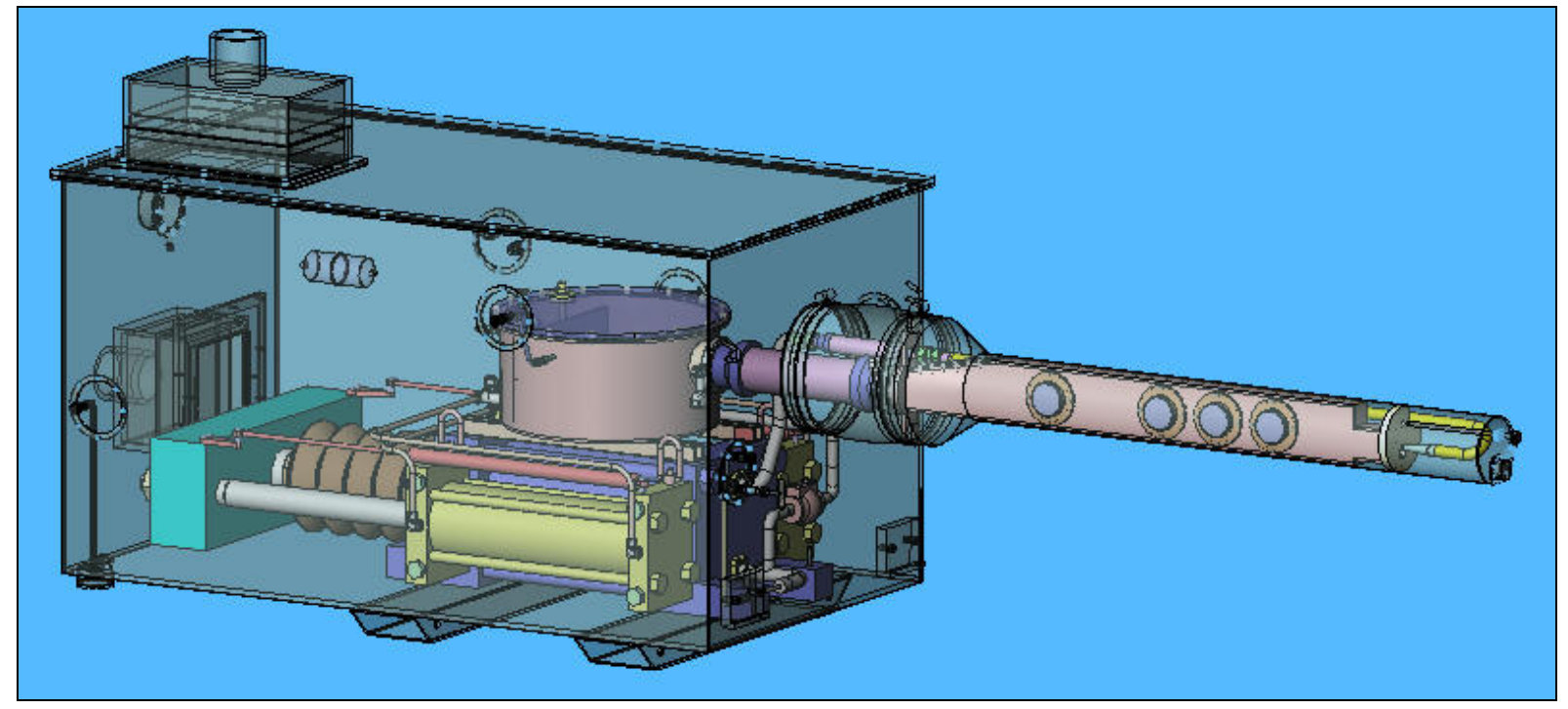

Fig. 1. Mercury target system within the secondary containment enclosure.

\subsection{Material Compatibility}

Two criteria were adopted for selecting materials for the design of the target system: (1) compatibility with elemental mercury (e.g., resistance to mercury-induced corrosion) and 
(2) transparency to magnetic fields (e.g., use of non-ferromagnetic materials). Elemental mercury dissolves metals such as copper that might normally be used for flange gaskets. Hence, any component or surface that could contact elemental mercury or its vapor is fabricated from materials that are relatively inert to mercury.

Non-magnetic materials are used exclusively to avoid the forces that are induced by magnetic fields on ferromagnetic materials. In addition, the gamma dose due to neutron-activated materials in the target structure is estimated to be less than $10^{4}$ rads, and all selected organic materials can easily withstand that level of radiation dose.

The following list summarizes the materials of construction for the MERIT system:

- austenitic stainless steel, type 316 or 304-pump cylinders, piping, fittings and connectors, the storage tank,

- Nitronic 50 - tie rods for the cylinder assembly,

- buna-N elastomer-gasket material for removable cover seals,

- Ti6Al4V alloy, grade 5 for the proton beam windows, grade 2 for the piping and nozzle,

- sapphire-laser diagnostic windows,

- Lexan ${ }^{\circledR}$ — secondary enclosure cover and the sump tank cover, and

- 6061 aluminum alloy_base support structure.

Fasteners and miscellaneous items are non-magnetic wherever practical. Gaskets are nonreactive with mercury and capable of withstanding radiation doses of at least $10^{5}$ rads.

For fire safety reasons, there is a particular interest in the use of non-metallic materials within the mercury delivery system. A list of these materials and their quantities is provided in Table 1.

Table 1. Non-metallic materials used in mercury delivery system

\begin{tabular}{|c|c|c|c|c|c|}
\hline Component & Description & Location & Materials & Quantity & Comments \\
\hline \multicolumn{6}{|c|}{ Hydraulic power unit } \\
\hline Power cable & Provided by CERN & $\begin{array}{l}\mathrm{TT} 2 \\
\text { tunnel }\end{array}$ & CERN approved & TBD & $\begin{array}{c}\text { CERN-approved electrical } \\
\text { power cable }\end{array}$ \\
\hline $\begin{array}{l}\text { Hydraulic } \\
\text { line—steel- } \\
\text { reinforced } \\
\text { hose }\end{array}$ & $\begin{array}{c}\text { Parker Tough } \\
\text { Cover®, } 451 \text { TC- } \\
12(3 / 4 \text { in. }), \\
\text { MSHA IC-40/26, } \\
\text { SAE } 100 R 17-12^{a}\end{array}$ & $\begin{array}{l}\mathrm{TT} 2 \\
\text { tunnel }\end{array}$ & $\begin{array}{l}\text { Synthetic rubber } \\
\text { tube, steel wire } \\
\text { reinforced, synthetic } \\
\text { rubber cover }\end{array}$ & $75 \mathrm{ft}$ & Magnetic hose \\
\hline $\begin{array}{l}\text { Hydraulic } \\
\text { line-suction }\end{array}$ & $\begin{array}{l}\text { Parker®, } 881-12 \\
(3 / 4 \text { in.), MSHA } \\
\text { 2G31C, SAE } \\
\text { 100R4-12 }\end{array}$ & $\begin{array}{l}\text { TT2 } \\
\text { tunnel }\end{array}$ & $\begin{array}{l}\text { Synthetic rubber } \\
\text { tube, steel wire } \\
\text { reinforced, synthetic } \\
\text { rubber cover }\end{array}$ & $6 \mathrm{ft}$ & None \\
\hline $\begin{array}{l}\text { Hydraulic } \\
\text { line—-supply }\end{array}$ & TC 782-16 & $\begin{array}{l}\text { TT2 } \\
\text { tunnel }\end{array}$ & $\begin{array}{l}\text { Synthetic rubber } \\
\text { tube, steel wire } \\
\text { reinforced, synthetic } \\
\text { rubber cover }\end{array}$ & $15 \mathrm{in.}$ & None \\
\hline
\end{tabular}


Table 1 (continued)

\begin{tabular}{|c|c|c|c|c|c|}
\hline Component & Description & Location & Materials & Quantity & Comments \\
\hline $\begin{array}{l}\text { Hydraulic } \\
\text { line-fiber- } \\
\text { reinforced } \\
\text { hose }\end{array}$ & $\begin{array}{l}\text { Parflex }{ }^{\circledR}, \\
575 \mathrm{X}-12\end{array}$ & $\begin{array}{l}\text { TT2A } \\
\text { tunnel }\end{array}$ & $\begin{array}{l}\text { Polymeric core, fiber } \\
\text { reinforced, urethane } \\
\text { cover }\end{array}$ & $25 \mathrm{ft}$ & Non-magnetic hose \\
\hline $\begin{array}{l}\text { Hydraulic } \\
\text { fluid }\end{array}$ & $\begin{array}{l}\text { Quintolubric }{ }^{\circledR} \\
88846\end{array}$ & $\begin{array}{l}\mathrm{TT} 2 \\
\text { tunnel }\end{array}$ & $\begin{array}{c}\text { Fire resistant, } \\
\text { synthetic fluid that } \\
\text { contains no } \\
\text { hazardous } \\
\text { ingredients }\end{array}$ & 40 gal & $\begin{array}{l}\text { Contained in the steel } \\
\text { reservoir tank on the } \\
\text { hydraulic unit and the lines; } \\
\text { a } 55 \text {-gal drum will contain } \\
\text { the remaining } 15 \text { gal of fluid }\end{array}$ \\
\hline $\begin{array}{l}\text { Expansion } \\
\text { tank }\end{array}$ & $\begin{array}{l}\text { Pentair® \#0835, } \\
\text { cylindrical bladder } \\
\text { tank mounted on } \\
\text { the hydraulic unit, } \\
5 \text { gal }\end{array}$ & $\begin{array}{l}\mathrm{TT} 2 \\
\text { tunnel }\end{array}$ & $\begin{array}{l}\text { Fiberglass wrapped, } \\
\text { polyethylene shell }\end{array}$ & 1 unit & $\begin{array}{l}\text { Parker Hannifin reservoir } \\
\text { isolation tank }\end{array}$ \\
\hline \multicolumn{6}{|c|}{ Mercury delivery system primary containment } \\
\hline $\begin{array}{c}\text { Lexan }{ }^{\circledR} \\
\text { cover }\end{array}$ & $\begin{array}{l}\text { Transparent top } \\
\text { cover of the sump } \\
\text { tank, } \\
\text { 22-in. diam } \times 1 / 2 \\
\text { in. thick } \\
\end{array}$ & $\begin{array}{l}\text { TT2A } \\
\text { tunnel }\end{array}$ & Polycarbonate & 1 piece & $\begin{array}{l}\text { Allows viewing of the } \\
\text { mercury stream returning to } \\
\text { the tank }\end{array}$ \\
\hline $\begin{array}{l}\text { Viewport } \\
\text { windows }\end{array}$ & $\begin{array}{l}\text { Circular disks 100- } \\
\text { mm OD } \times 6-\mathrm{mm} \\
\text { thick }\end{array}$ & $\begin{array}{l}\text { TT2A } \\
\text { tunnel }\end{array}$ & Sapphire & 8 pieces & $\begin{array}{l}\text { Allows viewing of the } \\
\text { mercury stream returning to } \\
\text { the tank }\end{array}$ \\
\hline \multicolumn{6}{|c|}{ Mercury delivery system secondary containment } \\
\hline Lexan cover & $\begin{array}{l}\text { Transparent top } \\
\text { cover of the } \\
\text { secondary } \\
\text { containment, } \\
70 \text { in. } \times 40 \text { in. } \times \\
1 / 2 \text { in. } \\
\end{array}$ & $\begin{array}{l}\text { TT2A } \\
\text { tunnel }\end{array}$ & Polycarbonate & 1 piece & $\begin{array}{l}\text { Allows visual inspection of } \\
\text { major components of the } \\
\text { primary containment }\end{array}$ \\
\hline Gaskets & Various & $\begin{array}{l}\text { TT2A } \\
\text { tunnel }\end{array}$ & Buna-N & Multiple & $\begin{array}{l}\text { Provides mechanical } \\
\text { fasealing of primary } \\
\text { containment }\end{array}$ \\
\hline $\begin{array}{l}\text { Elastomer } \\
\text { sheeting }\end{array}$ & $\begin{array}{l}\text { 45-mil-thick } \\
\text { sheeting }\end{array}$ & $\begin{array}{l}\text { TT2A } \\
\text { tunnel }\end{array}$ & EPDM rubber & $84 \mathrm{sq} \mathrm{ft}$ & $\begin{array}{l}\text { Optionally used as a } \\
\text { protective barrier under the } \\
\text { target equipment platform- } \\
\text { if used, berm material to } \\
\text { form dike would be needed }\end{array}$ \\
\hline \multicolumn{6}{|c|}{ Support baseplate } \\
\hline $\begin{array}{l}\text { Low friction } \\
\text { surface- } \\
\text { target cart } \\
\text { assembly }\end{array}$ & $\begin{array}{l}\text { Low-friction sheet } \\
\text { to allow for the } \\
\text { "sliding" } \\
\text { adjustment of the } \\
\text { secondary } \\
\text { containment box }\end{array}$ & TT2A & $\begin{array}{l}32 \text { in. } \times 46 \text { in. } \times \\
1 / 4 \text { in. thick, ultra } \\
\text { high molecular } \\
\text { weight polyethylene } \\
\text { (UHMW PE) }\end{array}$ & 1 sheet & $\begin{array}{l}\text { Does not contain halogens; } \\
\text { this material is sandwiched } \\
\text { between two aluminum } \\
\text { (6061-T651) plates, and only } \\
\text { its edges are exposed; } \\
\text { see dwg 203-HJT-0300 }\end{array}$ \\
\hline
\end{tabular}


Table 1 (continued)

\begin{tabular}{|c|c|c|c|c|c|}
\hline Component & Description & Location & Materials & Quantity & Comments \\
\hline $\begin{array}{c}\text { Low-friction } \\
\text { surface- } \\
\text { common } \\
\text { base } \\
\text { assembly }\end{array}$ & $\begin{array}{c}\text { Low-friction sheet } \\
\text { to allow for the } \\
\text { "sliding" } \\
\text { adjustment of the } \\
\text { solenoid }\end{array}$ & TT2A & $\begin{array}{c}38 \text { in. } \times 48 \text { in. } \times \\
1 / 4 \text { in. thick, ultra } \\
\text { high molecular } \\
\text { weight polyethylene } \\
\text { (UHMW PE) }\end{array}$ & 1 sheet & $\begin{array}{c}\text { Does not contain halogens; } \\
\text { this material is sandwiched } \\
\text { between two aluminum } \\
\text { (6061-T651) plates, and only } \\
\text { its edges are exposed; } \\
\text { see dwg 203-HJT-0100 }\end{array}$ \\
\hline \multicolumn{7}{|c|}{ Controls } & 250 ft & $\begin{array}{c}\text { Used only during the } \\
\text { equipment setup phase in } \\
\text { TT2 }\end{array}$ \\
\hline $\begin{array}{c}\text { E-stop power } \\
\text { cable }\end{array}$ & $\begin{array}{c}\text { P136-29, MSHA, } \\
\text { 14 AWG; U.L. } \\
\text { approved 2-wire, } \\
\text { single ground }\end{array}$ & $\begin{array}{c}\text { TT2 } \\
\text { tunnel }\end{array}$ & PVC insulation \\
\hline $\begin{array}{c}\text { Wiring in } \\
\text { control } \\
\text { cabinet }\end{array}$ & $\begin{array}{c}\text { 24-volt instrument } \\
\text { Circuit } \\
\text { boards }\end{array}$ & $\begin{array}{c}\text { TT2 } \\
\text { tunnel }\end{array}$ & $\begin{array}{c}\text { PVC insulation, } \\
\text { nylon jacket }\end{array}$ & $\begin{array}{c}\text { See } \\
\text { photo }\end{array}$ & $\begin{array}{c}\text { Less than several meters of } \\
\text { wire, enclosed in the steel } \\
\text { control cabinet }\end{array}$ \\
\hline
\end{tabular}

${ }^{a}$ Note: MSHA-Mine Safety and Health Administration 


\subsection{Design Specifications and Requirements}

The target system consists of four subsystems: (1) the primary containment structure, (2) the secondary containment structure, (3) a syringe pump system, and (4) the support base structure. The design for each subsystem takes into account the requirements for dealing with elemental mercury, a toxic heavy metal that will become mildly activated once beam tests commence, and the requirements for dealing with mildly radioactive structure at the completion of testing.

The system will operate within 1-atmosphere environments of air in both the primary and secondary containments. Air activation, that is, ${ }^{13} \mathrm{~N},{ }^{15} \mathrm{O}$, and ${ }^{41} \mathrm{Ar}$, will not be an issue for this system since the air environment is not purged after each pulse, and the containment boundaries remain intact for the duration of testing. If there is a need to breach either barrier after test operations commence, $1 \mathrm{~h}$ of waiting will be sufficient for the decay of these isotopes. This approach is much simpler than incorporating equipment to evacuate and backfill with helium because of complications associated with installing a mercury ventilation/filtration system.

The target system consists of the equipment to produce a mercury jet for a duration of up to $12 \mathrm{sec}$. For a 12-sec jet, a volume of 23 liters of mercury is required. Testing at ORNL and MIT will determine the minimum time required to develop a steady-state mercury jet, and hence, the minimum quantity of mercury needed for beam tests at CERN. Minimizing the amount of activated liquid mercury is an operational consideration and goal.

The equipment is designed so that the elemental mercury in the target equipment is doublecontained and mounted on a base structure that supports the target equipment and the solenoid system as an integrated unit. The support structure can be manually driven (pushed on Hilman ${ }^{\circledR}$ rollers) into or out of the axis of the proton beam line, and it has provisions to adjust the elevation and pitch of the integrated system.

The target system will be assembled initially with unlimited hands-on access but must be maintained and operated with minimal personal contact after beam operations commence. Therefore, design of the target system has taken into account the eventual disassembly and handling of the equipment for shipment back to ORNL. The design features incorporated into the target system considered handling mildly activated components that are mercury contaminated as well as handling activated mercury in order to minimize exposure to personnel.

\subsection{Design Specification-ISO 2919}

Design of the target system used the criteria of ISO 2919, Table 2 "Classification of Sealed Source Performance," Class 2, as a starting point. This requirement was suggested early in the project by the CERN Safety Commission and was considered to be the minimum requirement needed to start the design of MERIT. Furthermore, it was established that these requirements could be met by analysis or engineering judgment, in lieu of performance tests.

ISO 2919, Table 2, Class 2

Temperature: $-40^{\circ} \mathrm{C}(20$ minutes $),+80^{\circ} \mathrm{C}(1 \mathrm{~h})\left[-40^{\circ} \mathrm{F}\right.$ and $\left.+176^{\circ} \mathrm{F}\right]$

All of the materials listed in Section 1.3 are suitable for operation in the temperature range stated above, including the buna- $N$ elastomer which has an operating range of $-40^{\circ} \mathrm{C}$ to $+100^{\circ} \mathrm{C}$. Also, the Lexan ${ }^{\circledR}$ cover has an operating temperature range of $-135^{\circ} \mathrm{C}$ to $+115^{\circ} \mathrm{C}$. 
External Pressure: $25 \mathrm{kPa}$ absolute (60 psi) to atmospheric

This is not applicable to the secondary enclosure because it does not appear possible for the pressure in the tunnel to exceed one atmosphere.

Impact: 50 grams (1-3/4 oz) from 1 meter, or equivalent imparted energy

The most vulnerable components in the target system are the sapphire windows. A successful impact test on a 6-mm thick sapphire window was done using a $1.75-\mathrm{cm}$ diam "paintball," with a speed of $95 \mathrm{~m} / \mathrm{s}$. Its momentum was the same as that of a 7-mm diam mercury droplet with a velocity of $95 \mathrm{~m} / \mathrm{s}$. [1]

Vibration: 3 times 10 minutes, $25-500 \mathrm{~Hz}$ at $49 \mathrm{~m} / \mathrm{s}^{2}(5 \mathrm{~g}$, acceleration maximum amplitude)

Presumably, this could apply to the target equipment located in the TT2A tunnel to prevent the equipment from moving during a seismic event. If this is deemed to be a requirement, the base support structure can be anchored to the tunnel floor.

Puncture: 1 gram (0.03 oz) from 1 meter, or equivalent imparted energy

By inference, a sharp object with such little momentum will not penetrate any portion of the 12.7-mm thick Lexan ${ }^{\circledR}$ cover or the 6-mm thick stainless steel sides of the secondary enclosure.

\subsection{Geometry}

The geometric configuration of the target system is based on the following criteria that optimizes muon production and results in a full-beam interaction length of $30 \mathrm{~cm}$ :

- proton beam, solenoid axis, and mercury jet all reside in a common vertical plane;

- $\quad$ solenoid axis is tilted 67 milliradians $\left(3.84^{\circ}\right)$ with respect to proton beam;

- mercury jet flows from the "up-beam" to the "down-beam" direction, the same direction as the proton beam;

- mercury jet begins above the proton beam and crosses the beam at an angle of 33 milliradians $\left(1.89^{\circ}\right)$;

- the jet crosses the beam at $\mathrm{Z}=0$, the center of the solenoid and location of the highest intensity magnetic field;

- nominal height of the proton beam is $120 \mathrm{~cm}$ (47.64 in.) above the tunnel floor;

- service end of the solenoid is positioned in the "up-beam" direction; and

- the mercury pumping loop is located "down-beam" of the solenoid.

Relative to the magnetic axis, $\mathrm{Z}=0$ at the center of the solenoid bore, $-\mathrm{Z}$ refers to the "up-beam" end of the solenoid, and $+Z$ refers to the "down-beam" end.

The technical limitations of the CERN Proton-Synchrotron (PS) accelerator machine allows the extraction of beam pulses at $24 \mathrm{GeV} / \mathrm{c}$ with a length of up to 2 micro-seconds, which corresponds to a single-turn extraction. Beyond this time limit (multi-turn fast extraction), the 
kicker has to be fired at least two times to achieve pulse lengths longer than 2 micro-seconds. The capacity of the power supply for the kicker is limited such that for multiple kicks, the momentum of the beam has to be reduced to $14 \mathrm{GeV} / \mathrm{c}$. The aim of the experiment is to study pulse lengths of up to 100 micro-seconds.

Figure 2 shows the overall geometry of the target system. Note the horizontal "kick" of 7 milliradians $\left(0.4^{\circ}\right)$ in the proton beam starting at $\mathrm{Z}=0$ for a $24-\mathrm{GeV}$ beam energy. This kick increases to 12 milliradians $\left(0.7^{\circ}\right)$ for a $14-\mathrm{GeV}$ beam.

\section{MERIT Target Baseline Configuration}

23 Nov 2005

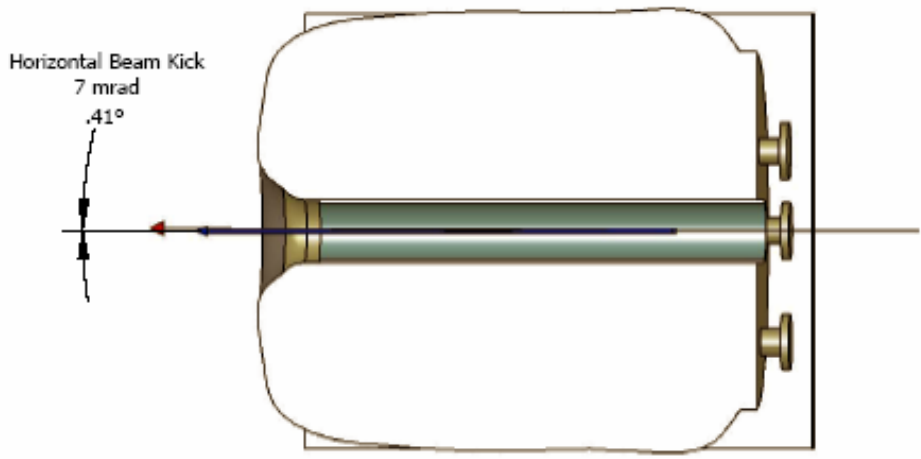

Plan View

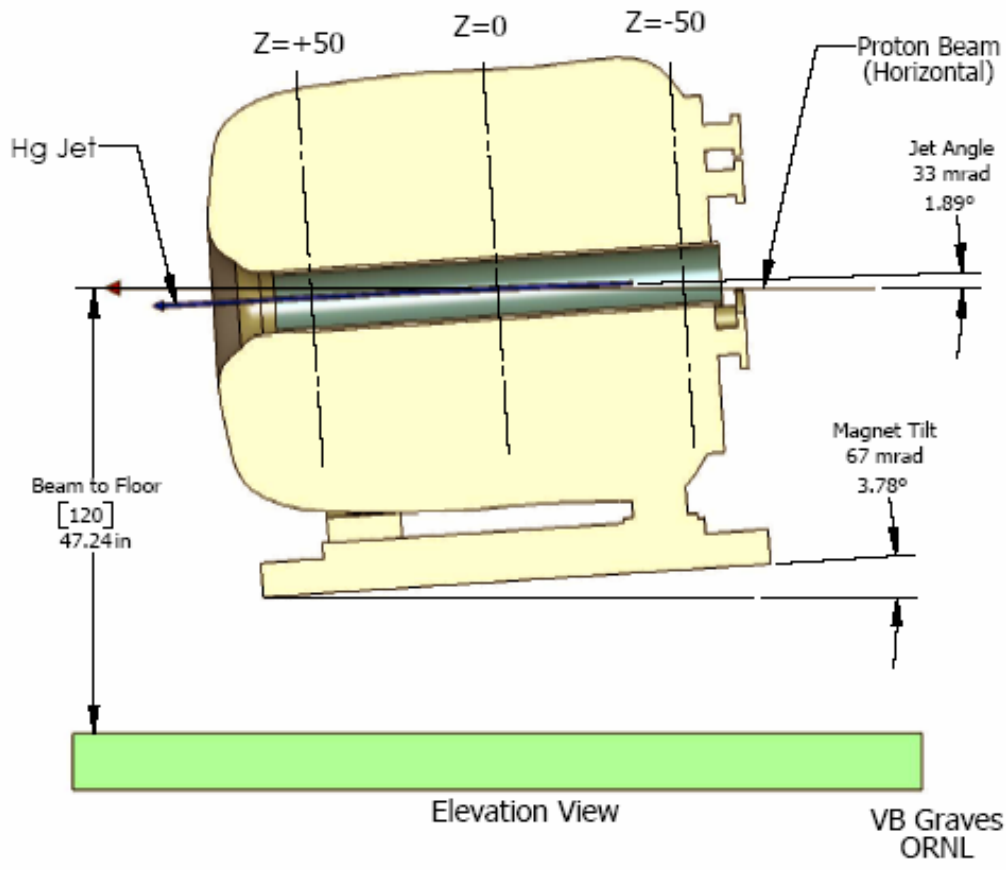

Fig. 2. MERIT baseline geometry configuration. 
Figure 3 shows a detailed view of the geometric relationships between the magnetic axis, the beam axis, and the mercury jet.

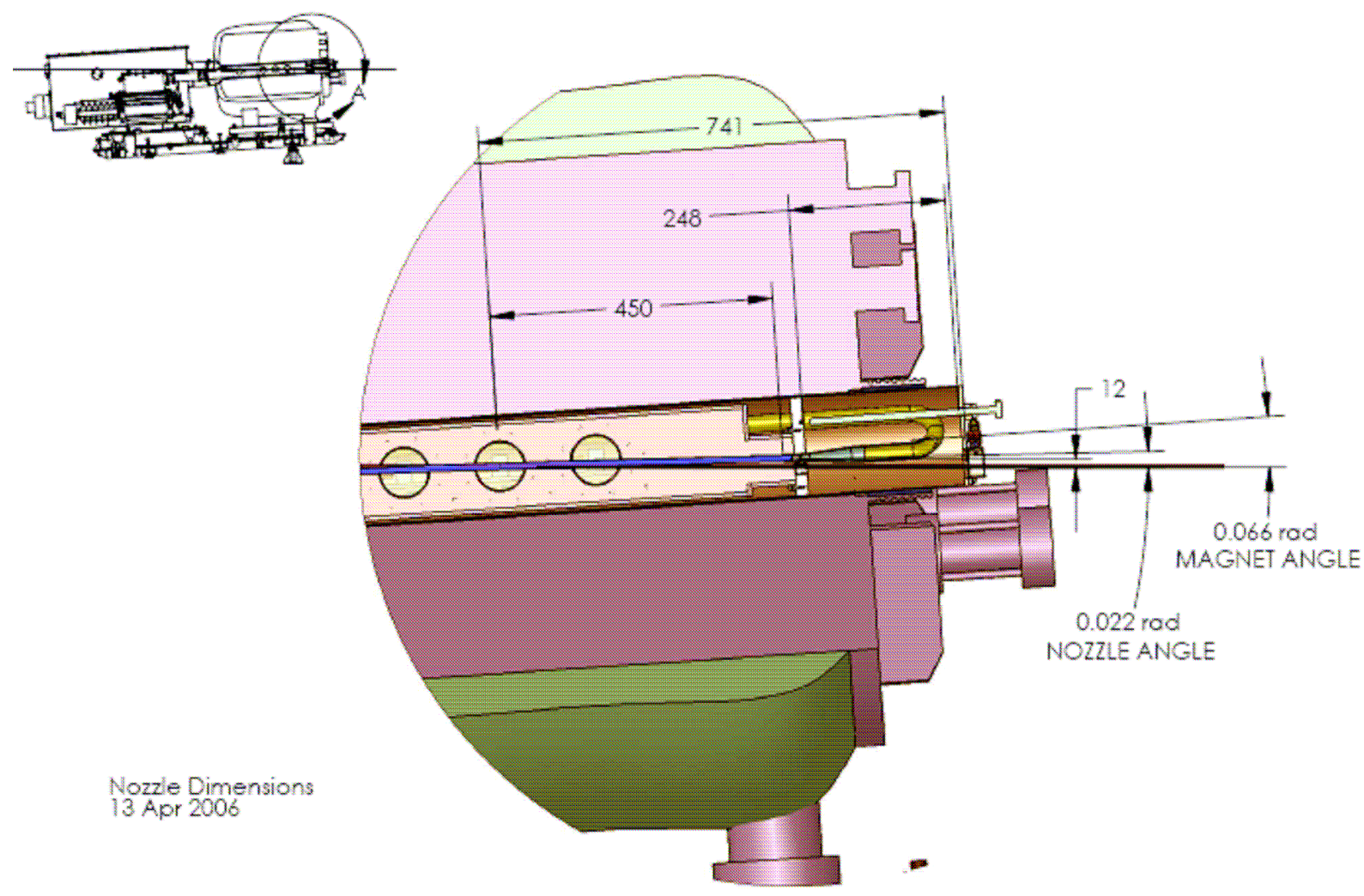

Fig. 3. Nozzle and solenoid relative to beam.

\subsection{Operating Temperature}

The operating temperature of the mercury is estimated to be between $15^{\circ} \mathrm{C}$ and $35^{\circ} \mathrm{C}$. Testing at ORNL will determine the actual temperature rise after each pulse of the jet by monitoring the temperature sensor located in the sump tank. The goal is to ensure that the temperature rise in the mercury inventory remains well below the boiling point of mercury $\left(357^{\circ} \mathrm{C}\right)$. This should be easily demonstrated because the dwell time between pulses is nominally $30 \mathrm{~min}$.

\subsection{Mercury Containment Boundaries}

\section{Primary Containment}

The primary containment boundary is defined as all mercury-wetted hardware. The primary containment includes the mercury cylinder, the nozzle and supply piping, the jet chamber with attached proton beam windows and optical diagnostic viewports, and the sump tank with its associated piping. The primary containment incorporates a minimal number of valves and fittings to reduce the possibility of leakage and to minimize flow losses in the mercury. Figure 4 shows the primary containment equipment. 


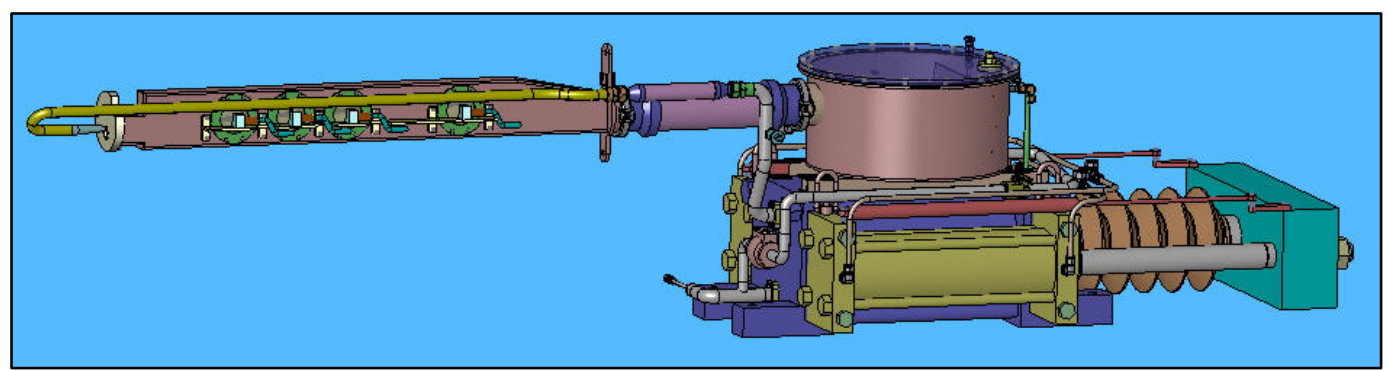

Fig. 4. Target system primary containment.

\section{$\underline{\text { Secondary Containment }}$}

The secondary containment provides the means to monitor for the presence of mercury vapor in the event of a leak in the primary containment boundary. Figure 5 is a schematic of the primary and secondary containment boundaries.

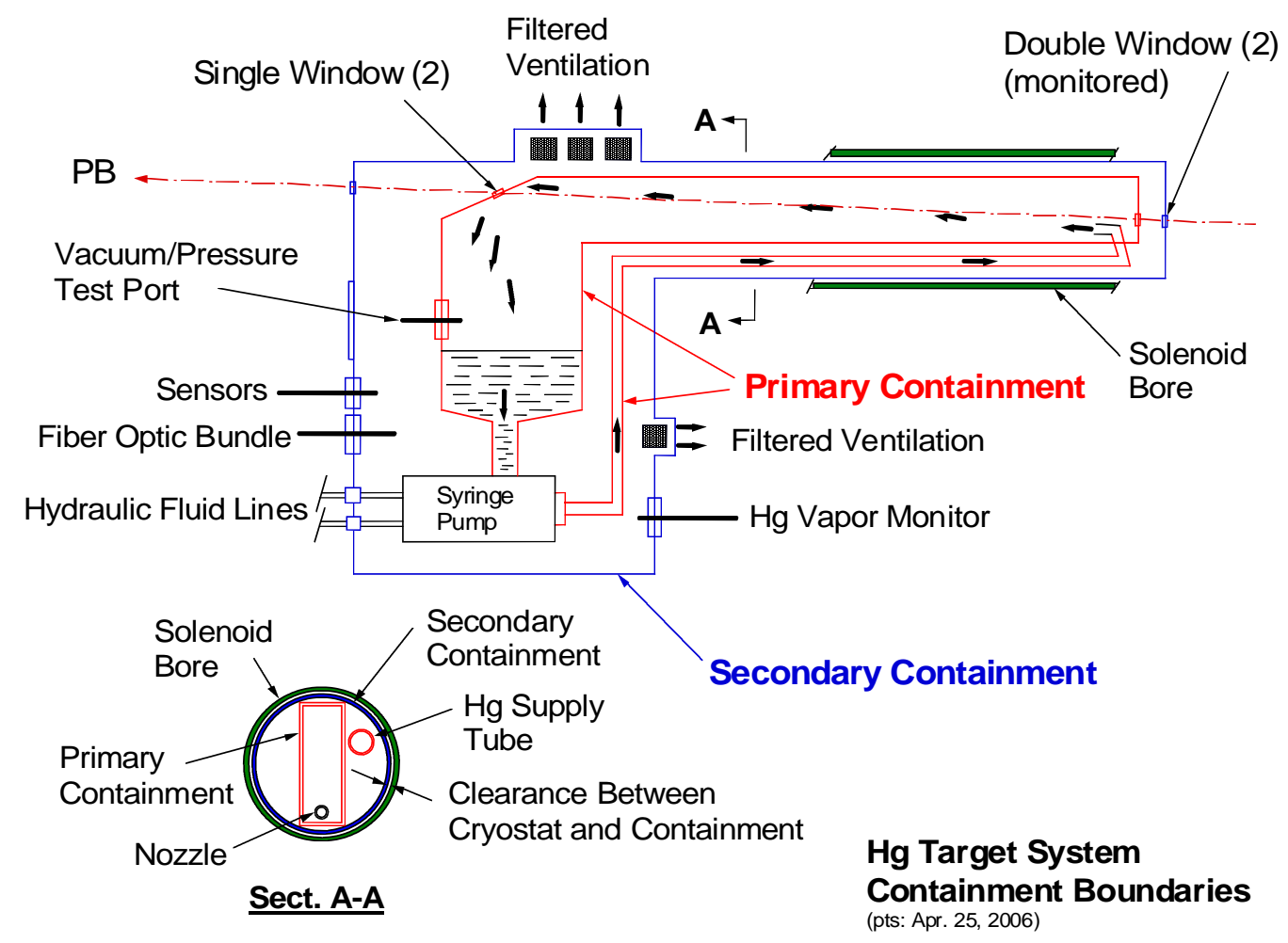

Fig. 5. Target-system containment boundary schematic. 


\subsection{Windows}

\section{Primary Containment Windows}

Two types of windows are mounted to the primary containment boundary, the proton beam windows and the optical diagnostic windows [2]. The proton beam windows are made of singlelayer, 1-mm-thick Ti6Al4V sheets. The deflector window, also made from Ti6Al4V, is $2 \mathrm{~mm}$ thick due to the possibility of the downstream jet impinging on this window. The diagnostic windows are optically transparent, single layer, $6 \mathrm{~mm}$ thick, and made from sapphire material. The diagnostic windows provide the ability to optically view the interaction region at four locations along the axis of the proton beam line. The diagnostic windows and the laser components will be provided by BNL. Since they were designed to meet the interface requirements of the primary containment, the diagnostic equipment was installed as a module.

\section{Secondary Containment Windows}

The proton beam windows that are mounted to the secondary containment are double windows with interstitial monitoring for failure due to beam interaction. The windows are made of 1-mmthick Ti6Al4V. Figure 6 shows a double window mounted to the secondary containment; the proton beam is shown in red.

In the MERIT mercury system, the beam passes through three windows prior to interaction with the mercury jet and three windows after jet interaction.

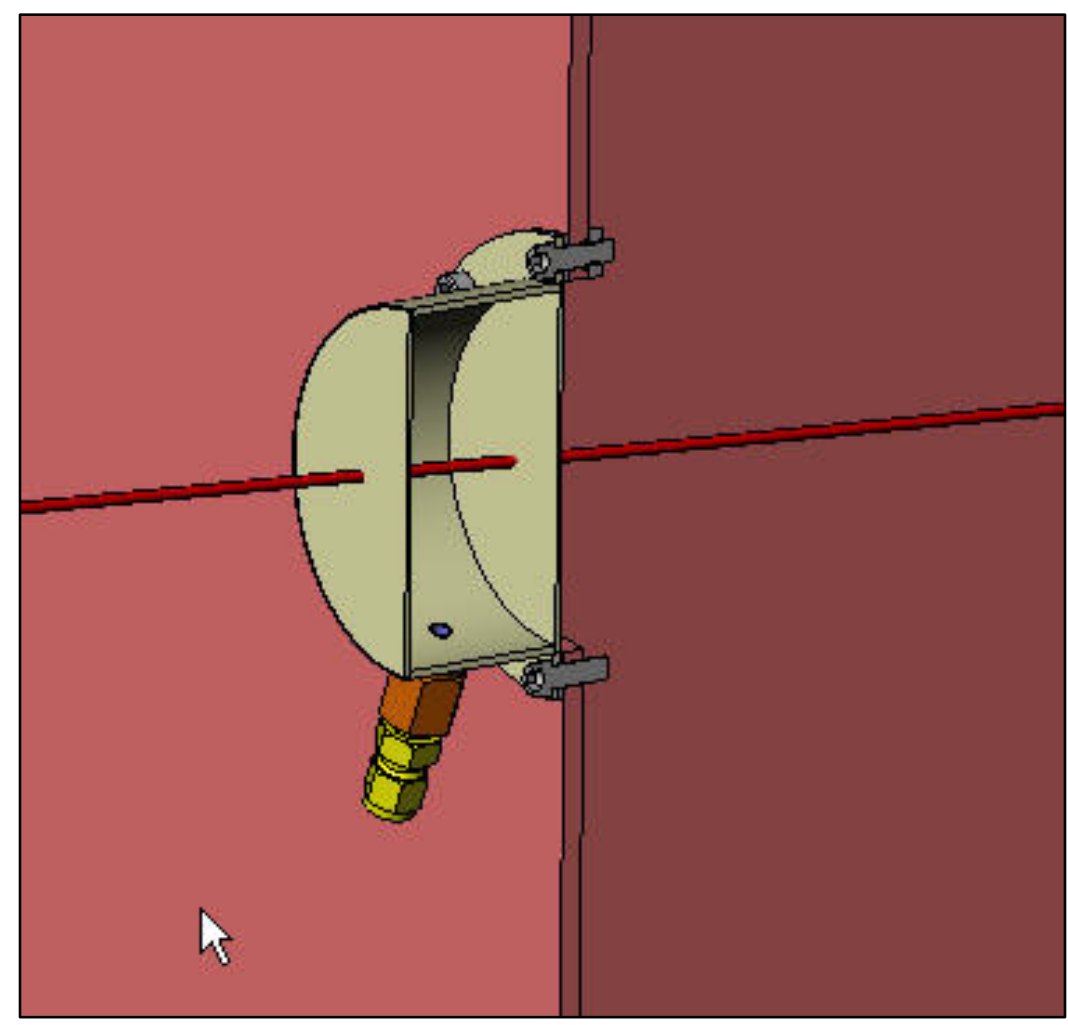

Fig. 6. Downstream beam window mounted to the secondary containment enclosure. 


\section{Diagnostic Windows}

The diagnostic windows are mounted on the primary containment at four viewing locations. Each window is made from 6-mm-thick sapphire and is mounted in a retaining ring. The backside viewports also contain a reflector assembly. Figure 7 is a section cut taken at $Z=0$ and shows the various components that make up the laser diagnostic as well as the containment boundaries, the mercury supply line, and the jet.

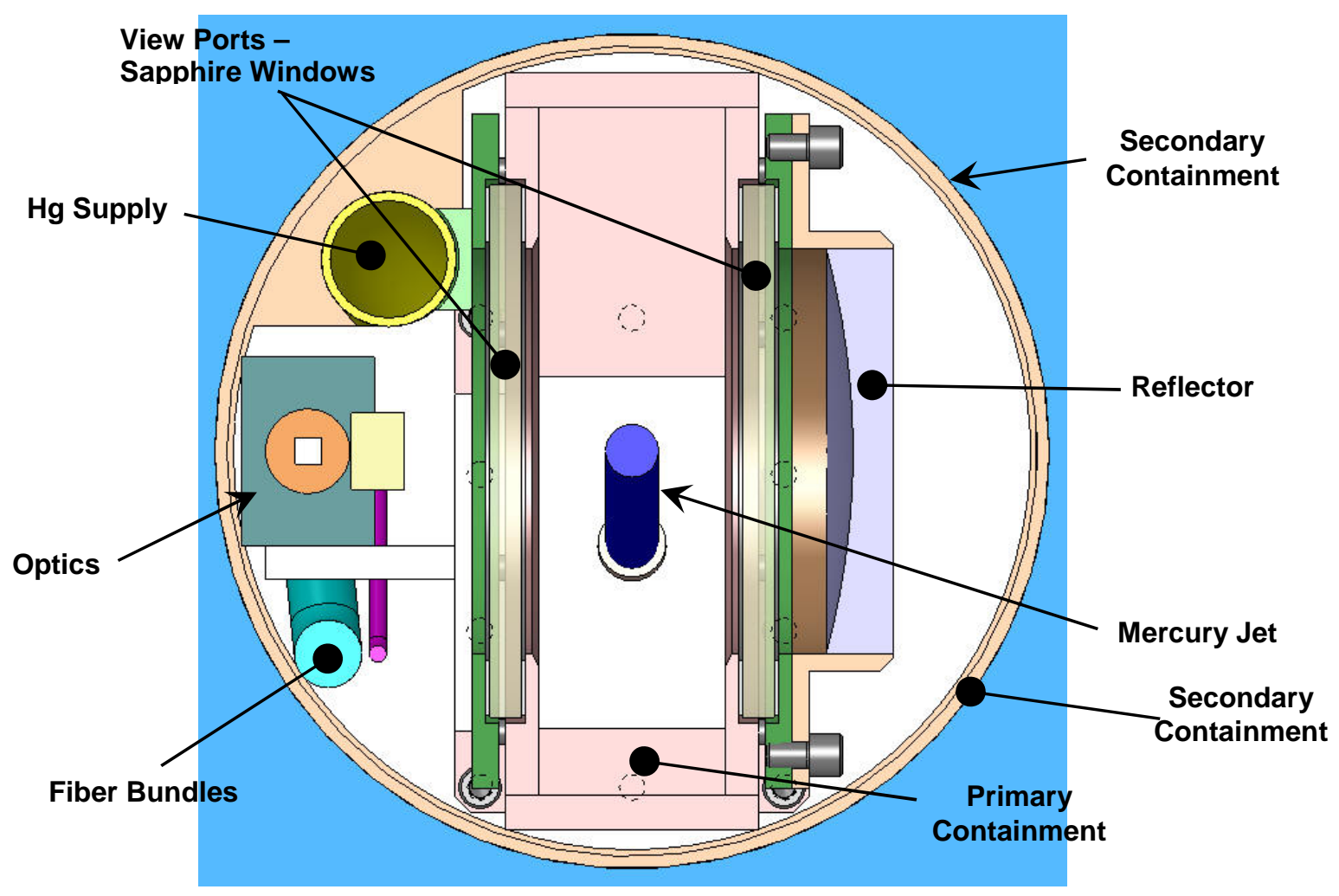

Fig. 7. Laser diagnostic components, windows, and reflector; section cut taken at $Z=0$.

Figure 8 shows a representative diagnostic support bracket and three of the four fiber bundles, prisms, and retaining rings and windows. BNL was responsible for the design and fabrication of the optical diagnostic components. Figure 9 is a window assembly that includes elastomer gaskets on both sides of each window, and Fig. 10 shows the reflector assemblies mounted opposite to each of the windows for the incoming laser light. The viewports are located at $\mathrm{Z}=-15,0,+15$, and $+30 \mathrm{~cm}$. 


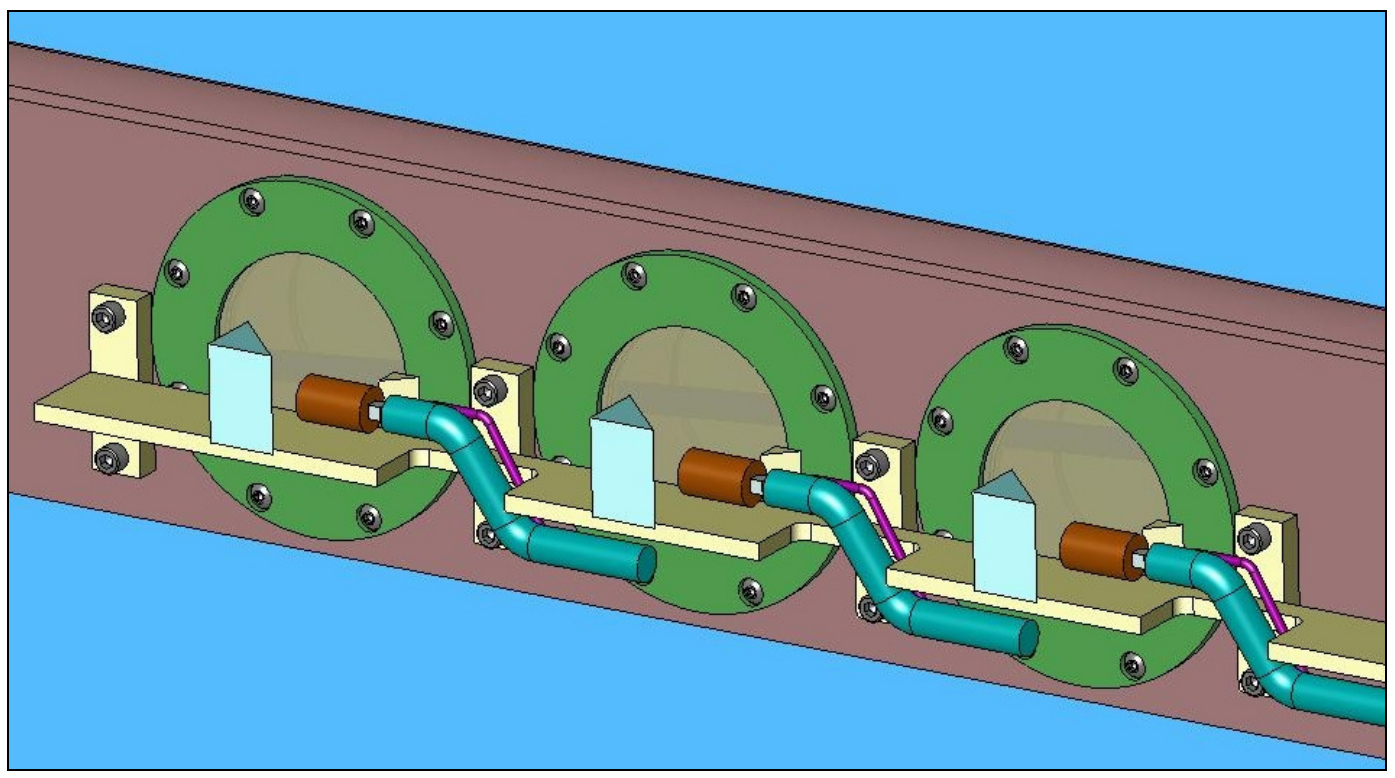

Fig. 8. Passive optical diagnostic components and support bracket.

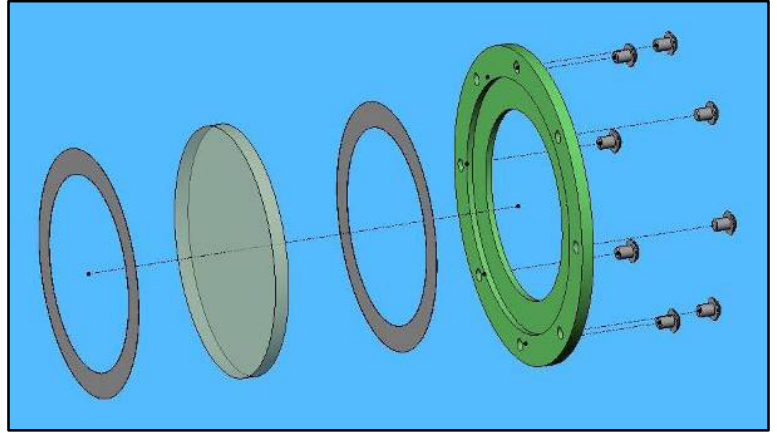

Fig. 9. Sapphire window mounted between elastomer gaskets.

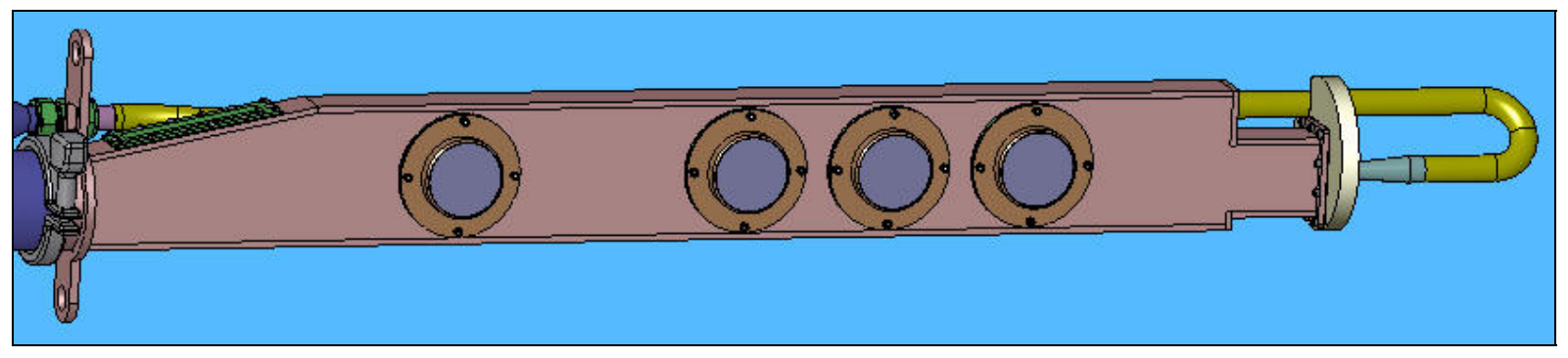

Fig. 10. Diagnostic reflector assemblies. 
Since these diagnostic assemblies have many potential leak paths, each gasketed joint will be leak-checked using the soap bubble technique prior to the start of water test operations, and again prior to starting tests with mercury.

\subsection{Alignment}

The target-system base support structure has provisions to align the assembled target for insertion into the solenoid bore, and provisions to position the assembled solenoid/target system to the proton beam line within $1 \mathrm{~mm}$. The position of the solenoid/target will be determined by taking measurements from fiducials mounted to the solenoid and target module along with beam diagnostic measurements made by the CERN PS group. Movement of the target module within the magnet bore is a concern, and a wedge system may be incorporated to hold the module rigidly within the bore.

\subsection{Assembly and Shipping}

The design and fabrication of the target system and the base support structure carefully considered the ease of assembly and disassembly, handling for transport, and handling for installation. Initially, the equipment will be shipped to MIT and back to ORNL by truck, and then to CERN in a sealand container. The target system was designed to meet the space requirements for moving components from above the ground at CERN into the tunnel areas leading to tunnel TT2A, and for the handling requirements needed by the CERN Rigging Group. Each major component has provisions for overhead lifting and pallet-like handling, and the base support structure has rotatable casters for moving the assembled target system into (and out of) the beam line. Section 1.0 discusses details about the packing and transportation of the target equipment (and the solenoid).

\subsection{Component Size and Weight}

Table 2 is a listing of the weight of each component that may be separately handled during installation at MIT or CERN.

Table 2. Estimated component sizes and weights

\begin{tabular}{|l|c|c|}
\hline & $\begin{array}{c}\text { Approximate dimensions } \\
\text { centimeters (in.) }\end{array}$ & $\begin{array}{c}\text { Estimated weight } \\
\text { kilograms (lb) }\end{array}$ \\
\hline MERIT (fully assembled on baseplate) & $406 \times 119 \times 165(160 \times 47 \times 65)$ & $7,250(16,000)$ \\
\hline Syringe pump within secondary containment & $396 \times 107 \times 135(155 \times 42 \times 53)$ & $1,360(3,000)$ \\
\hline Base support structure & $320 \times 127 \times 30(126 \times 50 \times 12)$ & $360(800)$ \\
\hline Target cart & $117 \times 84 \times 20(46 \times 33 \times 8)$ & $80(175)$ \\
\hline Target transporter & $157 \times 119 \times 30(62 \times 47 \times 12)$ & $160(350)$ \\
\hline Magnet beam support & $127 \times 25 \times 18(50 \times 10 \times 7)$ & $14(30)$ \\
\hline Hydraulic cart (w/oil) & $172 \times 102 \times 152(68 \times 40 \times 60)$ & $1,000(2,200)$ \\
\hline Hydraulic fluid drum & 61 diam $\times 97$ tall $(24$ diam $\times 38$ tall $)$ & $230(500)$ \\
\hline Mercury flask & 15 diam $\times 30$ tall $(6$ diam $\times 12$ tall $)$ & $34(76)$ \\
\hline Solenoid & $1800 \times 940 \times 1250(708 \times 370 \times 490)$ & $5,440(12,000)$ \\
\hline
\end{tabular}




\subsection{Instrumentation}

Various instruments connected to the MERIT remote-control station have been incorporated into the target system design to monitor the following parameters:

○ Mercury vapor sensor to monitor the secondary containment atmosphere

- The plan is to place the sensor in the TT2 tunnel out of the radiation environment, with a long sampling tube connected directly to the secondary containment shown in Fig. 6. Testing at ORNL determined that locating the vapor sensor up to 10 meters away could provide reliable monitoring information in a timely fashion.

○ Temperature sensor to monitor the mercury in the sump tank

- This sensor will be used to monitor the mercury temperature rise after each pulse.

- Position sensor mounted to each drive cylinder to monitor flow in the supply line

- Two position sensors (for redundancy), one mounted to each drive cylinder, will be used to calculate the flow rate of the mercury. The Labview controller will convert the linear displacement information into nozzle velocity.

- Pressure sensors in the hydraulic system, located at the hydraulic pump discharge (supply line) and the return line

- The arithmetic difference between these two sensors will indicate the pressure drop in the hydraulic loop and will be used to monitor performance of the drive cylinders.

○ Pressure sensor at the discharge end of the pump cylinder

- This sensor will monitor the mercury pressure near the mercury cylinder discharge, which will provide a means of determining total pressure drop in the mercury supply line. This information will be used to corroborate the results of the pipe flow analysis and will also quantify the additional pressure drop caused by the magnetic field.

○ Hydraulic reservoir low-level sensor with cutoff switch

- This sensor will monitor the hydraulic fluid level in the 150-liter (40-gal) reservoir tank and will automatically shut down the syringe pump system if there is a loss of fluid.

- Conductivity probe located at the low end of the secondary enclosure to monitor for a major leak

- In the event of a major leak from the primary containment, the conductivity probe will send a signal to the mercury system controller.

Table 3 is a listing of the various mercury system instruments arranged by type of sensor signal. 
Table 3. List of sensors for the target system

\begin{tabular}{|c|c|c|c|}
\hline \multicolumn{4}{|c|}{ Controlled components } \\
\hline Hydraulic pump & Proportional control valve & & \\
\hline \multicolumn{4}{|c|}{ Analog sensor inputs } \\
\hline $\mathrm{Hg}$ discharge pressure & Hg level & $\mathrm{Hg}$ vapor 1 & Hg vapor 2 \\
\hline Cylinder 1 position & Cylinder 2 position & $\begin{array}{l}\text { Beam window } 1 \\
\text { pressure }\end{array}$ & $\begin{array}{l}\text { Beam window } 2 \\
\text { pressure }\end{array}$ \\
\hline $\begin{array}{l}\text { Hydraulic fluid port } \\
\text { pressures }\end{array}$ & $\begin{array}{c}\text { Eight Resistance } \\
\text { Temperature Detectors } \\
\text { (RTD's) }\end{array}$ & & \\
\hline \multicolumn{4}{|c|}{ Digital sensor inputs } \\
\hline $\begin{array}{l}\text { Hydraulic filter dirty } \\
\text { switch }\end{array}$ & Hydraulic low-level switch & $\begin{array}{l}\text { Hydraulic fluid high } \\
\text { temperature }\end{array}$ & $\begin{array}{l}\text { Conductivity probe } \\
\text { leak detector }\end{array}$ \\
\hline Beam trigger & & & \\
\hline
\end{tabular}

It is important to keep in mind that the main purpose of the sensors is to provide the operator with information that cannot be viewed directly because of the hazardous environment during testing, and the fact that the operator will be located in a separate building.

Finally, although these are not instruments, it is worth mentioning that the top covers of the secondary enclosure and sump tank are clear Lexan ${ }^{\circledR}$. This permits visual inspection of the syringe pump equipment and also allows viewing the return flow of water or mercury into the sump tank during system testing.

\subsection{Stray Magnetic Fields}

The target system will operate in magnetic fields [3] as high as 15 Tesla at the center of the solenoid (at $Z=0, R=0$ ), decreasing to hundredths of a Tesla for equipment located away from the beam interaction point at $Z=0$. Figure 11 is a plot of the stray magnetic fields as a function of $\mathrm{R}_{\mathrm{xyz}}$ relative to the position of the pump system; the 15-Tesla location is at the center of the solenoid.

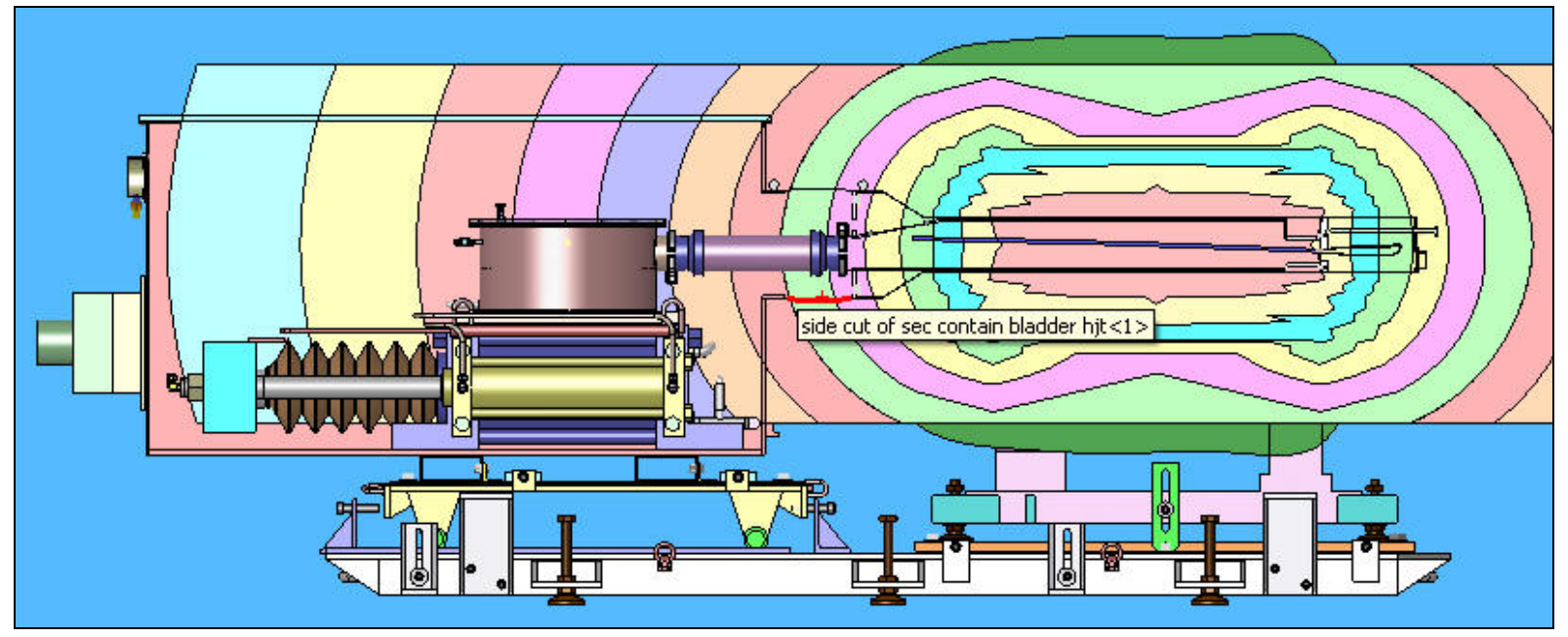

Fig. 11. Stray magnetic field plot around the solenoid and the target equipment. 
Figure 12 shows the magnitude of the field contours. The nozzle is located in a field that is $>9.7 \mathrm{~T}$, and the syringe pump cylinders are located in a field that ranges from $0.26-0.1 \mathrm{~T}$. The structural beam that connects the two drive cylinders to the pump cylinder will translate in a field that is $>0.03 \mathrm{~T}$. By using non-magnetic materials for the target system, the need to calculate and design for Lorentz forces was unnecessary.

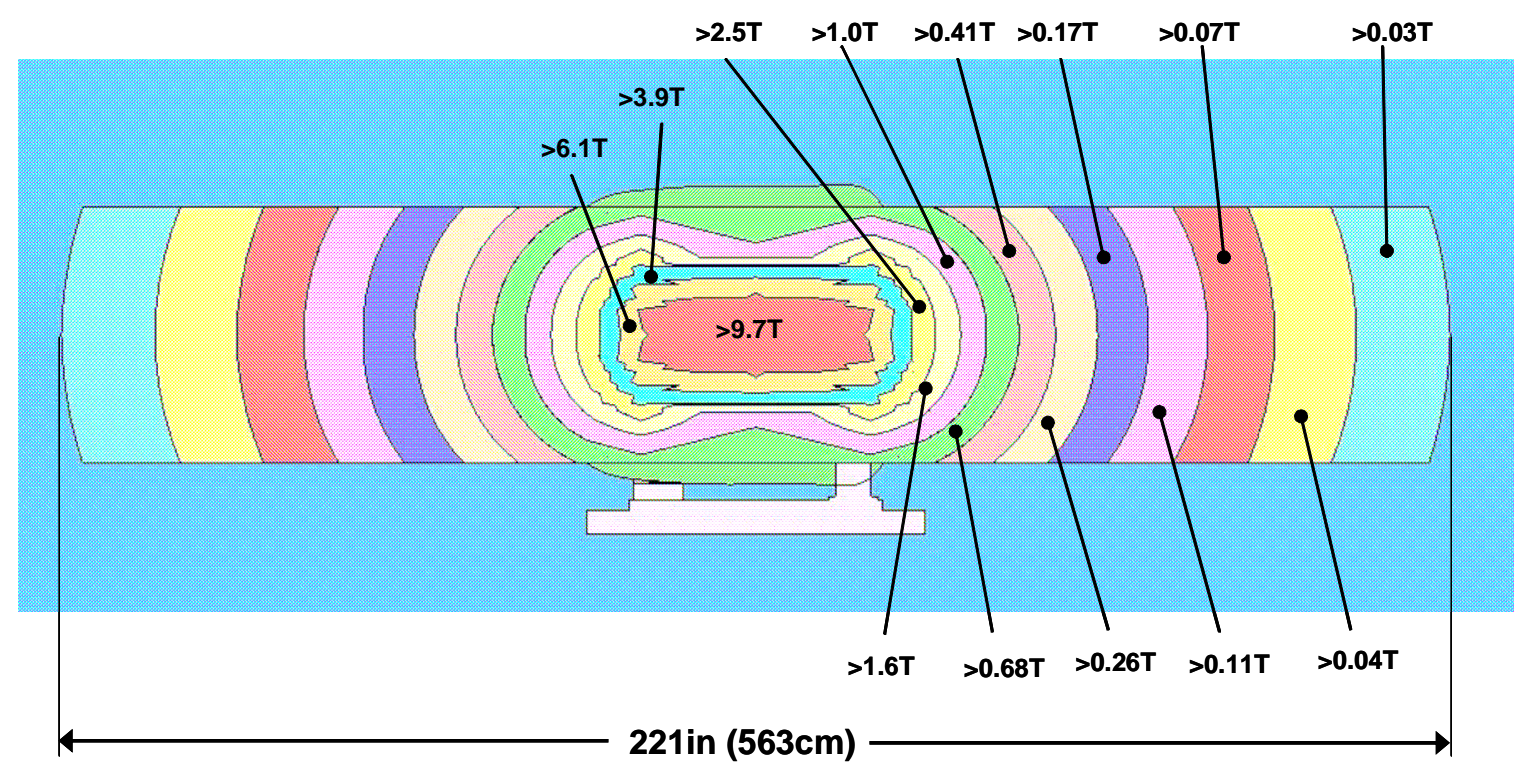

Fig. 12. Magnitude of the field contours.

\subsection{Radioactivation of Components}

Simulation analysis using the MARS 15 Code [4] indicated that the levels of radioactivity for the target system are low enough to permit hands-on access to most of the target equipment and the mercury inventory, after relatively short cool-down periods. Table 4 is a listing of representative components for the target equipment that shows absorbed dose, dose rates at shutdown, and dose rates after extended cool-down periods. The information was taken primarily from Reference 3.

Table 4. Radioactivity of target system components

\begin{tabular}{|c|c|c|c|c|c|}
\hline Component & $\begin{array}{c}\text { Absorbed dose } \\
\left(\mathbf{G r a y} / \mathbf{3}^{* 10^{15}}\right. \\
\text { protons) }\end{array}$ & $\begin{array}{c}\text { Residual dose } \\
\text { rate-at shutdown } \\
\left(\mathbf{m S v} / \mathbf{h} \mathbf{3}^{* 1 \mathbf{1 0}^{15}}\right. \\
\text { protons/30 day) }\end{array}$ & $\begin{array}{c}\text { Residual } \\
\text { dose rate- } \\
\text { at shutdown } \\
(\mathbf{m r e m} / \mathbf{h})\end{array}$ & $\begin{array}{c}\text { Residual dose rate- } \\
\mathbf{1 0 0 - h} \text { cool-down } \\
\text { (mSv/h 3*10 } \\
\text { protons/30 day) }\end{array}$ & $\begin{array}{c}\text { Residual dose } \\
\text { rate-100-h } \\
\text { cool-down } \\
\text { (mrem/h) }\end{array}$ \\
\hline $\begin{array}{c}\text { Equipment in } \\
\text { solenoid bore }\end{array}$ & $10^{4}-10^{6}$ & 1 & 100 & - & - \\
\hline $\begin{array}{c}\text { Equipment in } \\
\text { secondary } \\
\text { enclosure }\end{array}$ & $10^{2}-10^{4}$ & - & - & - & - \\
\hline Syringe Pump & - & $10^{-2}-10^{-3}$ & $1.0-0.1$ & - & - \\
\hline
\end{tabular}


Table 4 (continued)

\begin{tabular}{|c|c|c|c|c|c|}
\hline Component & $\begin{array}{c}\text { Absorbed dose } \\
\text { (Gray/3*10 } \\
\text { protons) }\end{array}$ & $\begin{array}{c}\text { Residual dose } \\
\text { rate-at shutdown } \\
\text { (mSv/h 3*10 } \\
\text { protons/30 day) }\end{array}$ & $\begin{array}{c}\text { Residual } \\
\text { dose rate- } \\
\text { at shutdown } \\
\text { (mrem/h) }\end{array}$ & $\begin{array}{c}\text { Residual dose rate- } \\
\mathbf{1 0 0 - h} \text { cool-down } \\
\text { (mSv/h 3*10 } \\
\text { protons/30 day) }\end{array}$ & $\begin{array}{c}\text { Residual dose } \\
\text { rate-100-h } \\
\text { cool-down } \\
\text { (mrem/h) }\end{array}$ \\
\hline $\begin{array}{c}\text { Top of } \\
\text { secondary } \\
\text { enclosure }\end{array}$ & - & $10^{-2}-10^{-4}$ & $1.0-0.01$ & - & - \\
\hline $\begin{array}{c}\text { Mercury vapor } \\
\text { monitor } \\
\text { (top of } \\
\text { enclosure) }\end{array}$ & $\begin{array}{c}14.0 \\
(<5-10 \text { krad for } \\
\text { electronics) }\end{array}$ & 0.95 & 95.0 & $<2.70 \times 10^{-3}$ & $<0.27$ \\
\hline Hydraulic fluid & 125 & 0.023 & 2.30 & $<1.13 \times 10^{-4}$ & $<0.01$ \\
\hline $\begin{array}{c}\text { Ventilation } \\
\text { filter in } \\
\text { secondary } \\
\text { enclosure }\end{array}$ & 505 & 1.55 & 155.0 & $<9.70 \times 10^{-4}$ & $<0.09$ \\
\hline Mercury & $10^{1}-10^{2}$ & $10^{-1}-10^{-2}$ & 10.0 & $30 \times 10^{-3 b}$ & $3.0^{b, c}$ \\
\hline
\end{tabular}

${ }^{a}$ Pure carbon material used for calculation; impregnated sulfur not included.

${ }^{b} 1$ day of decay at 1 meter distance; M. Magistris and M. Silari, EDMS No. 601754, CERN Technical Note CERN-SC-2005-049-RP-TN, June 16, 2005.

${ }^{c}$ After 1 month, dose rate at 1 -meter distance is $0.1 \mathrm{mrem} / \mathrm{h}$. 



\subsection{Component Design and Analysis}

\subsection{Flow Analysis}

An analysis of the mercury flow was performed using Applied Flow Technologies (AFT) Fathom software. Fathom is a not a computational fluid dynamics (CFD) program; rather, it is a tool used to model incompressible flow systems and includes provisions for modeling networked piping systems, pumps, valves, etc. It provides flow characteristics such as pressure and velocity as well as frictional losses throughout the entire piping system. It does not include any magnetohydrodynamic (MHD) effects, so only the no-magnetic field condition is simulated.

The mercury flow from the cylinder to the nozzle was modeled in Fathom, with geometry sizes, lengths, and elevation information obtained from the CAD model of the piping system. Fathom uses a junction-pipe terminology to describe a system: junctions are "nodes" such as tees and elbows, and pipes connect the junctions. A schematic of the model is shown in Fig. 13. The mercury cylinder was modeled as a constant flow source, and the nozzle exit was modeled as a 1-atmosphere pressure sink.

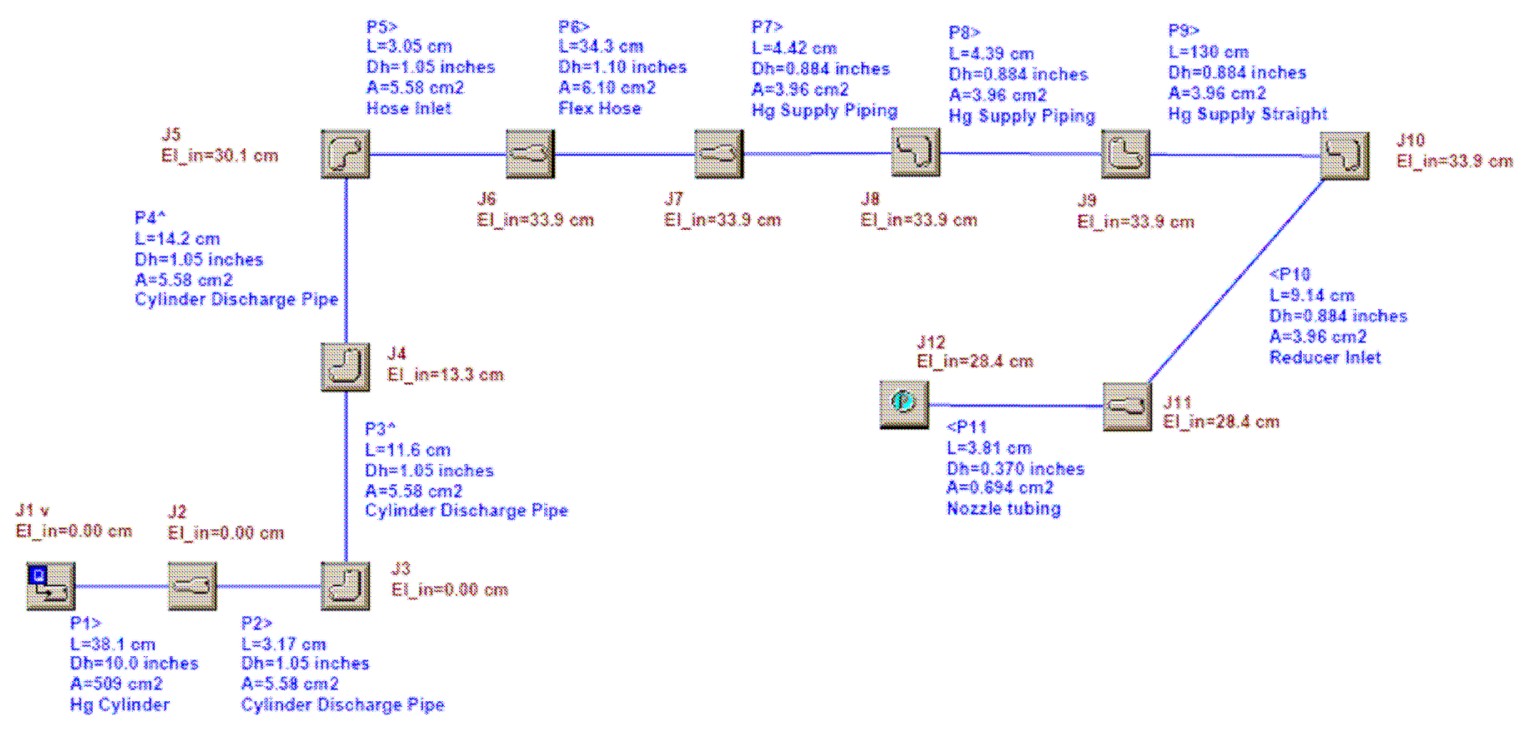

Fig. 13. Fathom input model.

By calculating the flow-induced pressure drops throughout the nozzle supply piping, an estimate of the maximum mercury cylinder pressure can be obtained. Results of this analysis (shown in Fig. 14) showed a cylinder pressure of approximately 45 bar $(650 \mathrm{psi})$ for nominal flow conditions of a 1-cm-diam, 20-meters/sec mercury jet, which requires 1.6 liters/sec (25 gpm). As described in Sections 3.2 and 3.3, the cylinder and primary containment have a design pressure of $100 \mathrm{bar}(1500 \mathrm{psi})$ to accommodate any underestimation of the system pressure drop as well as MHD-induced pressure losses. 


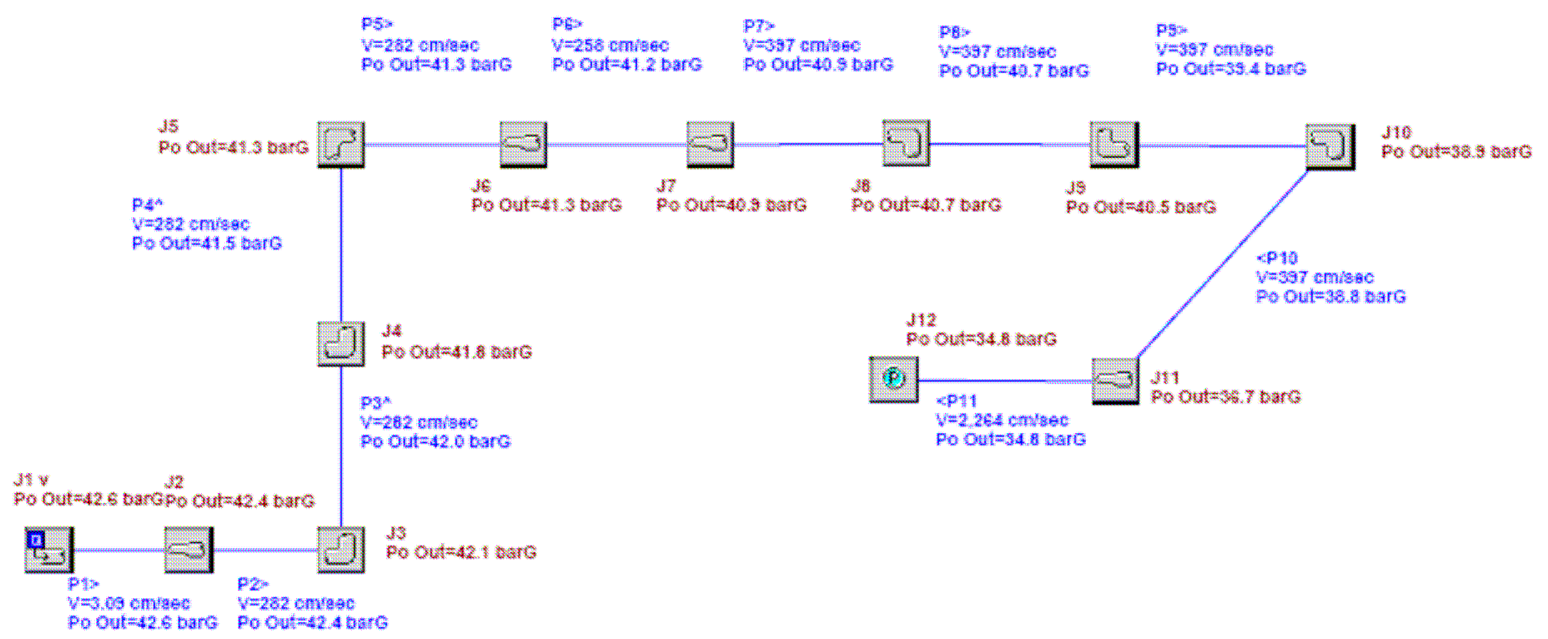

Fig. 14. Fathom stagnation pressure output.

\subsection{Syringe Pump System}

Due to the intermittent nature of the MERIT experiment and also due to pressure and temperature issues in using a centrifugal pump, a syringe pump was chosen as the mercury fluid mover. The mercury cylinder was sized to provide up to $12 \mathrm{sec}$ of jet at nominal flow conditions. Due to the geometric restrictions of the experiment equipment layout and installation of the system into the TT2A tunnel, the mercury cylinder size was chosen as 25.4-cm (10-in.) diameter and 38.1-cm (15-in.) stroke, with two side-mounted hydraulic cylinders that will provide motion to the syringe. The fully assembled pump system is shown in Fig. 15. A large tie-beam is used to connect the drive cylinder rods to the mercury cylinder rod; the two drive cylinders are actuated in unison through the hydraulic system piping. Since the three cylinders are only connected through the tie-beam, the cylinder volumes are completely separated, so no interaction between the mercury and the hydraulic fluid is possible. All cylinder and tie-beam materials are nonmagnetic due to the relative proximity to the high field of the solenoid.

The hydraulic power unit (HPU) which actuates the drive cylinders is shown in Fig. 16. The pump system will be located in the TT2 tunnel; hoses connecting the drive cylinders with the pump will traverse though the wall separating the TT2 and TT2A tunnels. Low-flammability, vegetable-oil-based hydraulic fluid is used for this experiment.

The HPU has on-board manual controls (shown in Fig. 17) for basic syringe pump operation, but they are not designed for the precise velocity control needed in the MERIT experiment. Power On/Off, system enable, local emergency stop, and HPU diagnostic indicators are the only local controls provided. A separate pendant-controlled emergency stop is also part of the HPU system. A laptop computer running Labview software will be used as the remote control system. More details of this control scheme are provided in Section 3.6. 


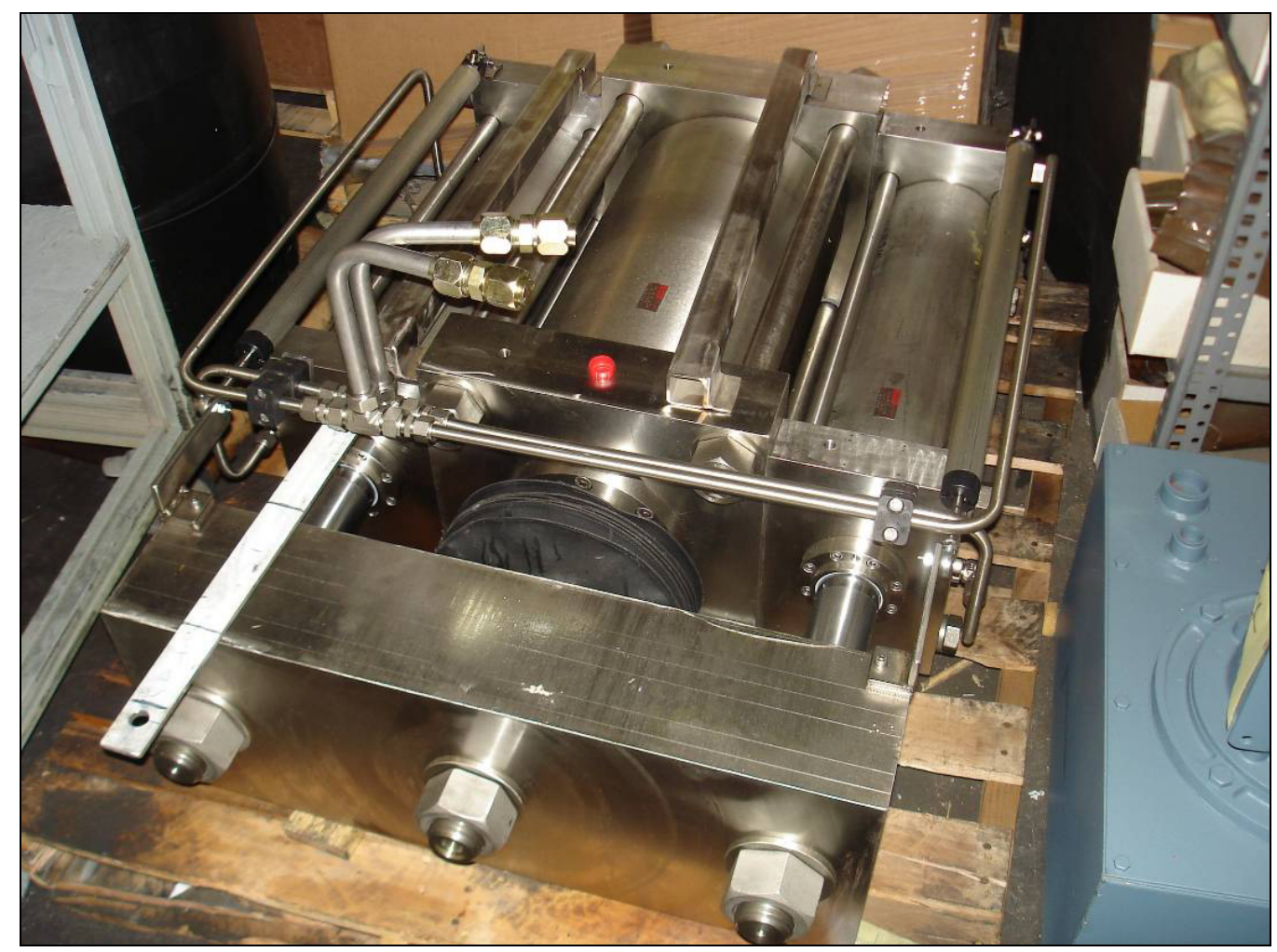

Fig. 15. Syringe pump cylinders.

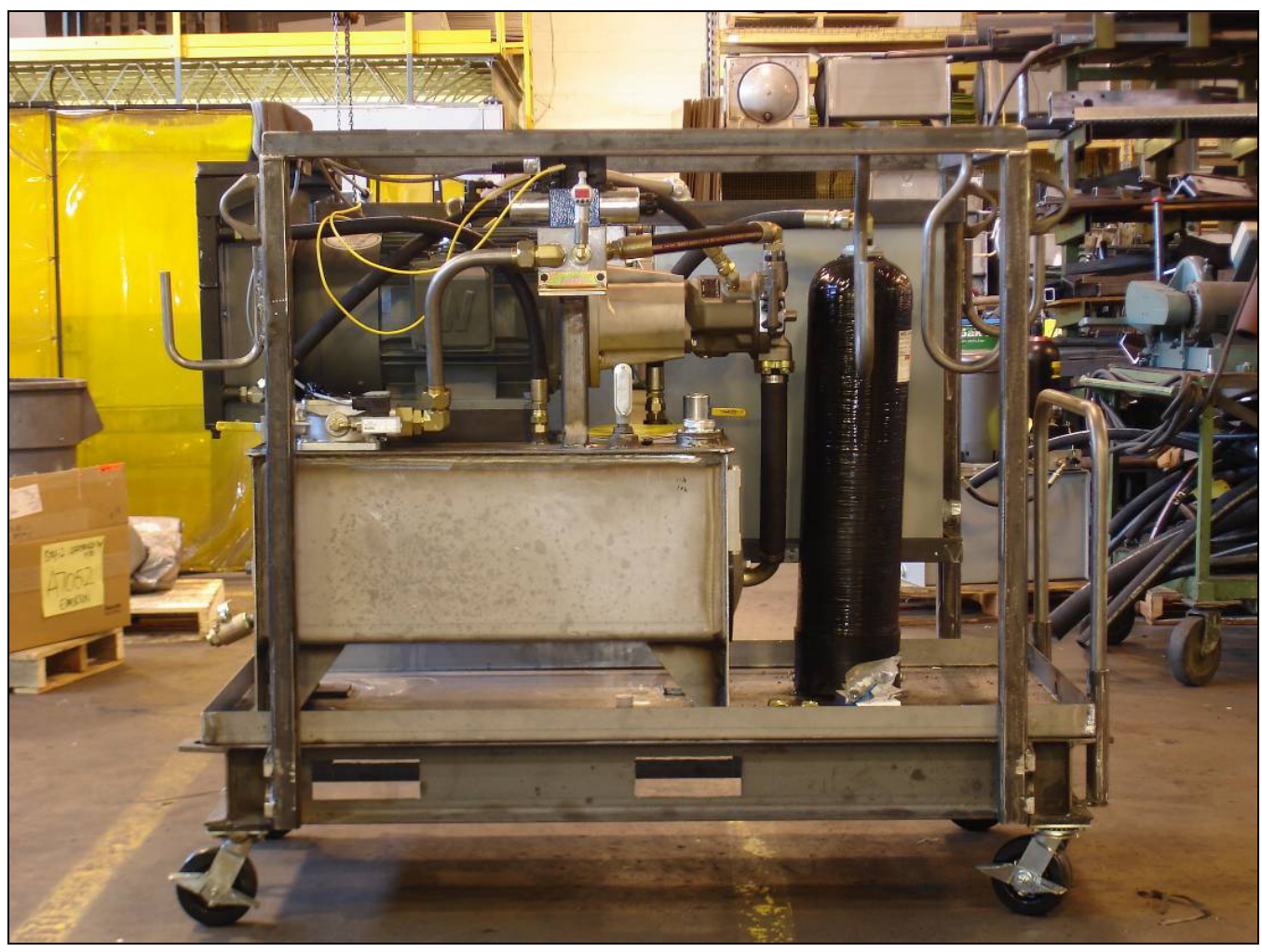

Fig. 16. Hydraulic pump system. 


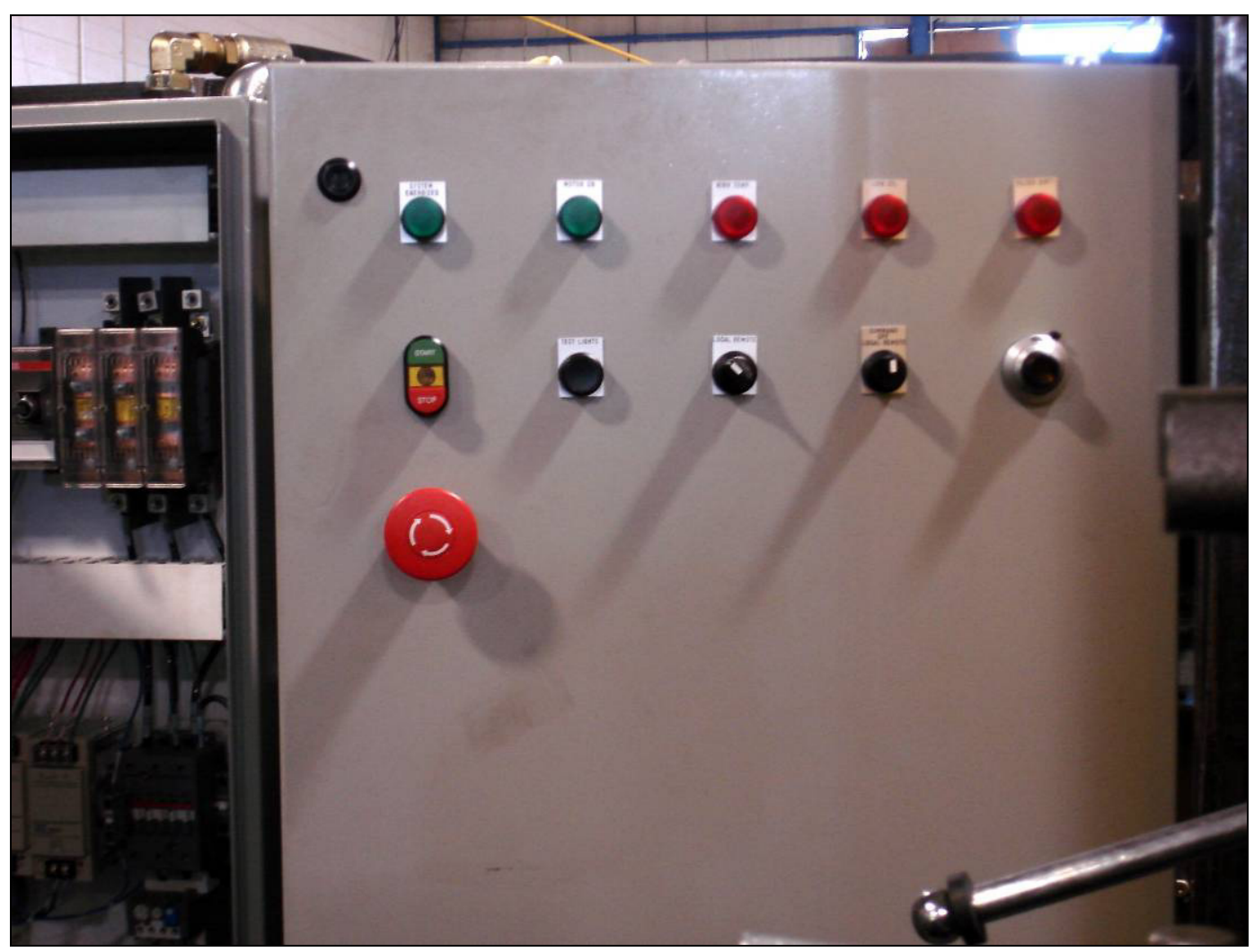

Fig. 17. Syringe HPU on-board controls.

Design and fabrication of the syringe pump system was performed by Airline Hydraulics Corporation (Bensalem, PA, USA). A summary of the syringe system design and performance characteristics is shown in Table 5.

Table 5. Syringe pump performance parameters

\begin{tabular}{|c|c|}
\hline Parameter & Value/description \\
\hline Design standard & $\begin{array}{c}\text { ANSI/B93.10-1996, Static Pressure Rating Methods of } \\
\text { Square Head Fluid Power Cylinders }\end{array}$ \\
\hline Dimensions & $\begin{array}{l}\text { Hg cylinder: } 25.4-\mathrm{cm} \text { (10-in.) diam, 38.1-cm (15-in.) stroke, } \\
\text { Drive cylinders: } 15.2-\mathrm{cm}(6-\mathrm{in} .) \text { diam, } \\
\text { 38.1-cm (15 in.) stroke }\end{array}$ \\
\hline Piston velocity & $3 \mathrm{~cm} / \mathrm{sec}(1.2 \mathrm{in} . / \mathrm{sec})$ at nominal condition \\
\hline Design pressure & $\begin{array}{l}\text { Hg cylinder: } 103 \text { bar }(1500 \mathrm{psi}) \\
\text { Drive cylinders: } 206 \text { bar }(3000 \mathrm{psi})\end{array}$ \\
\hline Pump pressure & 206 bar (3000 psi) \\
\hline Operational safety features & $\begin{array}{l}\text { Hydraulic fluid high-temperature switch } \\
\text { High-pressure relief valve }\end{array}$ \\
\hline Hoses & 3/8-in., stainless steel \\
\hline Hydraulic pump reservoir & $40 \mathrm{gal}$ \\
\hline Hydraulic fluid & Quintalubric-888 \\
\hline
\end{tabular}




\subsection{Primary Containment}

By definition, the primary containment system consists of all the mercury-wetted components and includes the mercury cylinder, nozzle and associated supply piping, jet chamber and optical view ports, primary beam windows, and the sump tank with its associated piping. Figure 18 shows a model of the entire primary containment system. With the exception of seals, all primary containment components are stainless steel, titanium, Teflon, or sapphire.

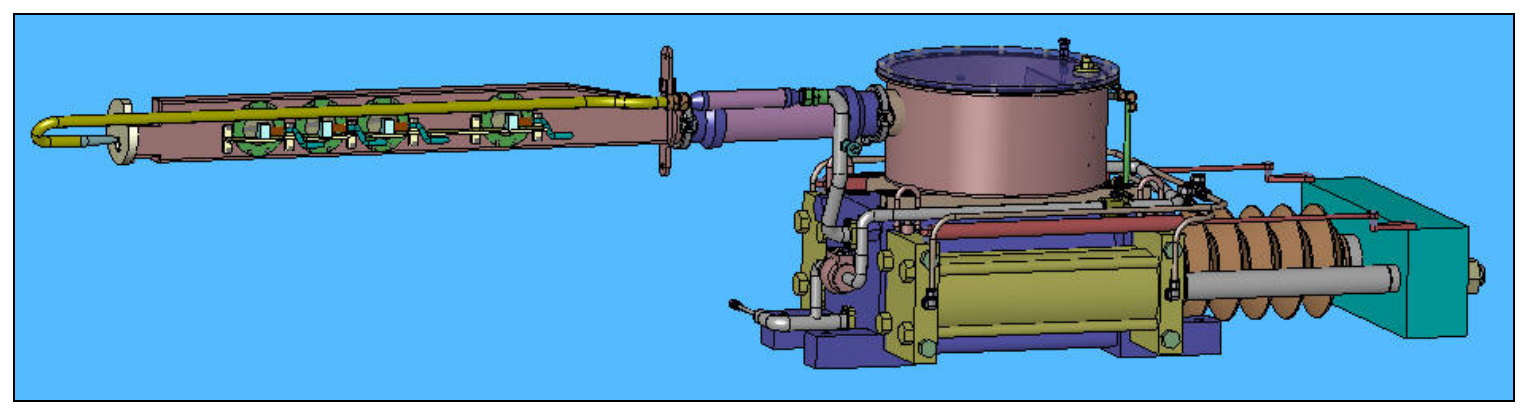

Fig. 18. Primary containment.

The target module portion of the mercury system was designed to fit within the bore of the solenoid. During the thermal cycle of the solenoid, its bore will shift vertically and axially on the order of a few millimeters. Because the target module rests in the solenoid bore, it has to accommodate these positional shifts. Hence, it incorporates flexible supply-and-return mercury flow paths through the use of short sections of hose while all other mercury flow-path components are rigid.

\section{$\underline{\text { Description and Pressures }}$}

Primary containment is designed as a closed-volume with a 1-atm air environment. The volume consists of the sump tank, both sides of the mercury cylinder, and all mercury piping. As the mercury cylinder is extended and retracted, the air volume on the rod end of the cylinder is connected to the sump tank through tubing, so if a significant quantity of mercury leaks past the piston seals, it would be directed back into the sump tank as the cylinder extended. In addition, the mercury cylinder rod may be exposed to mercury vapor inside the cylinder; the rod is covered with a bellows to prevent any vapors from entering the secondary containment, and the bellows is vented directly to the secondary containment (primary) charcoal filter.

While the entire primary containment is exposed to contact with mercury liquid or vapors, not all of it is exposed to high pressure. The mercury jet chamber, the return hose, the sump tank, and the sump-tank drain line to the check valve should never experience pressures over atmospheric during normal operations. Leak-checking operations may require that these components be pressurized to 1-atm gauge or possibly vacuum conditions.

No operating scenario is expected in which the sump tank will experience an over-pressure condition. However, should one occur, the sump tank incorporates a check-valve to protect the system, and the check-valve exhaust is vented to the charcoal filter. This protection system may actuate during the mercury fill operation since mercury will displace air inside the sump tank. 
Flow through the system is as follows and is partially shown in Fig. 19. The mercury cylinder is fitted with two flanged ports on the piston end; the lower one is the inlet, and the upper one is the discharge. Mercury is gravity-fed from the sump tank through a manual shut-off valve and a check-valve to the cylinder inlet as the cylinder is slowly extended. Since the manual valve is not accessible through the secondary containment, its primary use will be during ORNL testing, and it will remain open during shipment and installation at MIT and CERN. The mercury cylinder inlet also serves as the system drain and is plumbed through a manual valve and quickdisconnect to the secondary containment wall; the valve protects the quick-disconnect and will be exposed to cylinder pressure during each stroke of the cylinder. The check-valve prevents mercury from returning to the sump tank during a stroke.

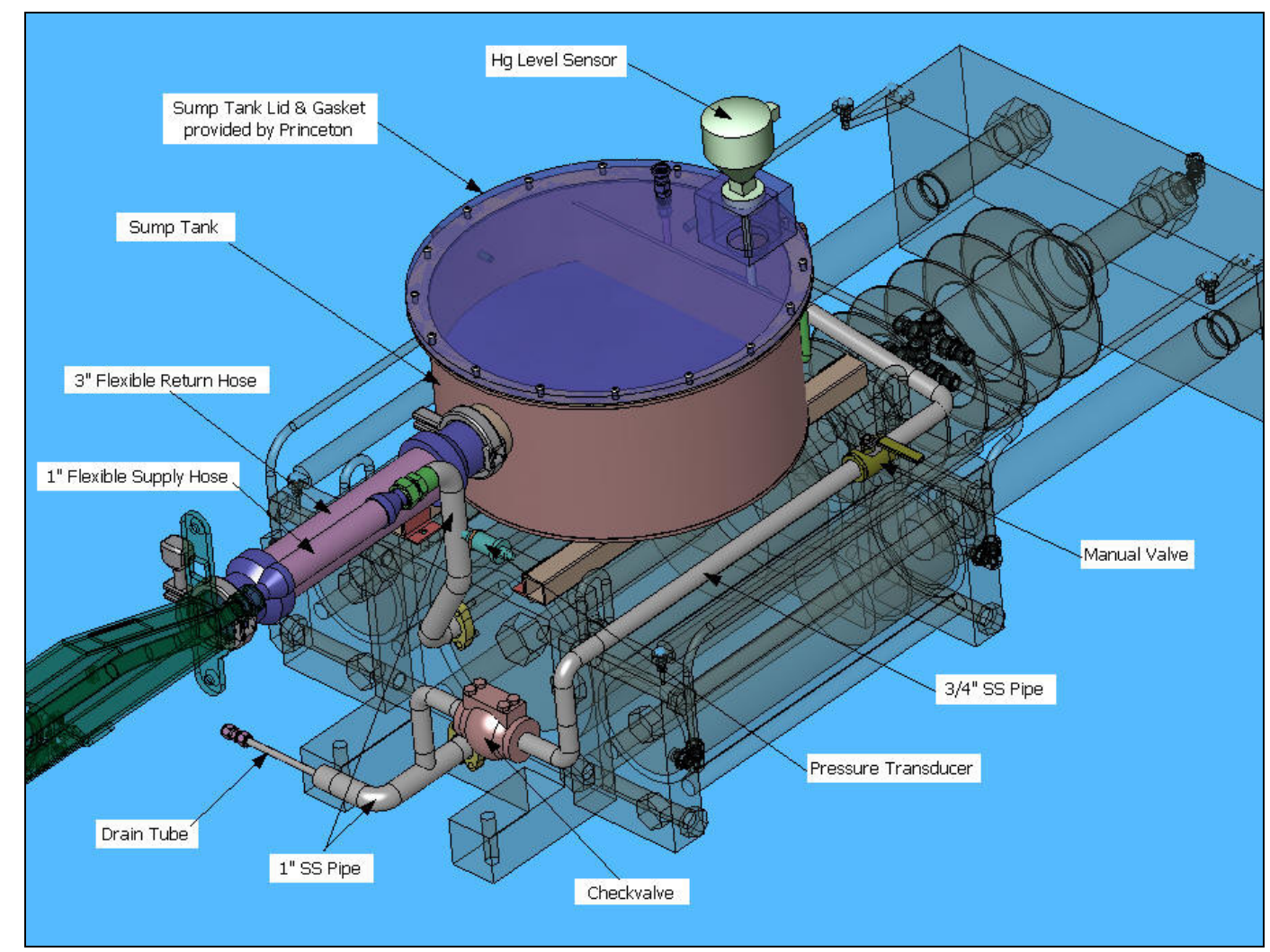

Fig. 19. Sump tank and piping.

During a pressure stroke, mercury is expelled from the cylinder through the discharge port and travels through the nozzle supply piping, performs a $180^{\circ}$ change of direction and a reduction in flow area, and is finally ejected into the jet chamber as a 1-cm-diam jet. The majority of the mercury supply piping is 1-in. Schedule 40 and 3/4-in. Schedule 10 welded piping and is fabricated to ASME IX standards. Commercially available components were used wherever possible. Table 6 lists all the components that will be pressurized during a stroke. It is noted that the mercury supply components were designed to match the pressure rating of the mercury cylinder, but since the mercury pressure increases from the nozzle to the cylinder, as long as the cylinder pressure does not exceed its rating, the pressure in the downstream components cannot exceed the cylinder pressure. The mercury pressure will be monitored close to the cylinder discharge, and the system pressures were fully characterized through testing at ORNL and MIT prior to equipment installation at CERN. 
Table 6. Mercury supply component pressure ratings

\begin{tabular}{|c|c|c|c|}
\hline Component & Material & Description & $\begin{array}{l}\text { Pressure rating, } \\
\text { bar (psi) }\end{array}$ \\
\hline Hg cylinder & SS & $\begin{array}{l}\text { 10-in. bore, } 15 \text {-in. stroke } \\
\text { hydraulic cylinder }\end{array}$ & $103(1500)$ \\
\hline Cylinder drain tubing & SS & 3/8-in., 0.065 -in. wall rigid tubing & $350(6500)$ \\
\hline Cylinder drain valve & SS & Swagelok SS-8UW-TP3 & $170(2500)$ \\
\hline $\begin{array}{c}\text { Cylinder drain quick- } \\
\text { disconnect }\end{array}$ & SS & Swagelok SS-QC6-S1-600 & $\begin{array}{l}103 \text { (1500) coupled, } \\
17 \text { (250) uncoupled } \\
\end{array}$ \\
\hline Cylinder discharge & SS & 1-in., SCH40 piping & $130(1900)$ \\
\hline $\mathrm{Hg}$ cylinder inlet piping & SS304L & 3/4-in. SCH40 piping & $\begin{array}{l}225 \text { (3300) per } \\
\text { ASME IX }\end{array}$ \\
\hline $\mathrm{Hg}$ cylinder inlet piping & SS304L & 1-in. SCH40 piping & $\begin{array}{l}210 \text { (3100) per } \\
\text { ASME IX }\end{array}$ \\
\hline $\begin{array}{l}\text { Hg cylinder inlet } \\
\text { checkvalve }\end{array}$ & SS & Warren $1503 \mathrm{HF}$ & $103(1500)$ \\
\hline Pipe weld connector & SS & Swagelok 1-in. SS-1610-1-16W & $165(2400)$ \\
\hline Flexible hose & SS/Teflon & Swagelok 8R series & $137(2000)$ \\
\hline Hg supply line & $\mathrm{Ti}$ & 3/4-in. SCH10 piping & $165(2400)$ \\
\hline $\mathrm{Hg}$ supply reducer & Ti6Al4V & Custom design & $180(2600)$ \\
\hline Nozzle & $\mathrm{Ti}$ & 12-mm, 1-mm wall rigid tubing & $200(2900)$ \\
\hline
\end{tabular}

As the jet leaves the nozzle, it will be contained within the jet chamber and may strike the titanium deflector plate that also serves as the primary exit beam window. To make the window design more conservative, the window thickness was increased from $1 \mathrm{~mm}$ to $2 \mathrm{~mm}$ to accommodate the impact loading of the mercury jet. The mercury exits the rectangular chamber and returns to the sump tank through a 4-in. flexible stainless-steel hose.

\section{Flow Forces}

The analysis of the flow forces in the mercury supply-line bend was performed for the worstcase flow problem. Figure 20 is a schematic diagram of the flow forces at the pipe bend.

Results of this analysis gave a resultant force of $2 \mathrm{kN}(450 \mathrm{lbf})$ in the $+X$ direction, which would tend to separate the nozzle flange from the jet chamber flange if the entire mercury flow path were rigidly constructed. However, the flexible hoses on both the supply and return flows will be more compliant than the flange interface, so the possibility of leakage due to this separating force is minimal. Movement of the entire target module due to the flow force is of more concern from an alignment standpoint, and testing at ORNL will determine whether physical restraints are needed. 


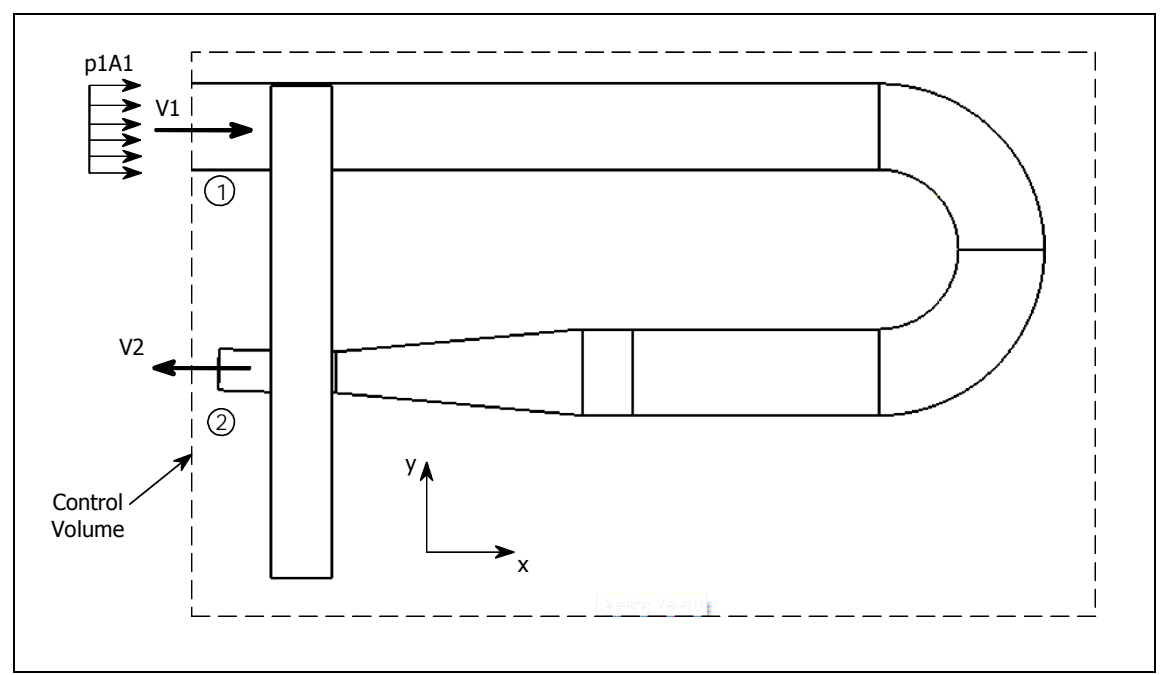

Fig. 20. Mercury axial flow force analysis.

\subsection{Secondary Containment}

The secondary containment portion of the mercury delivery system surrounds the primary containment and prevents any leaks of liquid mercury or mercury vapors from escaping into the TT2A tunnel during operations. Shown in Fig. 21, it is comprised of the following components:

- stainless-steel box housing the syringe cylinders and sump tank;

- Lexan cover with gasket;

- stainless-steel circular sleeve covering the jet chamber and optical diagnostics;

- flexible stainless-steel duct connecting the sleeve to the box;

- target module support structure used during shipping and handling;

- two double-beam windows with provisions for leakage monitoring;

- multiple ports to allow access to the interior volume for hydraulic fluid, mercury fill and drain, and sensors; and

- filtration systems to trap mercury vapors.

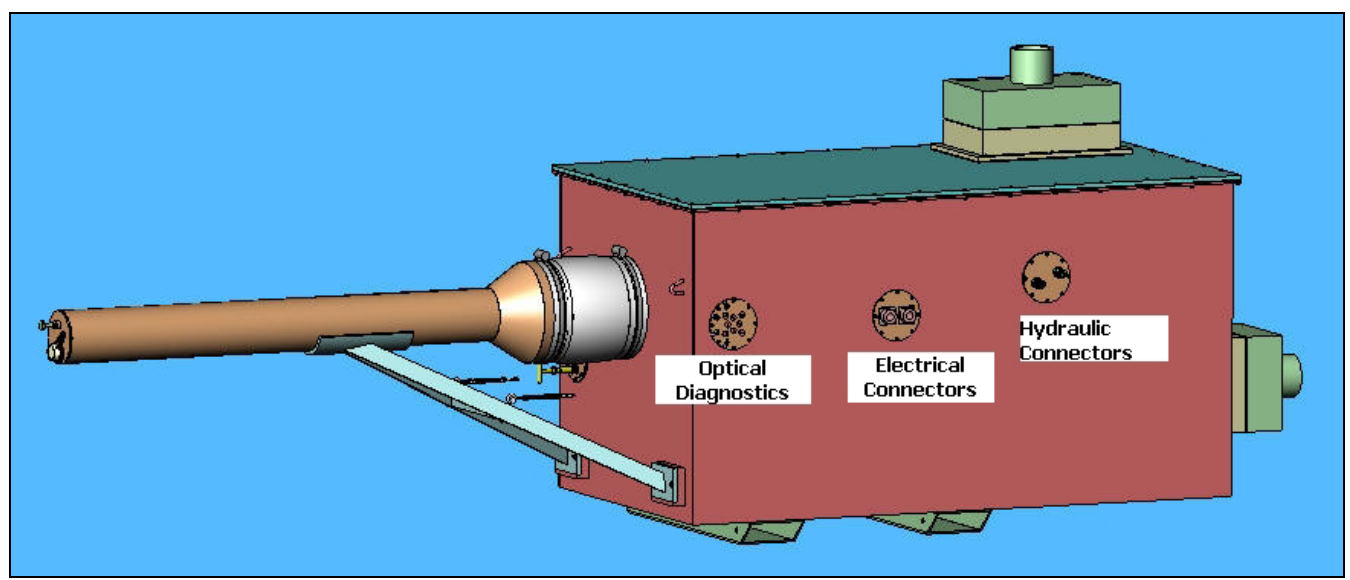

Fig. 21. Secondary containment left side. 
There are several ports into the secondary containment box. Each port cover flange utilizes a gasket to seal against the exterior of the box. The various flanges are shown in Figs. 21 and 22, and their functionality is as follows:

- Hydraulic: two quick-disconnects for the hydraulic fluid supply and return hoses.

- Electrical: two Amphenol ${ }^{\circledR}$ connectors for multi-conductor cables used for syringe and environment sensors.

- Optics: multiple optical fibers (light sources and receivers) for up to four view ports.

- Mercury drain: manual valve and quick-disconnect used to extract mercury from the delivery system without opening the secondary containment. An external pump will be used to extract the mercury. As mentioned in Section 3.3, the mercury drain port is exposed to full cylinder pressure during each jet formation. The manual valve serves as a protecting device so that the quick-disconnect is isolated from these pressure pulses; during system installation, this valve will be wire-tied in the closed position. It should be noted that with a special connecting plug installed, the quick-disconnect is also rated to accommodate full cylinder pressure.

- Mercury fill: quick-disconnect used to load mercury into the sump tank without opening the secondary containment.

- Emergency mercury extraction: quick-disconnect with rigid tubing into small sump within the secondary containment. Should a major breach of the primary containment occur, mercury will collect in this sump and can be removed using an external pump.

- Mercury vapor filters: two filter assemblies consisting of sulfur-impregnated charcoal and HEPA filters, along with a port for attaching an external ventilation system. Normally the ports will be capped; however, should an event occur such that elevated mercury vapor levels are observed, these ports can be used to remove the vapors from the containment. Having two ports allows one to be used as a fresh air inlet while vapors are extracted from the other. It also provides a mechanism to change filters.

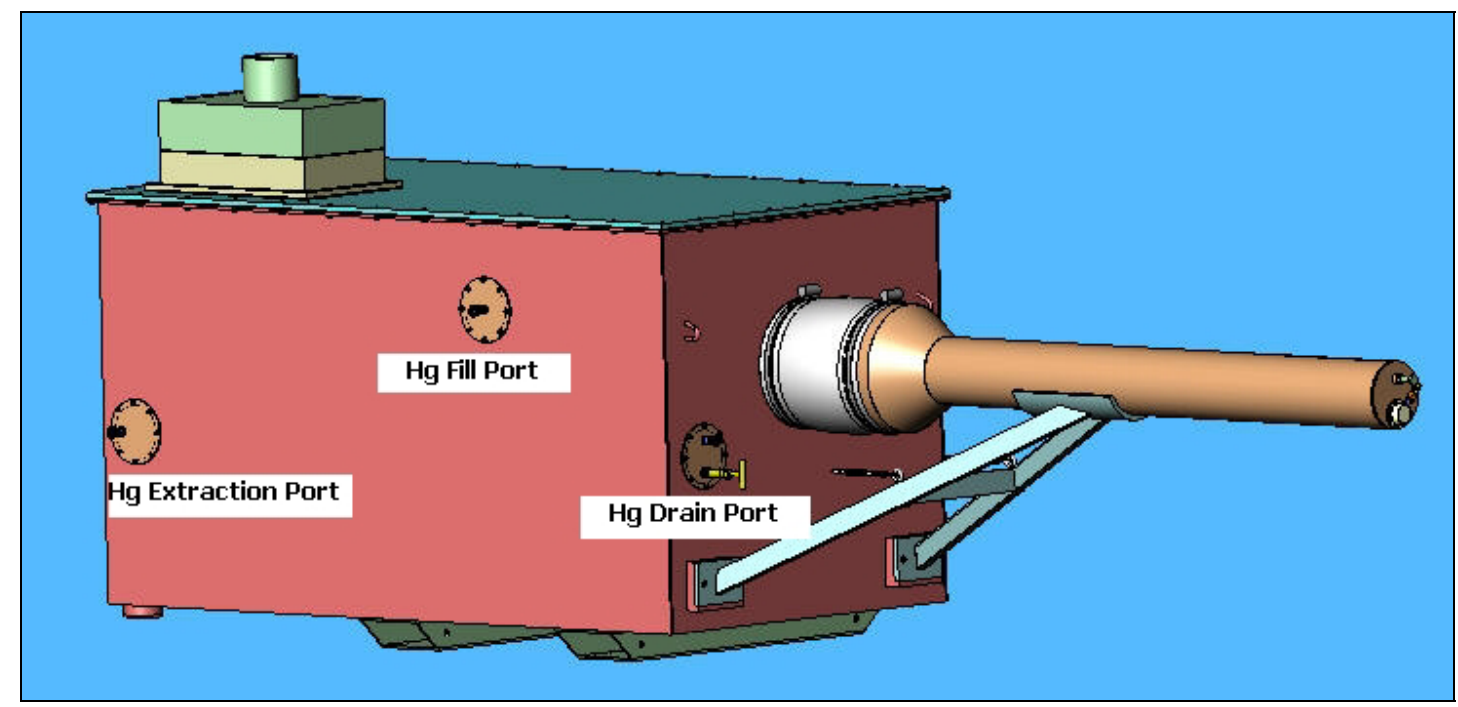

Fig. 22. Secondary containment right side. 
During mercury fill and drain operations, precautions will be taken to contain any leakage from making or breaking the quick-disconnect connections. This may consist of using wipes or containers during the connection or disconnection process.

The secondary containment box incorporates two stainless-steel rectangular tubes that support the system when sitting on the transport cart or during rigging operations. Nylon straps can be inserted through the tubes for lifting the assembly, and spreaders for the top of the box will be provided that prevent damage to the straps and to the sides of the enclosure.

\subsection{Baseplate Support Structures}

As shown in Fig. 3, the baseline geometry for the MERIT experiment requires that the magnetic axis be tilted with respect to the horizontal proton beam with the solenoid center in the beam path. Positioning the solenoid to meet these requirements dictates the need for a support structure. The integration of the solenoid with the mercury delivery system dictated a common support structure that allowed the assembled equipment to be handled as a single unit. Figure 23 shows the integrated equipment relative to the proton beam.

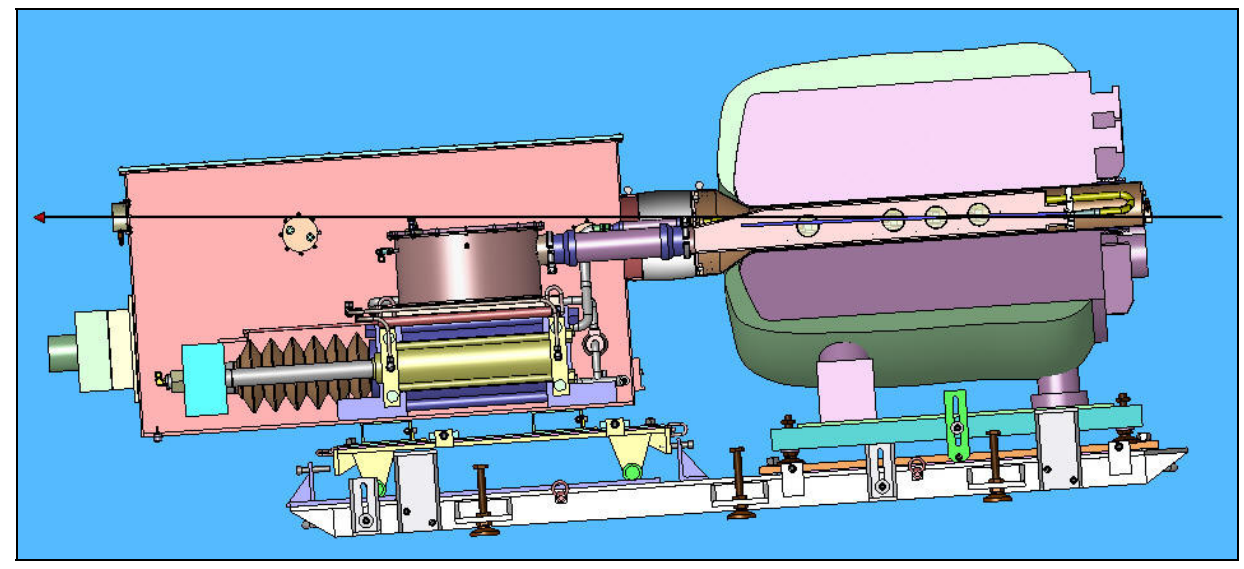

Fig. 23. Solenoid and mercury system on common baseplate.

Multiple structures are used to transport and support the solenoid and mercury delivery system during the installation and assembly. These are shown in Fig. 24 and are described below. Design of these structures was made using weight estimates of $53 \mathrm{kN}$ (12 tons) for the solenoid and $17.8 \mathrm{kN}$ ( 2 tons) for the mercury delivery system loaded with mercury.

It should be noted that several analyses were performed during the design of the support structures. Some of these are mentioned in this section.

\section{Common Baseplate}

The common baseplate shown in Fig. 25 is the primary experiment support structure, holding the mercury system and the solenoid in the correct tilt and elevation for the duration of the experiment. It also is designed to serve as the mobility platform for the solenoid within the CERN tunnels. It is imperative to note that although the common baseplate has built-in lift points, these are designed to carry only the baseplate itself. Under no circumstances should the baseplate be hoisted using these lift points while supporting either the solenoid or the mercury system! The lift points are removable; this may provide a means of operationally preventing inadvertent usage, along with appropriate labeling. 


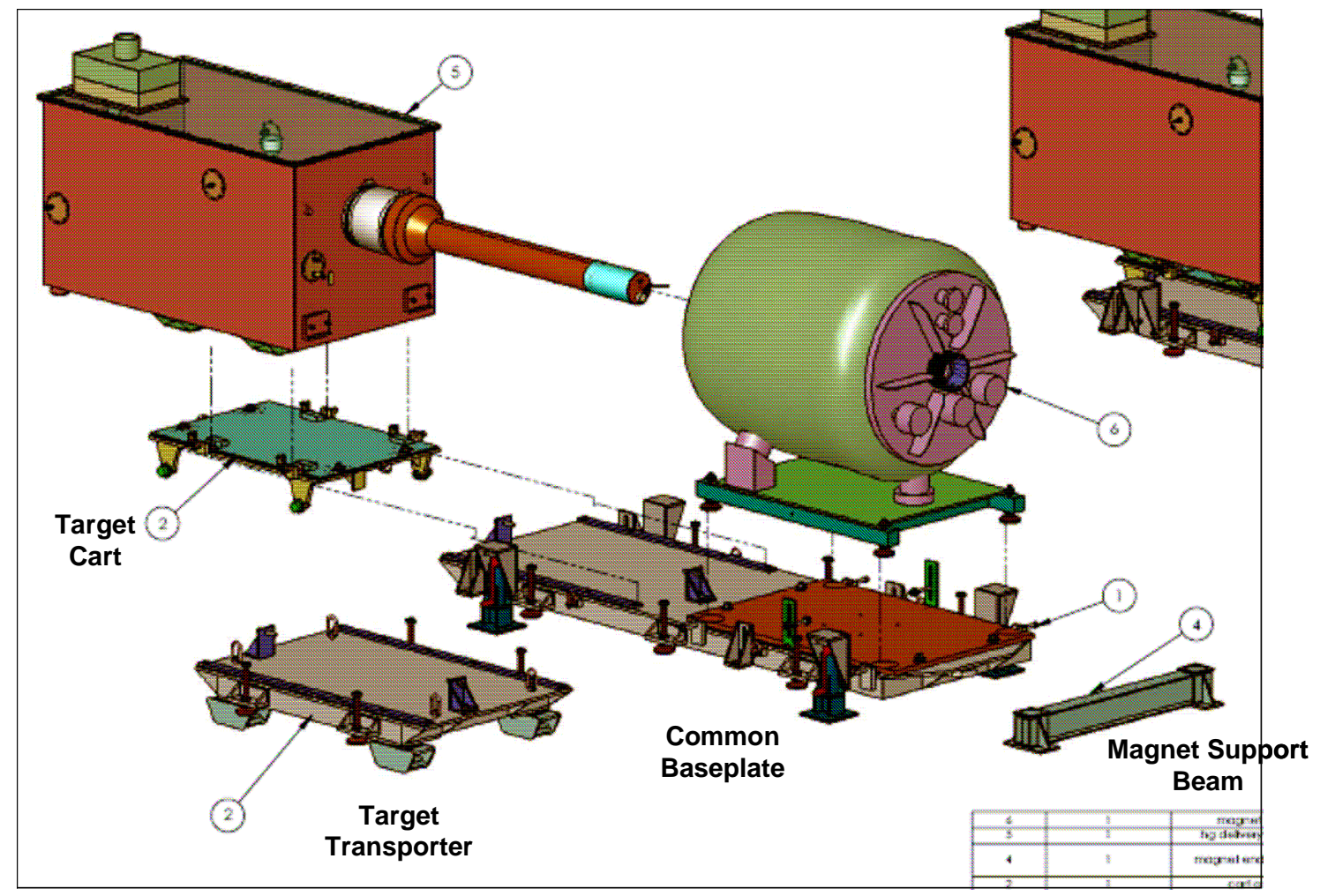

Fig. 24. Baseplate support-structures design drawing.

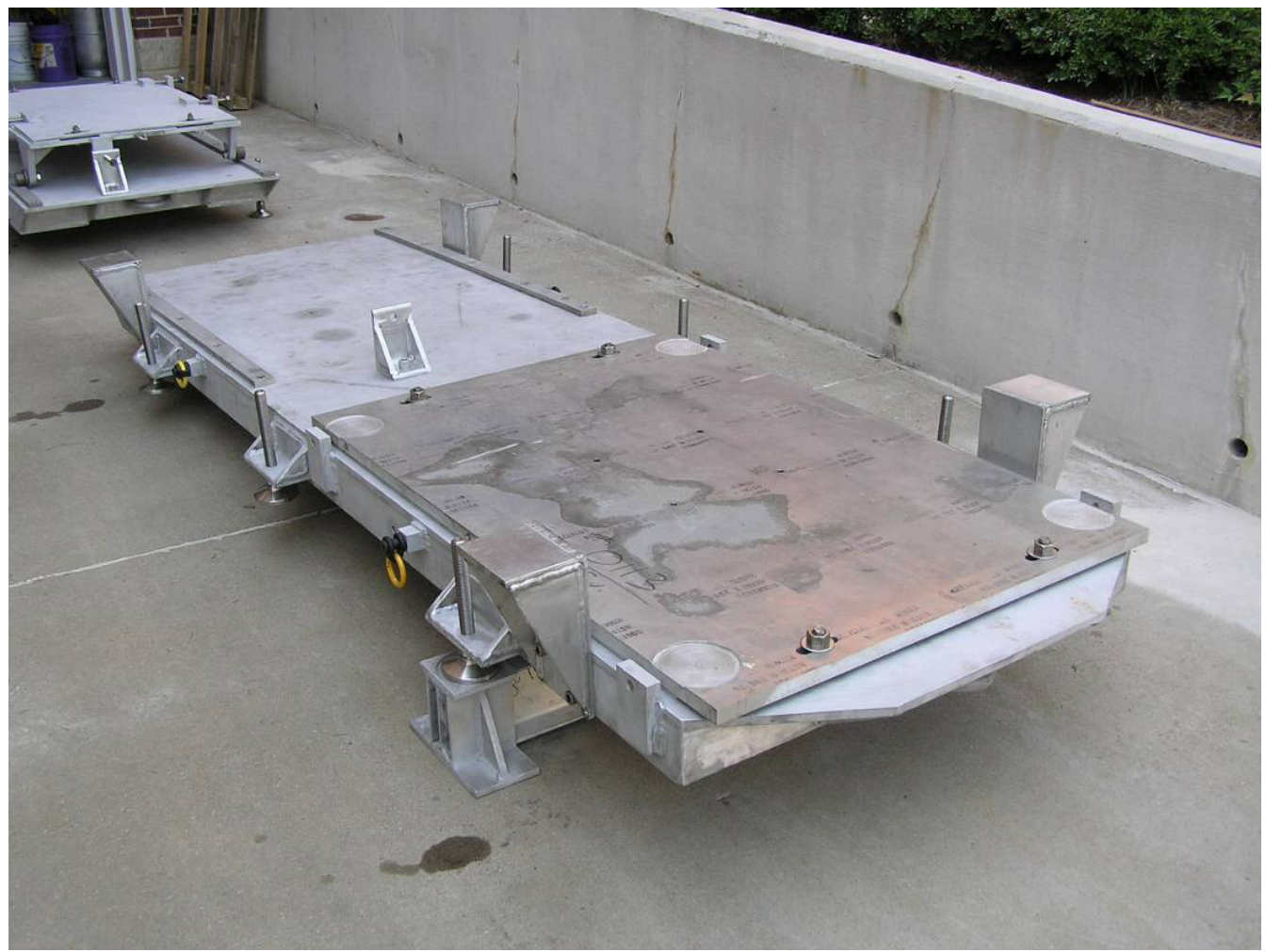

Fig. 25. Common baseplate and support beam. 
The common baseplate incorporates several design features and functions:

- Jack brackets: four detachable brackets used with hydraulic jacks to lift a loaded baseplate (with mercury system and solenoid onboard). These are separate from the builtin lift points, which are side-mounted swivel hoist rings.

- Anchor brackets: four adjustable brackets that can be used with concrete anchor bolts to fasten the baseplate to the floor.

- Levelers: six threaded leveling jacks that provide fine elevation/tilt adjustment of a loaded baseplate. These levelers support the weight of the baseplate during the experiment.

- Rails: two stainless-steel roller guides attached to the baseplate that allow the target cart to be transferred from the transporter to the common baseplate during target module insertion.

- Solenoid restraint brackets: two adjustable brackets which affix the magnet to the support plate upon which it sits.

- Cart positioning brackets: two brackets with jack bolts that hold the target cart in a fixed axial position during operations. Can also be used to provide fine axial positioning adjustment.

- Solenoid lateral positioning: two jack bolts on each side provide lateral position adjustment of the solenoid by sliding the magnet support plate over a low-friction surface.

- Tow hooks: one on each end used to maneuver the baseplate.

- Roller pads: three pads provide a means to set the baseplate onto high-capacity rollers during baseplate transport and gross positioning operations.

Due to the heavy weights that must be supported by the common baseplate, several stress analyses were performed to simulate various loading scenarios. In addition, analyses of certain critical welds were performed. The results of some of the analyses are shown as follows.

A basic analysis was performed to simulate the loading condition in which a loaded baseplate is supported by three rollers, as may occur during initial beam alignment operations. Results are shown in Fig. 26. The resulting safety factor distribution on one of the outer channels is shown in Fig. 27.

In this analysis the minimum calculated safety factor was 1.9 , which is less than the desired safety factor of 3 . However, the region of high stress was localized to small areas around bolt holes and was not indicative of general levels of high stress. Just outside these localized areas, the safety factor increased to 10 or more, so the structure was considered adequate for the loading condition. 


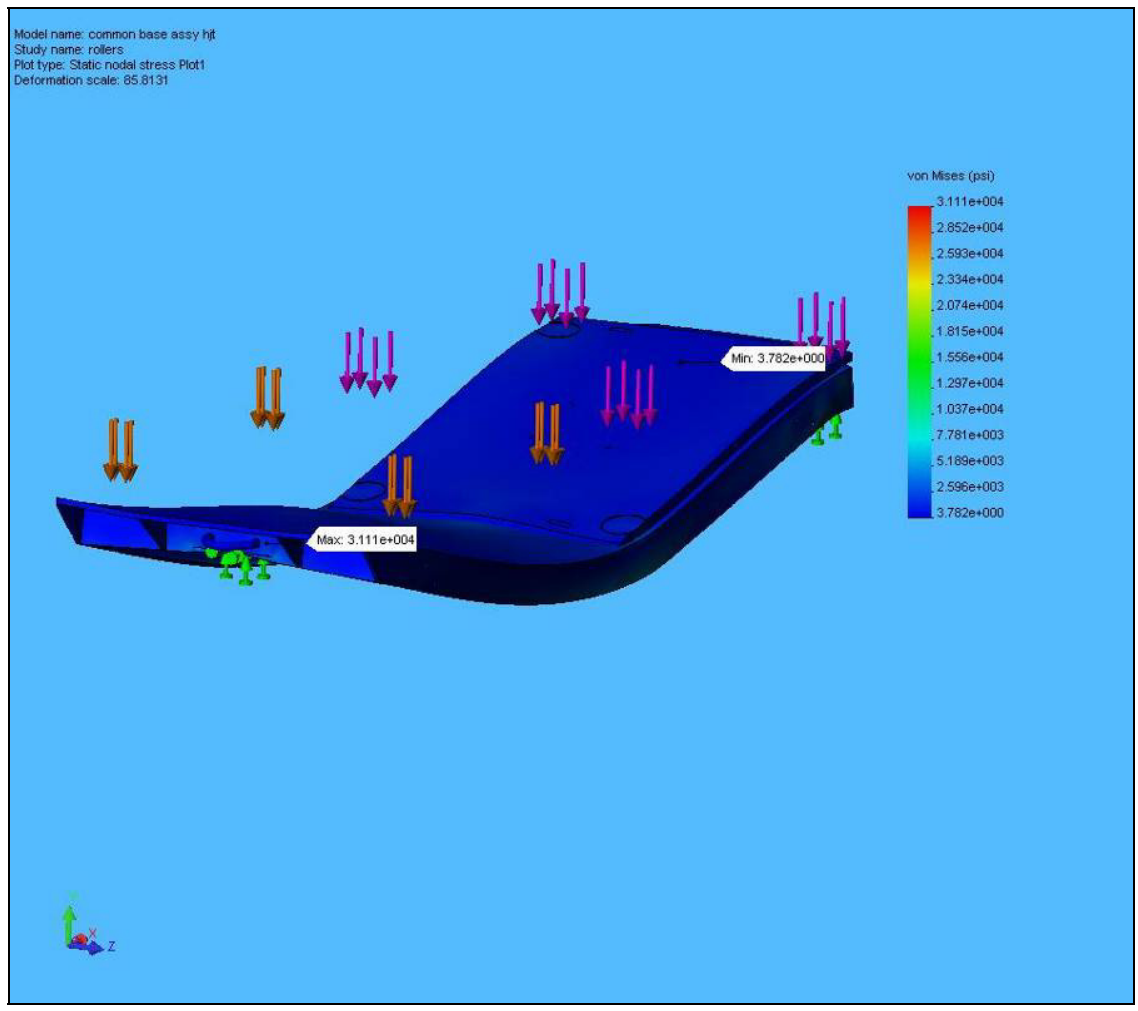

Fig. 26. Induced stresses of baseplate on three rollers.

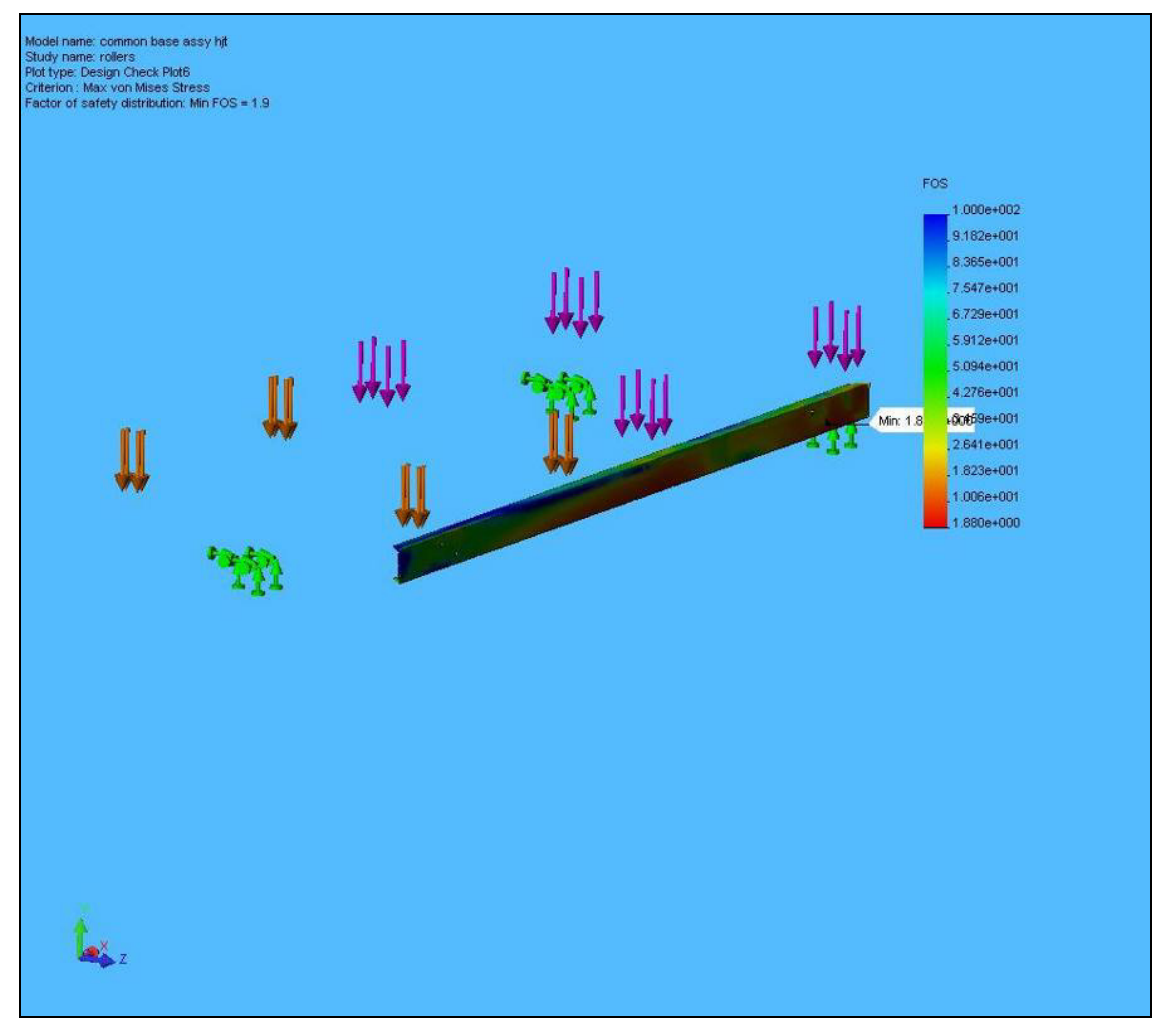

Fig. 27. Safety factor distribution for outer baseplate channel on three rollers. 
This type of result was also obtained when simulating the baseplate supported by four of the six levelers. Localized areas of high stresses were calculated near bolt holes, but overall stress levels were much lower. These localized stresses will tend to relieve themselves by locally deforming and are not considered to be a structural issue. In addition, load testing on the baseplate will be performed to ensure its load-carrying capacity.

For the loading case in which the loaded baseplate is supported by the four hydraulic jacks, the jacking bracket weldment was analyzed separately since the load is carried through this bracket. In this loading condition, the worst case is for those two brackets which are under the magnet; these brackets were estimated to carry $26.6 \mathrm{kN}$ (6000 lbf) each, evenly loaded on the two bolt holes. Results are shown in Fig. 28, with a minimum calculated safety factor of 1.4-in. localized regions around the bolt holes; the safety factor quickly increases to levels above 10 just outside the holes. Welds on this bracket were analyzed separately, and the analysis gave a safety factor $>9$.

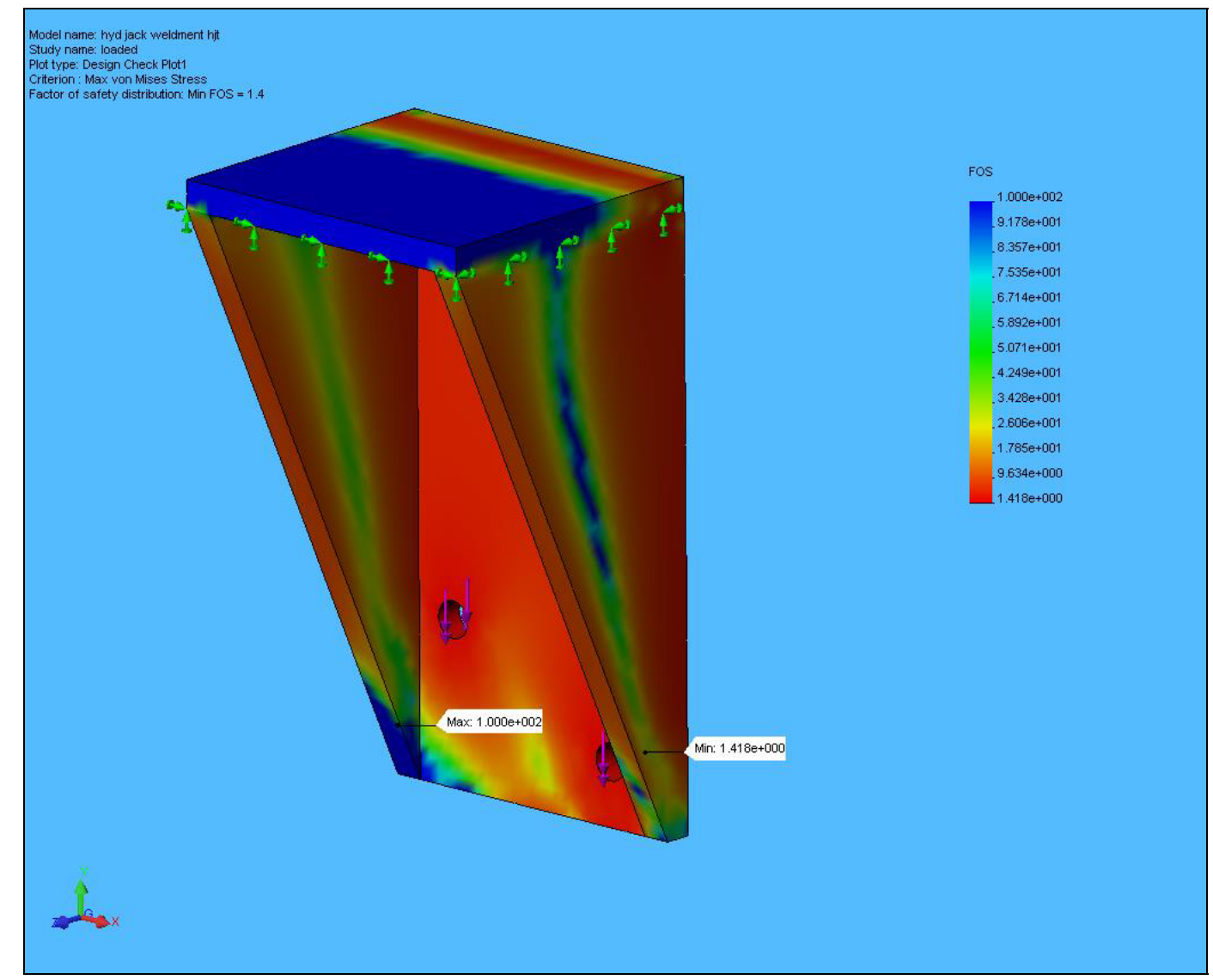

Fig. 28. Safety factor distribution for the jacking bracket weldment.

\section{Target Transporter}

The target transporter is used to move the mercury delivery system and target cart within the TT2 and TT2A tunnels and shares its basic design with the common baseplate. Temporary rollers provide the structure's mobility, and levelers are used as height adjusters and supports. Swivel hoist rings allow for lifting of the unloaded transporter, and tow hooks are available on each end. The transporter and cart are shown in Fig. 29. 


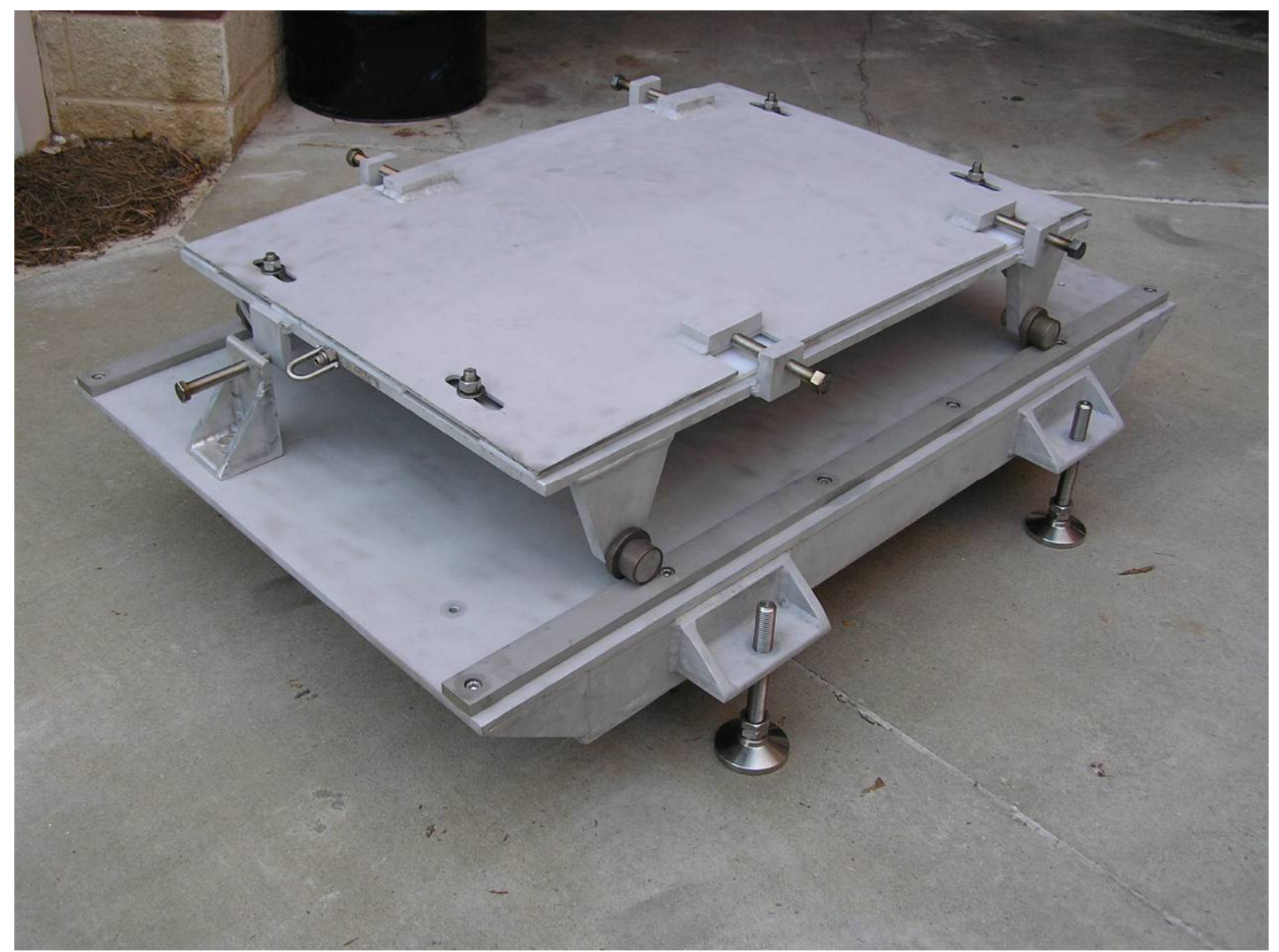

Fig. 29. Target cart and supporting transporter.

As the transporter framework matches that of the common baseplate except in length and the total load on the transporter is much less than the common baseplate, a separate analysis of the transporter frame was not performed.

\section{$\underline{\text { Target Cart }}$}

This component carries the weight of the mercury delivery system and allows it to transfer from the transporter frame to the common baseplate while inserting the target module into the bore of the solenoid. Primary material is aluminum. The cart incorporates the same lateral position adjustment system as the common baseplate, so the mercury system can be horizontally shifted with the solenoid for precise alignment with the beam. No vertical positioning adjustment is available; it is assumed the flexible components of the target module will accommodate minor vertical misalignment with the solenoid bore and that the leveling screws on the magnet can be used for final adjustment.

A finite-element analysis was performed on the primary cart structure. Results are shown in Fig. 30 and indicate the cart is capable of supporting the full weight of the mercury system with a minimum factor of safety (FOS) of 4. 


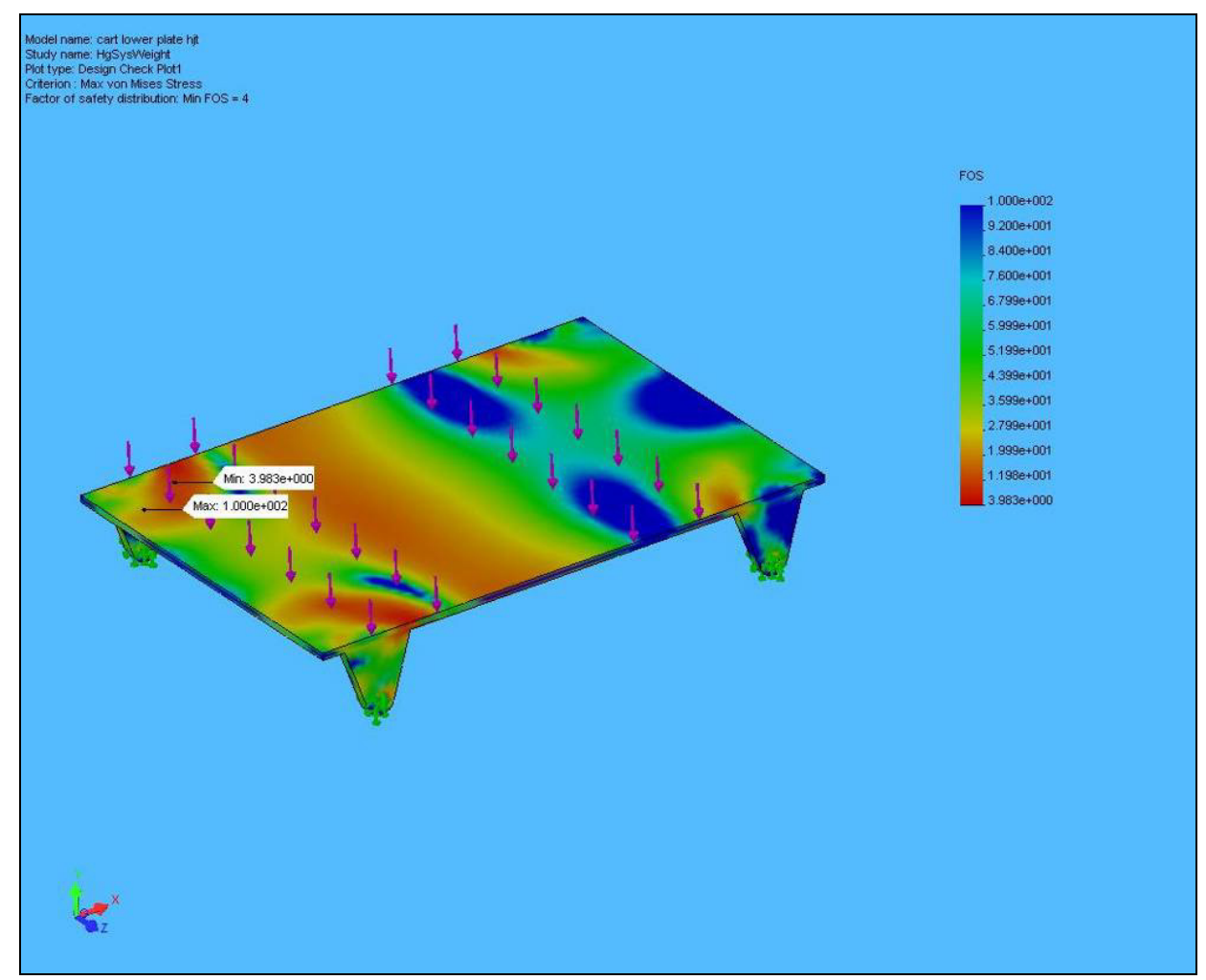

Fig. 30. Safety factor distribution for the cart structure.

\section{Magnet Support Beam}

The common baseplate uses threaded levelers to support the weight of the system. To position the magnet center in the beamline, however, requires one pair of levelers to extend close to their upper limit, which causes a stability concern. To eliminate this concern, a separate structural support beam was designed to take up most of the space (approximately $15 \mathrm{~cm}$ ) and allow the levelers to be near their lower limit. The aluminum beam structure will be inserted under the baseplate while it is being supported with the lifting jacks.

A structural analysis was made of the beam, and the results are shown in Fig. 31. The minimum FOS was calculated to be 13 .

\section{Baseplate Load Testing}

The baseplate support structures were successfully load tested at ORNL to validate analyses and the design of the structures. Weights were $113 \%$ of the estimated loading condition to be experienced at CERN. The load test setup can be seen in Fig. 32.

\subsection{Control System}

As mentioned in Section 3.2, the syringe-pump hydraulic power unit was supplied with some minimal onboard controls to provide basic syringe control. This control will not be adequate for the MERIT experiment. Figure 33 shows the location of the experimental equipment in TT2A and the location of the HPU in TT2. The originally proposed location for the remote control room was the ISR tunnel, but the final location appears to be Building 272. 


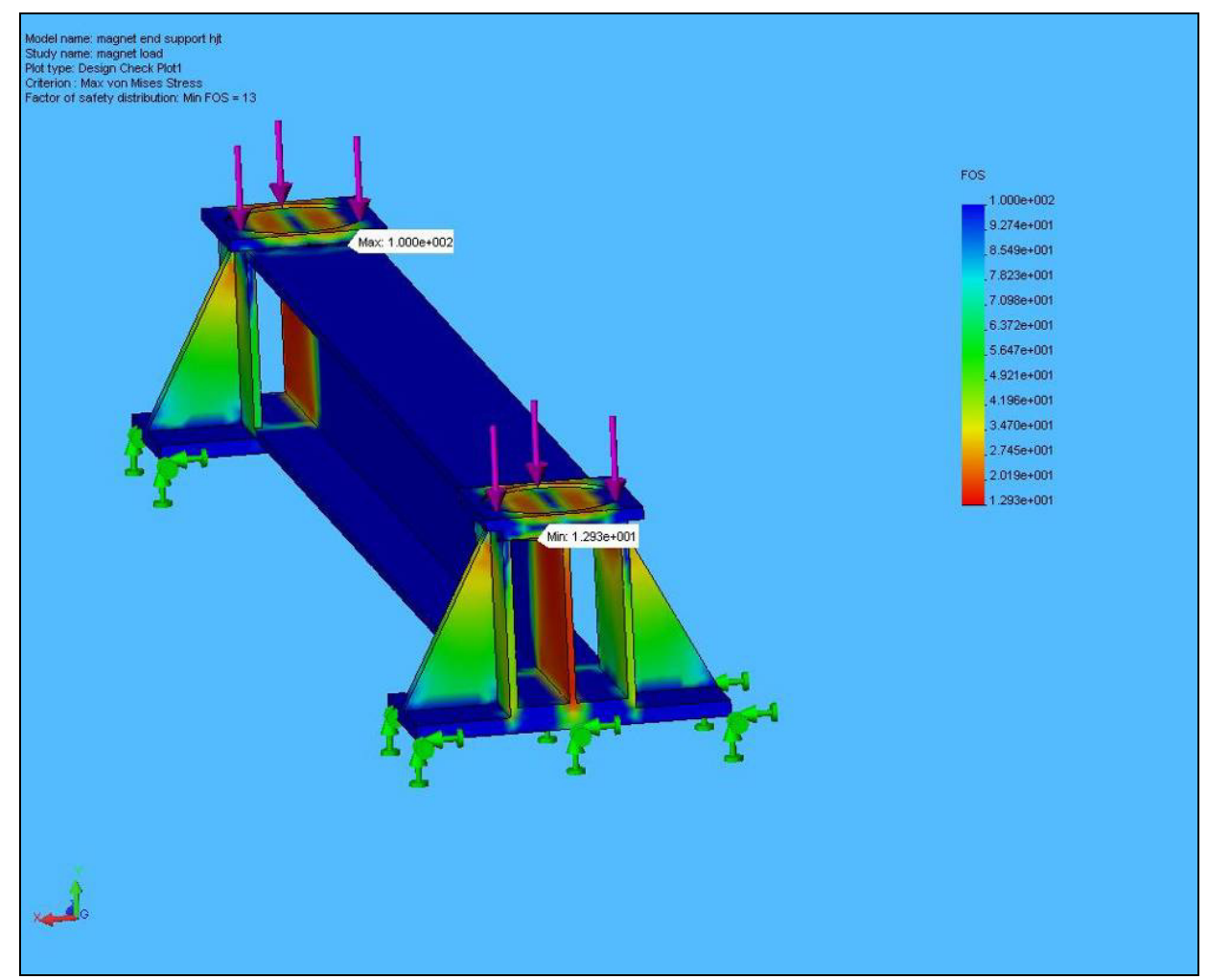

Fig. 31. Safety factor distribution for solenoid support beam.

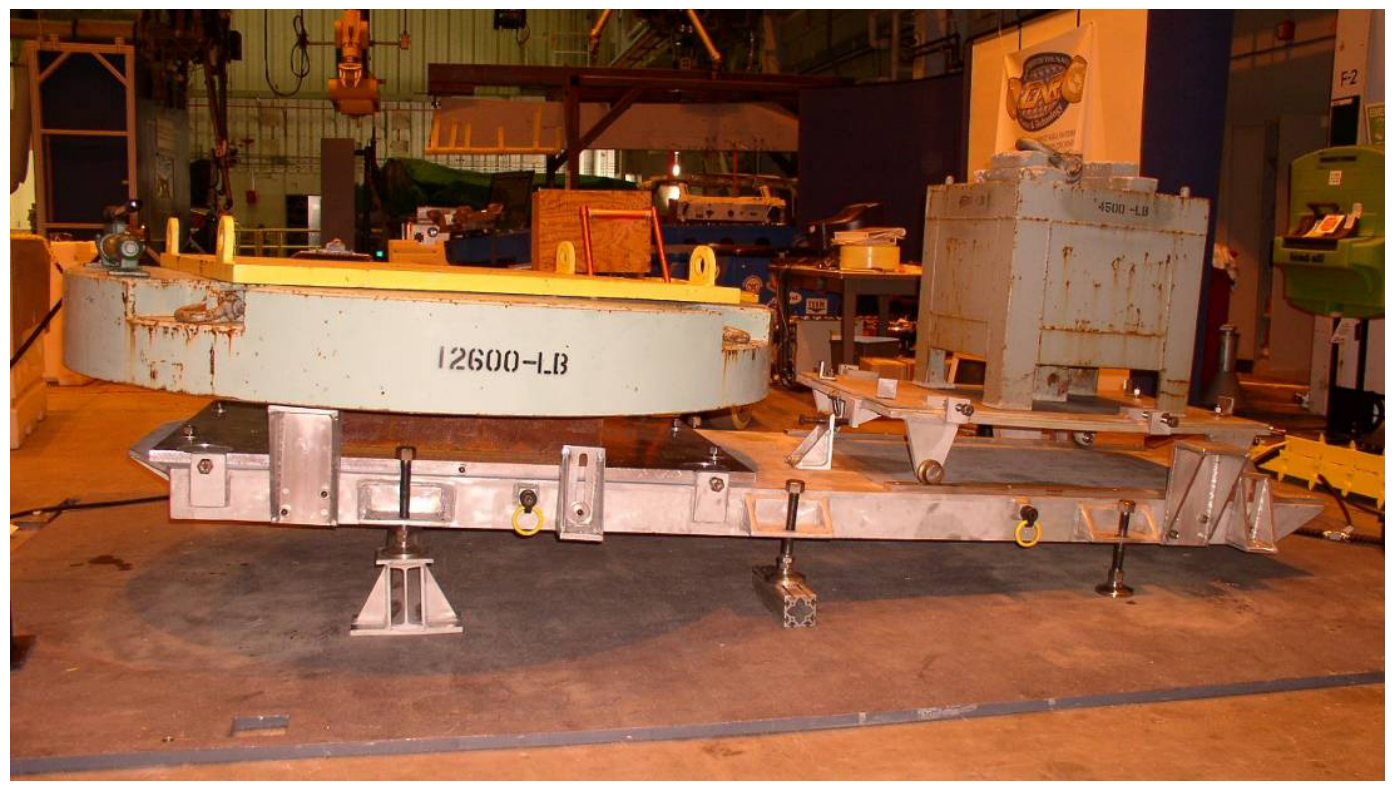

Fig. 32. Baseplate load testing. 


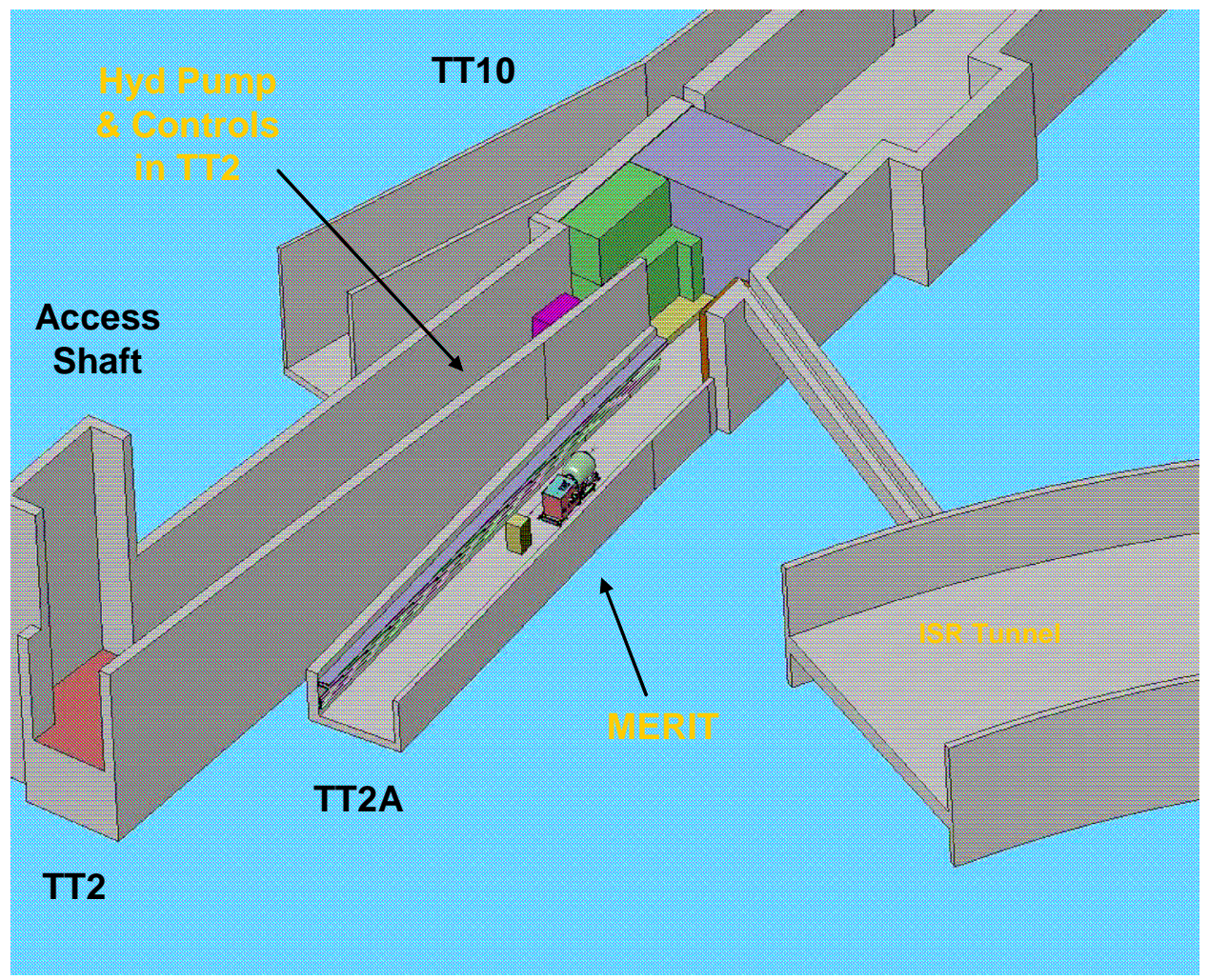

Fig. 33. MERIT layout in the CERN tunnels.

As system design progressed, it was noted that the control system would require a great deal of flexibility to be able to incorporate various types of sensors. Labview ${ }^{\circledR}$ was chosen as the control system software package, and it will be run on a laptop computer in the remote control room and separated from the experimental area by a great distance. It is not practical to run sensor wires over such a great distance for a short-term experiment like MERIT, so the controls approach taken was to place Labview®-compatible sensor modules inside the HPU control cabinet and communicate with them over an Ethernet network. In this approach, all the MERIT sensors terminate in the TT2 tunnel, whether they originated in TT2 or TT2A.

From a system safety viewpoint, a remote emergency stop is required that is independent of the MERIT control system. The syringe system was procured with a 76 -meter $(250-\mathrm{ft})$ emergency stop pendant directly wired into the HPU power cabinet based on the original ISR control room location. Now that the final control room location greatly exceeds this distance, another means of controlling power to the HPU will be required.

The Labview-based control system has been completed, and the basic screen layout can be seen in Fig. 34. The system provides the following capabilities/functions:

- Jet configuration: the velocity profile of the jet can be configured within the constraints of loaded mercury volume and available piston stroke.

- Operation: provides control of the syringe HPU. Supports manual and triggered operating modes

- Performance: graphical representation of syringe movement and sensor feedback during operating cycle 
- Data logging: provides capability to record history file

- Operator feedback and status messages

- Status/alarm indicators

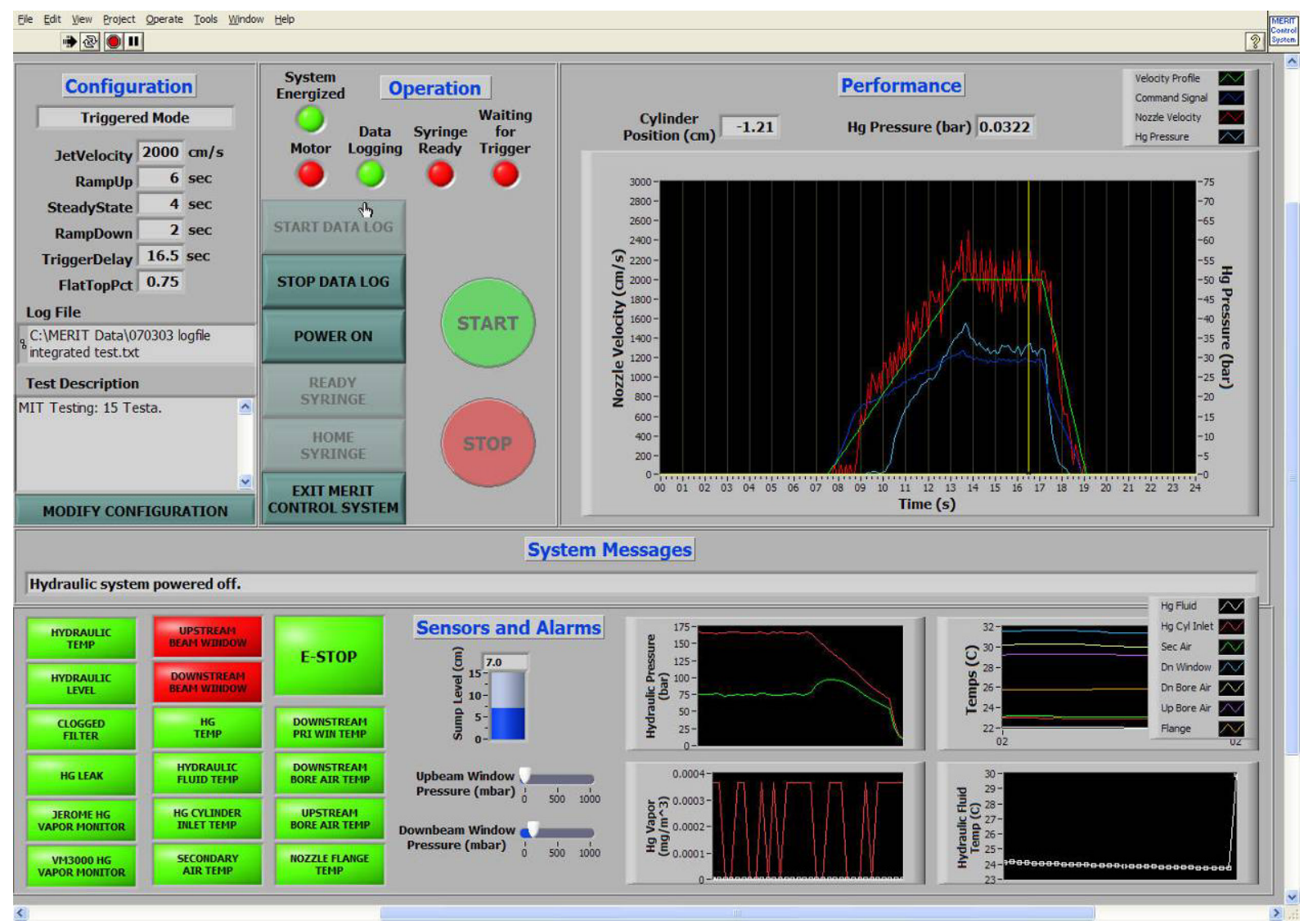

Fig. 34. Labview control system operator interface. 



\subsection{Operations and Testing}

\subsection{Filling and Draining Mercury}

A fundamental requirement for designing the mercury delivery system was that filling and draining mercury from the system must be accomplished without opening the secondary containment. The secondary containment (enclosure) is designed with a fill-port located on a sidewall of the enclosure. The port connects directly to the sump tank as shown in Fig. 35. The drain port is located at the front of the enclosure and is shown in Fig. 22.

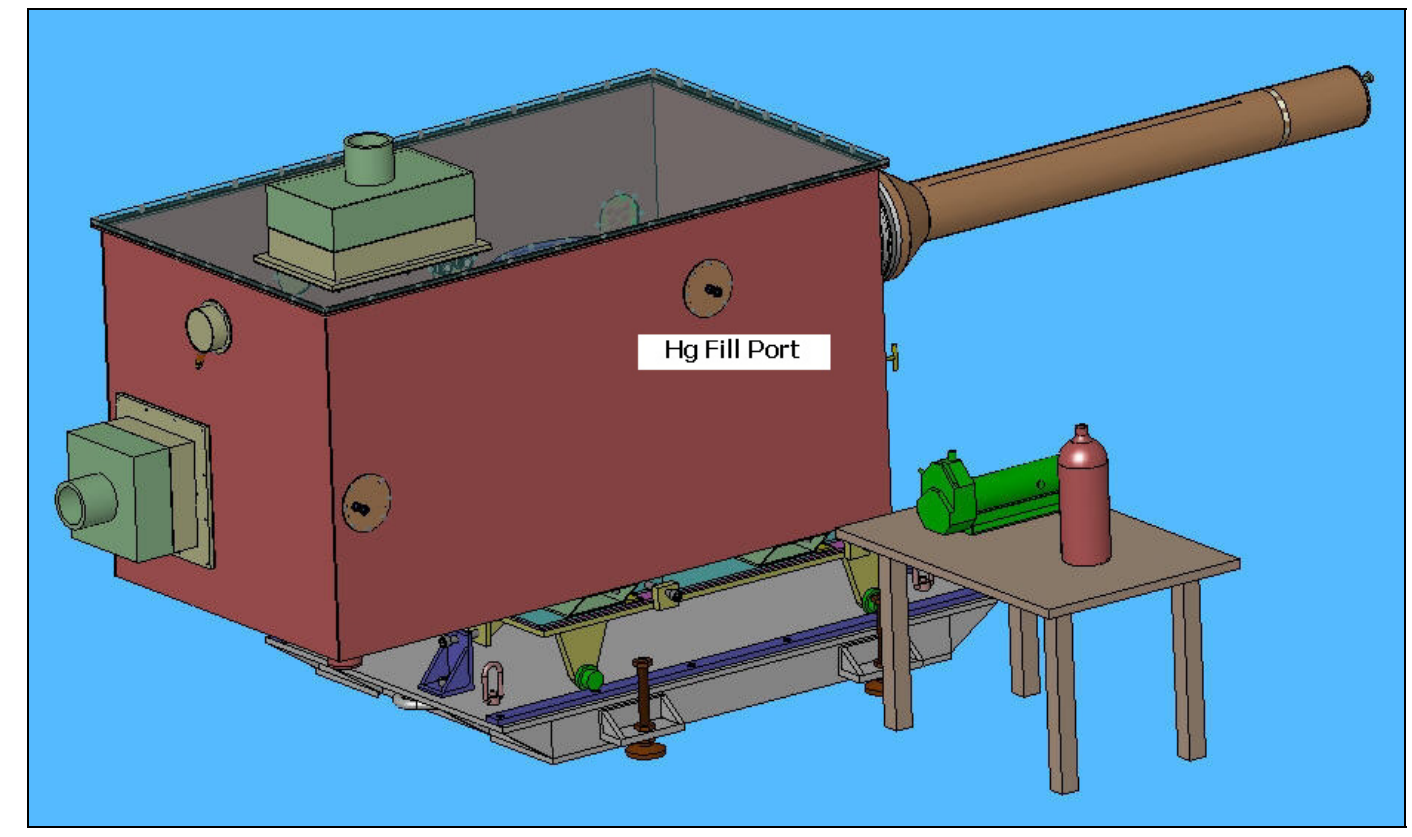

Fig. 35. Mercury fill port.

A peristaltic pump will be used to transfer mercury from standard 2-liter flasks by means of a stainless-steel tube connected to flexible Tygon ${ }^{\circledR}$ tubing. (The flasks are U.S. Department of Transportation-approved containers for transporting mercury.) Figure 36 is the actual pump that will be used for MERIT mercury transfer operations. Its use for transferring mercury was successfully demonstrated at ORNL. It is important to mention that during mercury transfer operations, only the inner wall of the tubing is in contact with mercury, and that the pump mechanism is never in contact with mercury. Therefore, only the tubing becomes contaminated. 


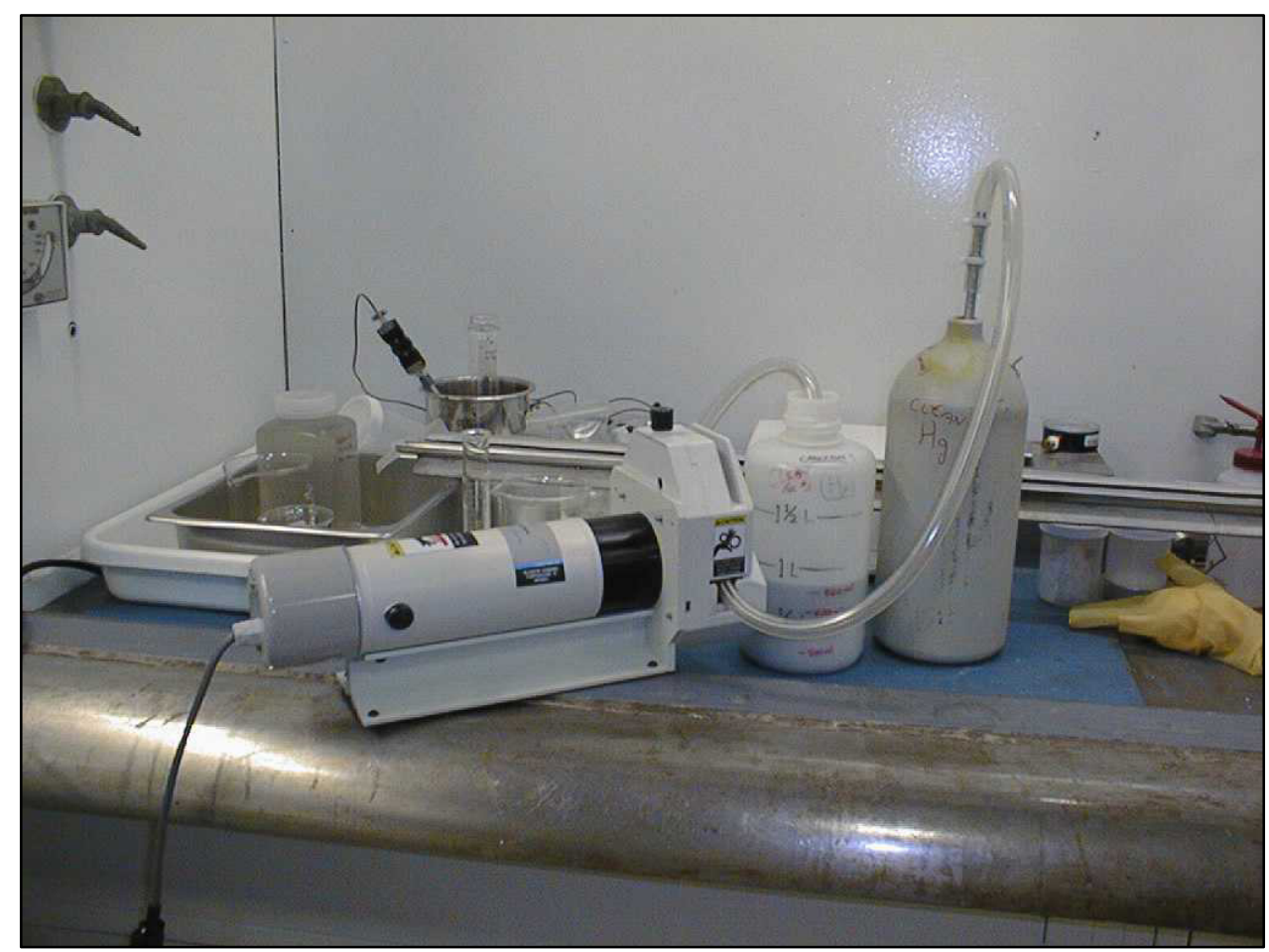

Fig. 36. Peristaltic pump for transferring mercury.

\section{Mercury Fill Procedure}

The procedure for transferring mercury into the sump tank is as follows:

1. Position the pump and the flask at an elevation higher than the fill port.

2. Place the pump and flask in a plastic tray lined with gauze, or provide other suitable containment for spill control.

3. Check that all of the auxiliary support equipment is in place and properly operating, namely, the digital scale, portable vapor monitor, portable snorkel, etc.; connect the Tygon ${ }^{\circledR}$ tube fitting to the fill port connector.

4. Weigh and record the flask weight (the tare for each numbered flask will have been determined from the tests at ORNL).

5. Remove the flask plug and insert the stainless-steel suction tube that is attached to the other end of the Tygon ${ }^{\circledR}$ tube; start the pump. (The pump settings will have been predetermined and preset from testing at ORNL.)

6. Siphon the mercury from the flask until the suction in the tube is lost; record the weight of the empty flask.

The air that is displaced during the fill operation, up to 23 liters, will be vented from the sump tank directly to the primary filter unit located on top of the enclosure. The air passing through the filter material will be monitored for mercury vapor as well as being collected into the portable snorkel. 
Since the exact volume of mercury needed for testing at CERN will have been determined from the tests at ORNL and MIT, a careful accounting of the weight will verify the quantity of mercury installed in the target.

\section{Mercury Drain Procedure}

The baseline method for transferring mercury from the target will use the peristaltic pump. The pump will be connected to the quick-disconnect fitting on the secondary enclosure that leads to the sump tank drain tube. The secondary enclosure will remain closed during this operation.

An alternative method for transferring mercury out of the target will be investigated as part of the ORNL testing. This method is believed to eliminate the possibility of "over filling" a flask. The procedure is as follows:

1. Place a 3-liter clear plastic bottle, marked with a 2-liter "fill line" under the drain port. Connect a flexible tube with a quick-disconnect to the mercury drain port on the secondary enclosure.

2. Using the drain valve as a flow control device, gravity-drain two liters of mercury into the 3-liter bottle. A manual- or check-valve with a quick-disconnect fitting will be attached to the mercury fill port to allow air into the sump tank to prevent a vapor lock caused by the draining mercury.

3. Using the peristaltic pump, transfer 2-liters of mercury from the plastic bottle to a steel flask; install the flask plug and record the weight.

4. Repeat steps 2 and 3 until all mercury that can be gravity-drained from the system has been removed.

5. Remove mercury remaining in the sump tank or the drain line using the peristaltic pump.

By accounting for the weight of mercury removed from the target, an accurate estimate can be made of the volume of mercury remaining in the system. This amount must be recorded in the transportation documents for the return shipment of the target equipment to ORNL.

\subsection{Mercury Vapor Filtration}

The secondary enclosure has two sulfur-impregnated charcoal filter assemblies-the larger one mounted on the top cover, and the smaller one mounted on the down beam wall. These filters are an adaptation of filter used in the portable snorkel. The primary filter on the top cover measures $432 \times 255 \times 51 \mathrm{~mm}(17 \times 10 \times 2$ in. $)$, and the secondary filter on the back wall measures $267 \times$ $267 \times 38 \mathrm{~mm}(10-1 / 2 \times 10-1 / 2 \times 1-1 / 2 \mathrm{in}$.). Figure 2 shows the location of the filters. Each filter is designed to connect with the $127-\mathrm{mm}$ (5-in.)-diam hose of the portable snorkel.

During routine target equipment operations, each filter port remains closed so that there is no exchange of the air environment between the secondary enclosure and the TT2A Tunnel. The two air environments are at pressure equilibrium as long as the temperature in the enclosure remains approximately at the temperature in the tunnel. (The temperature rise of the mercury and the air in the enclosure will be recorded between pulses during the ORNL tests.) Therefore, the air in the secondary enclosure that is under continuous monitoring for mercury vapor is isolated from the tunnel air. 
Prior to installing mercury into the sump tank, the cover on the primary filter will be removed and the volume of air that is displaced from the sump tank will be "pushed" through the primary filter and monitored for mercury vapor levels using the portable vapor monitor. If any vapor is detected, the snorkel can be attached to provide a double level of filtration to prevent mercury vapor from being pushed into the tunnel environment. The effectiveness of "single" and "double" filtration will be demonstrated as part of the testing at ORNL.

\section{Filter Lifetime Estimate}

An estimate of filter lifetime was made based on the calculations used for ORNL's Target Test Facility and the data provided by the manufacturer of the filter material. The sample calculation shown below yields a lifetime of $185 \mathrm{~h}$ of vapor exposure before the filter is $12 \%$ saturated.

- Flow Rate $110 \mathrm{cfm}$ (through the snorkel filter)

- Temperature $25^{\circ} \mathrm{C}$ (vapor temperature)

- Filter Efficiency $99.0 \%$ (vendor information)

- Filter Weight 6 lb (80\% charcoal, 20\% sulfur)

- Allowable Filter Saturation 12\% (vendor information)

- Filter Life $185 \mathrm{~h}$

(Note: The calculation does not include the reduction for adsorption of humidity.)

The following equations were used for the calculation [5].

Saturation Pressure

$$
\log P_{\text {sat }}=-3105.5 / T_{0_{K}} \dashv 4.9294 \quad \text { (bar) }
$$

Saturation Concentration

$$
C_{\text {sat }}=2.445 P_{\text {sat }} / T_{{ }_{K}}\left(\mathrm{Kg}_{\mathrm{Hg}} / \mathrm{m}^{3}\right) \quad\left(P_{\text {sat }} \text { mbar }\right)
$$

\section{Filter Replacement Procedure}

If it becomes necessary to replace either the primary filter or the secondary filter, the portable snorkel will be used to maintain a negative pressure in the secondary enclosure, while at the same time filtering the extracted air. The procedure for replacing the primary filter is described below for a routine operation where the secondary enclosure vapor monitor shows no indication of vapors. The actual procedure will be demonstrated as part of the testing at ORNL.

1. The operator will be dressed with proper personal protection equipment (PPE); the assistant operator will handle the portable vapor monitor.

2. Connect the snorkel hose to the secondary filter port; turn on the snorkel to achieve a low flow rate, that is, 280 liters/min $(5-10 \mathrm{cfm})$.

3. Remove the 5-in.-diam cover from the primary filter to permit an inflow of air into the secondary enclosure. 
4. Remove the filter pack assembly and increase the snorkel flow rate to a level to be determined during ORNL testing; continue monitoring for vapor in the vicinity of the filter. Place the filter in a plastic bag and seal the bag.

5. Install a new filter; decrease the flow to the snorkel to zero and cover the primary port.

The same procedure will be used for replacing the secondary filter except in step 2, the snorkel hose will be connected to the primary filter port.

\subsection{Off-Normal Conditions}

Several off-normal conditions were postulated and are discussed below. Two of these would impact the operations of the target system: the first is measurable vapor in the secondary enclosure, the second is a spill from the primary enclosure into the secondary enclosure but contained in the secondary. The others conditions were factored into the system design and are not thought of in the context of operations.

\section{Vapor Leak Into Secondary Containment}

The secondary containment is continuously monitored for mercury vapor. A Jerome 431-X monitor located in the adjacent tunnel (TT2) samples the containment volume every $5 \mathrm{~min}$ through a flexible tube. Through its interface with the Labview ${ }^{\circledR}$ control system, it will send a visual and audible signal if the threshold limit values (TLV's) for vapor have been reached. The system will be configured to match the threshold setting used for the Target Test Facility $\left(0.0125 \mathrm{mg} / \mathrm{m}^{3}\right)$ and can easily be changed to meet other levels. The following TLV's are the current U.S. and ORNL standards.

- OSHA TLV: $0.050 \mathrm{mg} / \mathrm{m}^{3}$ for up to a 10 -h workday, $40 \mathrm{~h}$ per week

- ORNL TLV: $0.025 \mathrm{mg} / \mathrm{m}^{3}$

- TTF action level (when respirators are required): $0.0125 \mathrm{mg} / \mathrm{m}^{3}$

Upon receiving an alarm signal, the operator will check the conductivity probe sensor for indications of a major leak from the primary containment, the secondary vapor monitor in the tunnel. If there is a zero-reading from the conductivity probe, and the other sensors including the secondary vapor monitor are sending normal signals, it may be concluded that (a) there is a minor leak from the primary containment or (b) the vapor monitor sent a false-positive signal.

To verify if the monitor is functioning properly, the spare (portable) sensor will be exchanged with the monitor in tunnel TT2, where immediate personnel access is possible. Regardless of the outcome of the monitor test, operations may continue until the end of a shift. At that time, a decision will be made to make a visual inspection of the system. As shown in Table 4, the dose rate at the top of the secondary enclosure at shutdown (or immediately thereafter) will be $<1 \mathrm{mrem} / \mathrm{h}$ and will be low enough for visual inspection.

While this inspection is occurring in TT2, the vapor monitor located in the tunnel (TT2A) near the target equipment will be checked for indications of vapor. If vapor is present only in the secondary enclosure, it will remain contained unless there is a break in the enclosure, or leakage from one or both of the enclosure filters. The portable monitor will be used to check for any of these possible occurrences, if vapor was detected in the tunnel. If the tunnel does not contain 
vapor, and there is only evidence of vapor leakage into the secondary enclosure, that is, no elemental mercury in the enclosure sump, it is assumed that operations will resume.

\section{Mercury Leak into Secondary Containment}

Although highly unlikely, if elemental mercury is detected in the secondary enclosure by the conductivity probe or by visual inspection, there will be no doubt that the integrity of the primary containment was breached. Based on the operations requirement that the primary containment shall not be opened during the lifetime of the experiment at CERN, test operations will cease and a cool-down period of up to 1 month will commence. According to Table 4 , the mercury after that cool-down period will have a contact dose of $<10^{-2} \mathrm{mSv} / \mathrm{h}(<1 \mathrm{mrem} / \mathrm{h})$, low enough to extract mercury from the target and refill the mercury flasks.

The target, being a double-contained system, is designed so that unloading mercury can be accomplished without opening the secondary containment. Hence, the vapor will remain contained as long as the secondary enclosure is not opened. The (activated) mercury will be removed from the syringe pump system in the same manner described in Section 4.1, with the exception that Health Physics surveillance and oversight will be required because of the activation of the mercury.

\section{System Overpressure}

The mercury delivery system is an open system, and only by having a blockage at the nozzle would it be possible to over-pressurize the equipment. While no practical method of totally blocking the mercury is envisioned, if a total blockage should somehow occur, the mercury channel would become a static pressure system and hydraulic system pressure could increase above its nominal level of 200 bar (3000 psi). However, the hydraulic pump has a built-in relief valve pre-set at 220 bar (3200 psi). Upon reaching the relief setting, hydraulic fluid would be diverted directly from the pump back into the reservoir, thereby preventing an over-pressure condition in either the hydraulic or mercury fluid systems.

\section{Power Failure}

A loss of electrical power to the mercury delivery system (or emergency stop) will immediately shut down the hydraulic pump and thus the movement of the syringe pistons. It may be possible that this could cause a "water hammer" shock effect in the flow loop if a portion of the mercury flow becomes separated. This will be investigated as part of the ORNL tests.

\section{Loss of Network Connectivity}

The Labview ${ }^{\circledR}$ hardware has an internal system controller that provides network connectivity to the laptop computer. That connectivity includes the provision for a "watchdog" timer to detect loss of communication. Should such loss occur, the hardware controller will be configured to power down the hydraulic pump and return the system to an inoperable state.

\subsection{Equipment for Mercury Handling}

A kit consisting of miscellaneous small tools, cleanup materials, various plastic containers, and personal protection equipment (PPE), will travel with the target system to MIT and CERN. The kit will provide self-sufficiency for all activities that deal with the target equipment and mercury 
handling, including installation, equipment check out, spill control, and cleanup. Table 7 is a listing of the equipment that will be available for use to support target operations.

\section{Table 7. Miscellaneous experiment support equipment}

\begin{tabular}{|c|c|}
\hline Item & Comments \\
\hline \multicolumn{2}{|l|}{ Vacuum cleaner-Tiger Vac ${ }^{\circledR}$} \\
\hline \multicolumn{2}{|l|}{ Portable snorkel—Scavenger ${ }^{\circledR}$} \\
\hline Spare filters & Sulfur impregnated charcoal and HEPA filters \\
\hline \multicolumn{2}{|l|}{ Vapor monitor } \\
\hline \multicolumn{2}{|l|}{ Vapor monitor calibration kit } \\
\hline 55-gal drum & Satellite accumulation area (SAA) \\
\hline Plastic sheeting-roll & Heavy gauge plastic sheeting $-10 \mathrm{ft}$ wide \\
\hline Peristaltic pump & Available from ORNL \\
\hline \multicolumn{2}{|l|}{ Tygon tubing } \\
\hline Hg flasks (quantity TBD) & $\begin{array}{l}\text { U.S. Department of Transportation approved; } \\
\text { standard 76-lb steel flask }\end{array}$ \\
\hline \multicolumn{2}{|l|}{ Merc-X cleaning solvent } \\
\hline \multicolumn{2}{|l|}{ Sponges } \\
\hline \multicolumn{2}{|l|}{ Plastic buckets } \\
\hline \multicolumn{2}{|l|}{ Plastic pans } \\
\hline Teflon tape (yellow) & Sealing flasks; yellow tape is more durable than white \\
\hline \multicolumn{2}{|l|}{ Gauze-roll } \\
\hline Small tools & Wrenches, screwdrivers, ... \\
\hline Bungee cords & Assorted lengths \\
\hline Vinyl tape & Yellow, 4 rolls \\
\hline Plastic bags & Assorted sizes-1 gal to 20 gal \\
\hline Plastic bottles & 1-, 2-, 3-liter sizes-4 of each required \\
\hline \multicolumn{2}{|l|}{ Lab coats } \\
\hline \multicolumn{2}{|l|}{ Shoe covers } \\
\hline \multicolumn{2}{|l|}{ Safety glasses } \\
\hline \multicolumn{2}{|l|}{ Ear plugs } \\
\hline \multicolumn{2}{|l|}{ Tyvek hooded suits } \\
\hline \multicolumn{2}{|l|}{ Nitrile gloves } \\
\hline \multicolumn{2}{|l|}{ Full face mask w/Hg cartridges } \\
\hline Miniature aspirator pump & Used to collect small quantities of mercury \\
\hline \multicolumn{2}{|l|}{ Flashlights } \\
\hline \multicolumn{2}{|l|}{ Swagelok quick disconnect fittings } \\
\hline Scale & Digital—weighing $\mathrm{Hg}$ \\
\hline Hand pump & Transfer hydraulic fluid \\
\hline Plastic bin-50 gal & Storage chests for miscellaneous equipment -2 required \\
\hline Berm material & $30 \mathrm{ft}$ required \\
\hline
\end{tabular}




\subsection{Equipment Maintenance}

There is virtually no scheduled maintenance for the target system, except for routine visual inspections, checking performance of the various sensors, and testing the control system for emergency stop operations.

The target system will be assembled initially "hands on" without restriction except for safe mercury-handling protocol. Thereafter, the target will be maintained and operated with minimal personal contact after beam operations commence in order to achieve as low as reasonably acceptable (ALARA) exposure to the operators. With this in mind, the design for the target system incorporated the use of dripless quick-disconnect connections and fasteners and hardware suitable for minimizing handling time and the need for subsequent maintenance. 


\subsection{Facility Interfaces}

\subsection{Electrical}

The mercury delivery system will require a $30-\mathrm{kW}$ power supply, $480 \mathrm{VAC} / 3 \mathrm{PH} / 60 \mathrm{~Hz}$ for operation at MIT and $360 \mathrm{VAC} / 3 \mathrm{PH} / 50 \mathrm{~Hz}$ for operation at CERN. In addition, the power source will require a means to be de-energized from the MERIT control room should an off-normal condition occur.

\subsection{Ethernet}

Mercury system control requires network wiring between the remote control room and the hydraulic power unit in the TT2A tunnel. A dedicated network is preferred, but access using CERN's standard network may be acceptable if permitted by CERN network policies.

\subsection{Target Equipment Installation}

The target equipment is designed for handling by forklift or crane. The intended sequence for getting the equipment into TT2A is as follows: After the target is lowered into tunnel TT2 from ground level, it will be moved along the down-slope of the tunnel using the CERN "turtle." The target is configured so that it can make the turn into tunnel TT2A, mounted on the transfer cart. Figures 37 and 38 show the sequence for installing the target and the solenoid.

1. Lower the target transporter (using built-in swivel hoist rings) onto a horizontal surface (wedge) sitting on the TT2 sloped floor. Use one of the built-in tow hooks to attach the transporter to the CERN "turtle" or other fixed object.

2. Lower the mercury system with attached target cart (using straps through the tubes under the secondary containment) onto the target transporter.

3. Using the turtle, pull the system off the wedge, remove the wedge, and then move the system into TT2A.

4. Lower the common baseplate (using built-in swivel hoist rings) onto the wedge. Use one of the built-in tow hooks to attach the baseplate to the turtle or other fixed object.

5. Lower the solenoid onto the common baseplate.

6. Using the turtle, pull the system off the wedge, remove the wedge, and then move the system into TT2A.

7. Lower the hydraulic power unit (using built-in lift points) onto the wedge. Attach to the turtle or other fixed object.

8. Using the turtle, pull the power unit off the wedge, remove the wedge, and then move the system into position within TT2.

Once the MERIT equipment is positioned in the TT2A tunnel, Figs. 37 and 38 show the sequence for inserting the mercury system into the solenoid.

Mercury will be loaded as described in Section 4.1 after the target is in position in the beam line. 

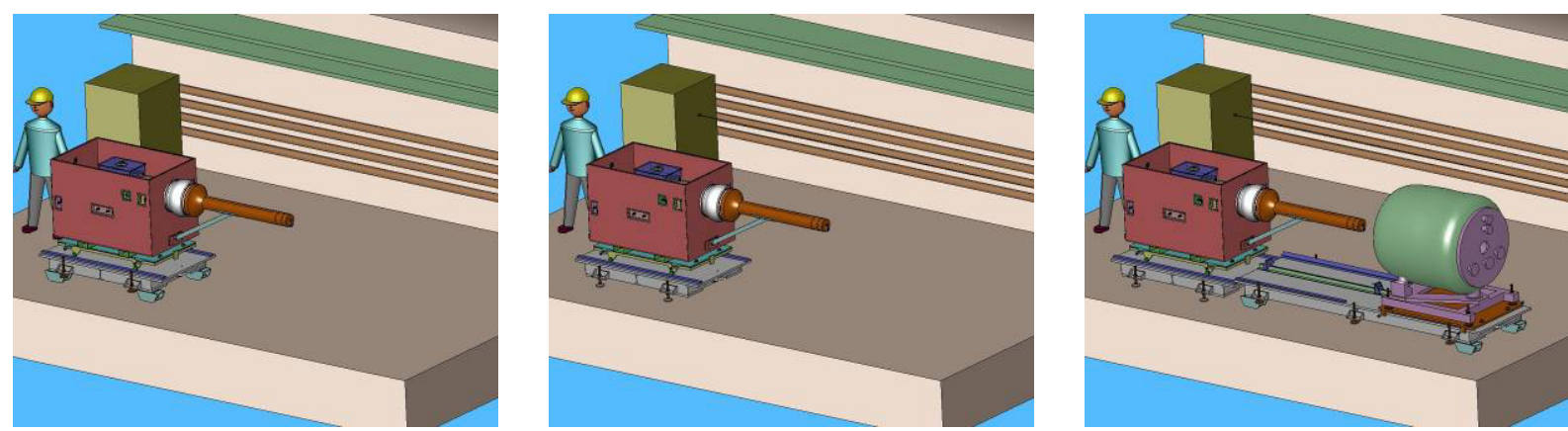

Fig. 37. Target equipment moving into TT2A.
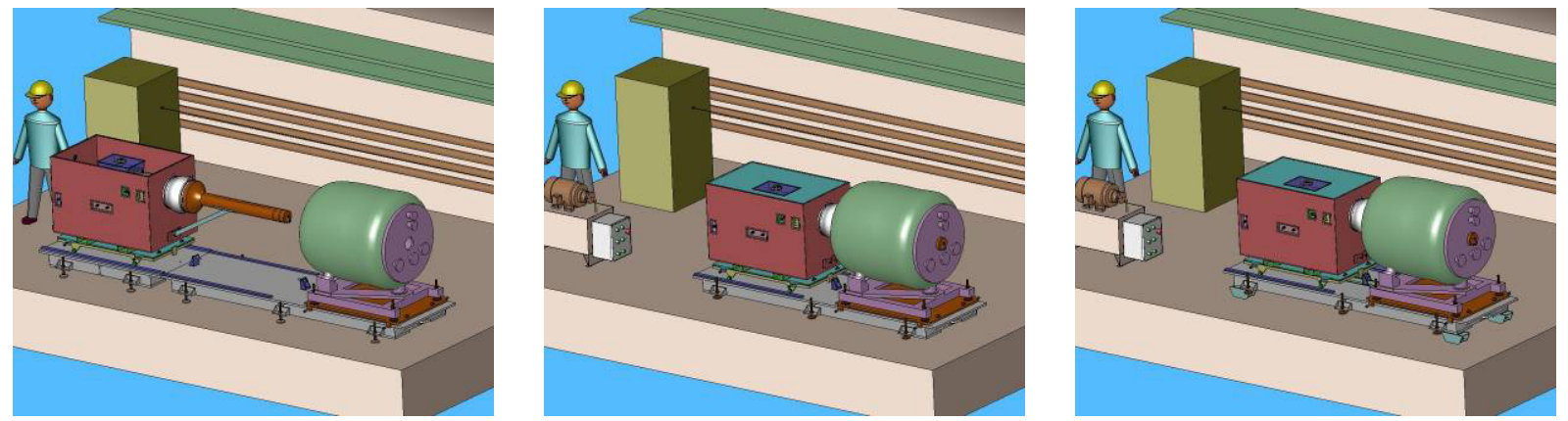

Fig. 38. Target equipment inserted into solenoid. 


\subsection{Packing and Transportation}

The ORNL Transportation Group has been consulted during the past 6 months to ensure that the target equipment design meets the criteria for truck shipment to MIT, shipment to CERN in a short sealand container $2.4 \mathrm{~m}$ wide $\times 2.4 \mathrm{~m}$ high $\times 6.1 \mathrm{~m}$ long $(8 \mathrm{ft} \times 8 \mathrm{ft} \times 20 \mathrm{ft})$, and the return shipment of mildly activated components back to ORNL. In addition, meetings with environmental, safety, and health (ES\&H) personnel to ensure that ES\&H criteria were being met. Figure 39 is a layout of the sealand container showing the target equipment and the solenoid. (Note that this is a first draft and is not an optimized arrangement.)

After completion of the ORNL tests, the mercury will be removed from the target and put back into the standard 2-liter shipping flasks. The target system and all related equipment will be sent to MIT via a dedicated truck for integrated system tests. Upon completing those tests, the target system and the solenoid will be shipped to ORNL, where the equipment will be loaded into a certified sealand container. The ORNL Transportation Group will prepare the necessary documents for international shipping and make arrangements for truck transport to a local seaport, trans-Atlantic surface shipping, and truck transport to CERN. It is presumed that CERN will make similar arrangements for the return shipment of equipment to ORNL.

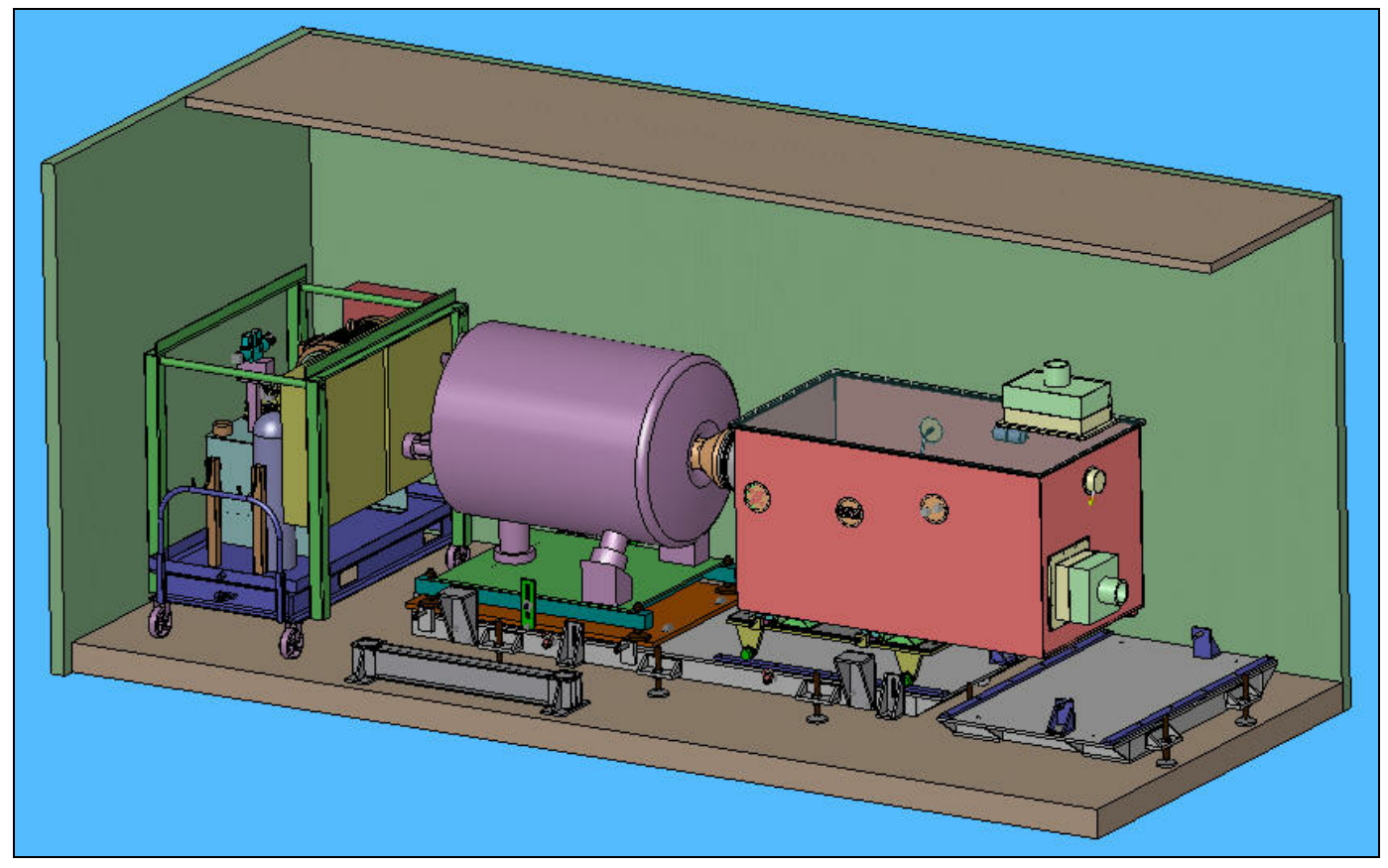

Fig. 39. Target equipment and solenoid inside a short sealand container. 



\subsection{Equipment Decommissioning and Disposition}

After completing the testing at CERN, it is presumed that the target/solenoid equipment will remain undisturbed for several weeks so that the inventory of mercury will cool to a dose rate approaching $<10^{-2} \mathrm{mSv} / \mathrm{h}(1.0 \mathrm{mrem} / \mathrm{h})$. The mercury will then be removed from the target and stored in steel flasks. Then, the target/solenoid will be moved out of the beam line and left in tunnel TT2A for additional time. After another 2-4 weeks, virtually all components will have a dose rate that is low enough $\left(10^{-4} \mathrm{mSv} / \mathrm{h}-0.01 \mathrm{mrem} / \mathrm{h}\right)$, to permit unlimited handling for radiation-trained workers.

At that time, the target can be removed from the solenoid, and all equipment can be brought to ground level for placement into the sealand container. The original packing materials and crates will be reused, and presumably the CERN Transportation Group will make arrangements for the return shipment to ORNL.

\subsection{Estimated Dose Exposure to Personnel}

The dose received by personnel during the decommissioning of the target system is estimated for the scenario described in the paragraph above. It is a conservative estimate because the decommissioning activities are assumed to occur only several weeks after completing the MERIT tests. If these tasks are done after the target equipment is idle for periods longer than 3-4 weeks, the corresponding accumulated dose levels will be less.

Table 8 is a breakdown of the five main tasks that expose personnel to the activated components of the MERIT equipment. The total dose that could be received by personnel engaged in decommissioning the target and the solenoid, with activities distributed over many weeks, is approximately $0.35 \mathrm{mSv}(35 \mathrm{mrem})$. This is the total estimated dose distributed among 6 personnel, so an average dose per person would be approximately $0.06 \mathrm{mSv}(6 \mathrm{mrem}) \mathrm{spread}$ out over 4-5 workdays. 
Table 8. Estimated personnel dose rates for decommissioning MERIT

\begin{tabular}{|c|c|c|c|c|c|c|c|c|c|}
\hline & \multirow{2}{*}{\begin{tabular}{|c|}
$\begin{array}{c}\text { Dose } \\
\text { rate }^{a}\end{array}$ \\
$(\mathrm{mSv} / \mathbf{h})$ \\
\end{tabular}} & \multirow{2}{*}{$\begin{array}{c}\begin{array}{c}\text { Dose } \\
\text { rate }^{a}\end{array} \\
(\mathrm{mr} / \mathrm{h})\end{array}$} & \multirow{2}{*}{$\begin{array}{l}\text { No of } \\
\text { people }\end{array}$} & \multirow{2}{*}{$\begin{array}{l}\text { Time } \\
\text { (h) }\end{array}$} & \multirow{2}{*}{$\begin{array}{l}\text { Contingency } \\
\text { factor }^{b}\end{array}$} & \multicolumn{2}{|c|}{ Dose per person } & \multicolumn{2}{|c|}{$\begin{array}{c}\text { Total dose for } \\
\text { operation }\end{array}$} \\
\hline & & & & & & $(\mathbf{m S v})$ & (mr) & $(\mathbf{m S v})$ & (mr) \\
\hline $\begin{array}{l}\text { After several weeks, remove } \\
\text { Hg from target loop; store in } \\
\text { standard "76-lb" bottles in } \\
\text { TT2A }\end{array}$ & $1.00 \mathrm{E}-02$ & $1.00 \mathrm{E}+00$ & 2 & 4 & 2 & $8.00 \mathrm{E}-02$ & $8.00 \mathrm{E}+00$ & $1.60 \mathrm{E}-01$ & $1.60 \mathrm{E}+01$ \\
\hline $\begin{array}{l}\text { 2. Remove the hydraulic fluid; } \\
\text { store it in its } 55 \text {-gal drum in } \\
\text { the adjacent tunnel }{ }^{c}\end{array}$ & $1.13 \mathrm{E}-04$ & $1.00 \mathrm{E}-02$ & 2 & 2 & 2 & $4.52 \mathrm{E}-04$ & $4.00 \mathrm{E}-02$ & $9.04 \mathrm{E}-04$ & $8.00 \mathrm{E}-02$ \\
\hline $\begin{array}{l}\text { 3. Upon removal of } \mathrm{Hg} \text {, move } \\
\text { the target and the solenoid } \\
\text { out of the beamline to the } \\
\text { opposite tunnel wall; } \\
\text { equipment remains in TT2A }\end{array}$ & $1.00 \mathrm{E}-02$ & $1.00 \mathrm{E}+00$ & 4 & 2 & 2 & $4.00 \mathrm{E}-02$ & $4.00 \mathrm{E}+00$ & $1.60 \mathrm{E}-01$ & $1.60 \mathrm{E}+01$ \\
\hline $\begin{array}{l}\text { 4. After an additional } \\
2-4 \text { weeks, remove target } \\
\text { from solenoid and transport } \\
\text { all equipment to ground level }\end{array}$ & $1.00 \mathrm{E}-04$ & $1.00 \mathrm{E}-02$ & 4 & 16 & 2 & $3.20 \mathrm{E}-03$ & $3.20 \mathrm{E}-01$ & $1.28 \mathrm{E}-02$ & $1.28 \mathrm{E}+00$ \\
\hline $\begin{array}{l}\text { 5. Pack the target and solenoid } \\
\text { into their original shipping } \\
\text { crates; store them above } \\
\text { ground until shipping } \\
\text { arrangements have been } \\
\text { made }\end{array}$ & $1.00 \mathrm{E}-04$ & $1.00 \mathrm{E}-02$ & 4 & 16 & 2 & $3.20 \mathrm{E}-03$ & $3.20 \mathrm{E}-01$ & $1.28 \mathrm{E}-02$ & $1.28 \mathrm{E}+00$ \\
\hline $\begin{array}{r}\text { Total accumulated dose for the } \\
\text { dismantling operations }\end{array}$ & & & & & & $1.27 \mathrm{E}-01$ & $1.27 \mathrm{E}+01$ & $3.47 \mathrm{E}-01$ & $3.46 \mathrm{E}+01$ \\
\hline
\end{tabular}

${ }^{a}$ Data taken from Table 4, Section 2.11.

${ }^{b}$ The contingency factor is arbitrarily chosen to be 2 ; this accounts for unforeseen factors and effectively doubles the exposure time.

${ }^{c}$ The shutdown dose rate in the hydraulic fluid at the end of testing is estimated to be $0.023 \mathrm{mSv} / \mathrm{h}(2.3 \mathrm{mr} / \mathrm{h})$; therefore, a rad area boundary must be set up in the adjacent tunnel around the hydraulic power unit during MERIT tests and monitored by Health Physics personnel. After $100 \mathrm{~h}$ of cool-down, the dose rate is estimated to be $<1.13 \times$ $10^{-4} \mathrm{mSv} / \mathrm{h}(<0.01 \mathrm{mr} / \mathrm{h})$. 


\subsection{Assembled Equipment Configuration}

Assembly and successful operational testing of the mercury delivery system took place at ORNL in February 2007. The as-built condition of the syringe pump is shown in Fig. 40, and the project team is shown in Fig. 41. Integrated systems testing with the solenoid was completed in March 2007 at the Massachusetts Institute of Technology's Plasma Science and Fusion Center in Cambridge.

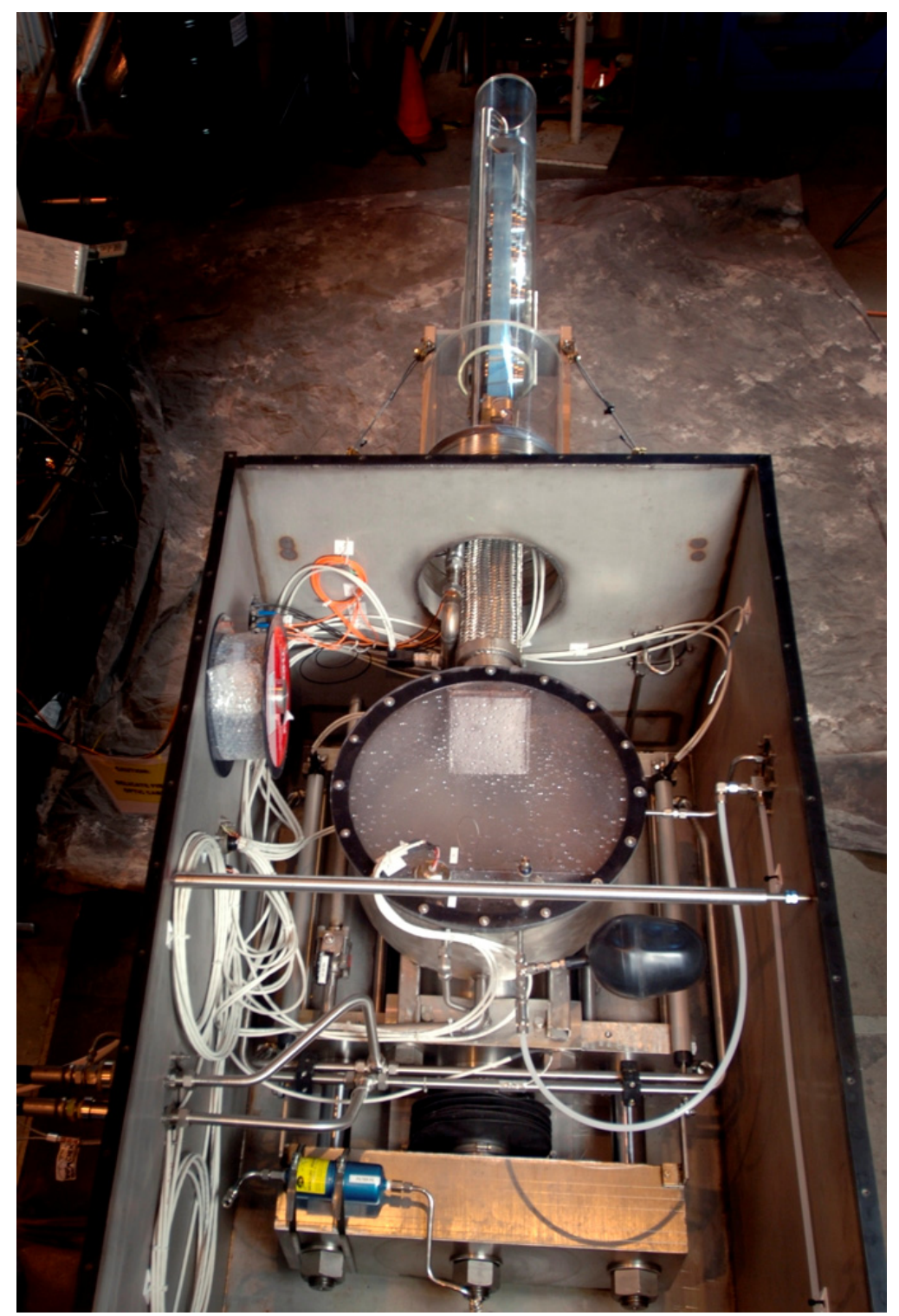

Fig. 40. Syringe pump hardware. 


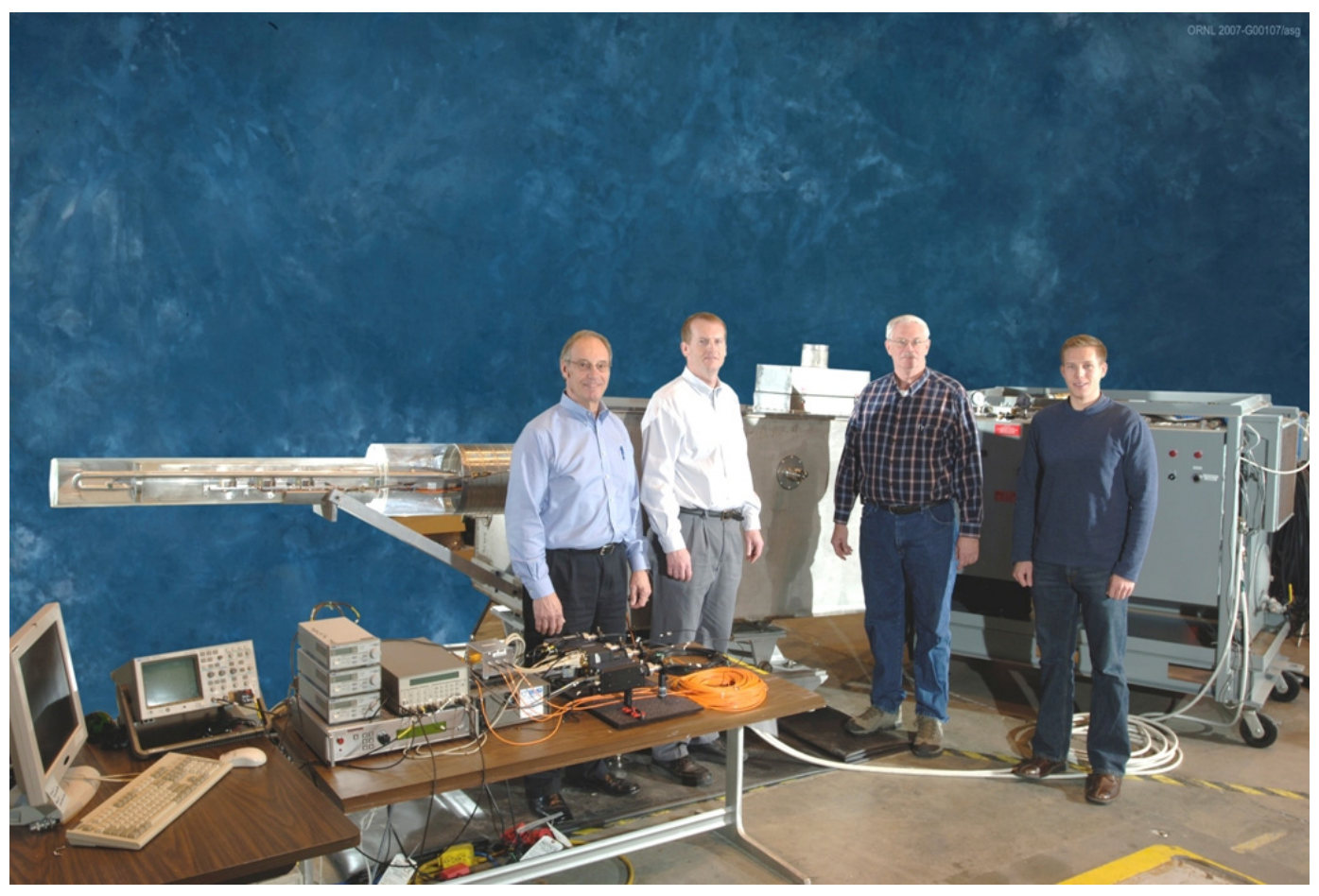

Fig. 41. MERIT mercury delivery system and project team (L-R): P. Spampinato, V. Graves, R. Hobson, A. Carroll. 


\subsection{References}

1. K. McDonald and H.-J. Park, "Sapphire Window Impact Test," Princeton University, January 26, 2006. http://www.hep.princeton.edu/ mcdonald/mumu/target/

2. N. Simos, "MERIT Experiment Window Study—Proton Beam Windows—Optical Windows," Brookhaven National Laboratory, presented at the BNL Collaboration Meeting, December 12, 2005.

3. H. Kirk, "Solenoid Field Map.txt," Brookhaven National Laboratory, September 21, 2004.

4. S. Striganov, Fermi National Laboratory, "MARS Simulation of the Mercury Target Experiment," presented at the MIT Collaboration Meeting, October 18, 2005.

5. Qecksilber und seine Gefahren, Swiss government worker safety report, SBA No. 145, Luzern. 
